\title{
MANAGED RETREAT COMPONENTS AND COSTING IN A COASTAL SETTING
}

BY

\section{SAMUEL ERIC OLUFSON}

\author{
A 120 point thesis \\ submitted to the Victoria University of Wellington \\ in fulfilment of the requirements for the degree of \\ Master of Science
}

Victoria University of Wellington

(2019) 



\begin{abstract}
$\underline{\text { Abstract }}$
Climate change impacts are beginning to be felt across the world. Therefore, the development and understanding of adaptation options is becoming more important. Sea-level rise and its associated impacts are predicted to continue and accelerate well into the next century. As such, it is important that adaptation options which reduce risks associated with sea-level rise are developed and are well understood. Managed retreat is one such option. While research on managed retreat is increasing, there is a lack of literature that identifies what managed retreat comprises, how to plan and stage the option over time, and how to cost it as an adaptation option.
\end{abstract}

This thesis aims to address this gap in the literature by answering the following three questions: (1) what are the issues related to implementing managed retreat as an adaptation strategy in coastal areas, now, and moving into the future?; (2) what are the components of managed retreat?; and (3) what framework could be developed for costing managed retreat?

A qualitative 'desk-top' approach was taken to deconstruct the components of managed retreat across space and time and to develop a framework for costing the components as part of an adaptation strategy. An in-depth analysis of literature, enabled an understanding of managed retreat implementation, and also informed the development of a component typology and costing framework for the adaptation option. The typology and framework were then tested for relevance and utility for decision making through a series of semi-structured discussions with key informants working in climate change adaptation.

Using the component typology and costing framework, a new approach is presented for staging and costing managed retreat, over time and in different contexts. The typology and framework contribute knowledge and guidance for local governments and infrastructure agencies when discussing managed retreat with their communities, for identifying and staging managed retreat, and for the costing of components. It does this by presenting components in stages as overlapping and parallel pathways, providing groupings of components according to types of costs, and identifying appropriate costing methodologies that enable the implementation of managed retreat. To conclude, the thesis suggests areas for future research on managed retreat. 


\section{Acknowledgements}

There are a number of people that I would like to formally acknowledge for their assistance, guidance and encouragement throughout the development of this thesis. They have played an influential part in ensuring the completion of this Master's thesis. I must thank the 'Living at the Edge' programme (part of the Resilience to Nature's National Science Challenge) for financially supporting this research. Thank you for providing me with this experience and opportunity which otherwise would not have been possible.

I would like to express my gratitude to both of my supervisors, Dr Judy Lawrence and Dr Adolf Stroombergen, for their constant support, encouragement, and assistance. Their valuable and constructive suggestions throughout the development of this thesis have been essential for the completion and quality of this thesis. Their willingness to give their time so generously is much appreciated. I would also like to thank my administrative supervisor Professor James Renwick from the School of Geography, Environment and Earth Sciences at Victoria University of Wellington.

I would also like to extend my gratitude to everyone who contributed to this thesis through our discussions. This also includes my fellow researchers within the 'Living at the Edge' programme They were valuable for testing my ideas and draft typology and framework so I could better tailor them for relevance and utility for their use. Thank you for your time, expertise and knowledge, it is very much appreciated.

Personally, I would like to thank my family and friends for their support over the past year while this thesis was completed. I have received ongoing and consistent encouragement from you which has played a vital role in the completion of this thesis. My full gratitude for your ongoing encouragement and moral support cannot be fully expressed in these few short words. A special thank you must go to Marie Helliwell for reading my thesis, your suggestions have helped make this thesis what it is.

To Mum and Dad, your support and encouragement while I have completed this thesis has been of great value and I have been incredibly fortunate to have spent this experience with you. 


\section{$\underline{\text { Table of Contents }}$}

Abstract

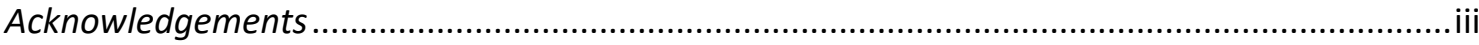

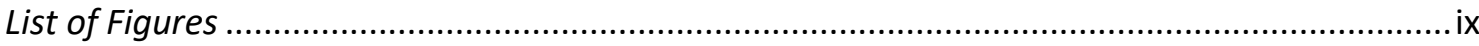

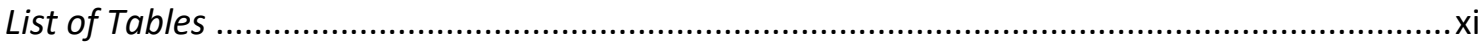

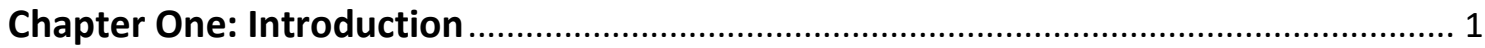

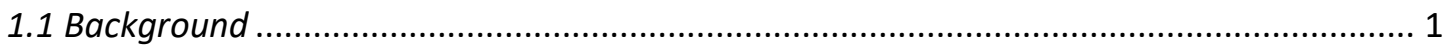

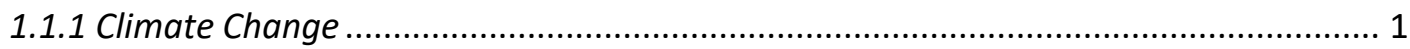

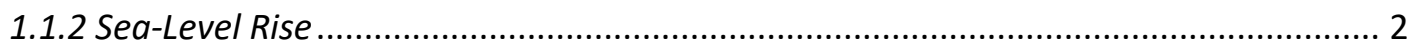

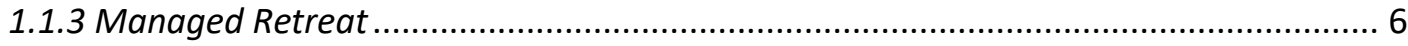

1.2 New Zealand Context .................................................................................................. 7

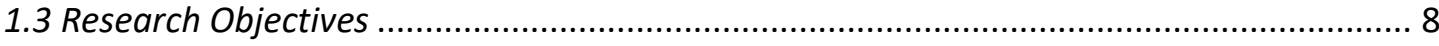

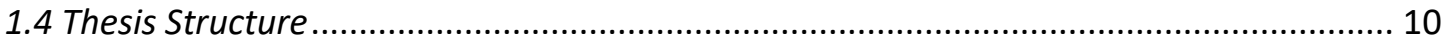

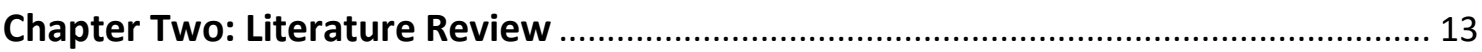

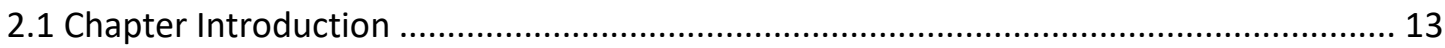

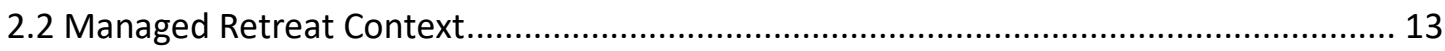

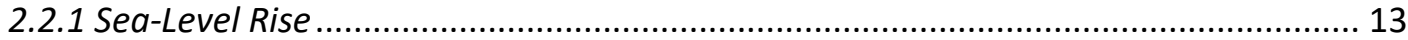

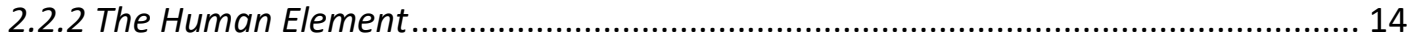

2.2.3 Managed Retreat as an Adaptation Option .............................................................. 15

2.2.4 Elements of Managed Retreat .................................................................................. 16

2.2.5 Managed Retreat in New Zealand ................................................................... 18

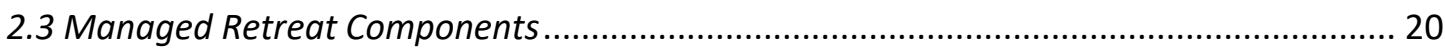

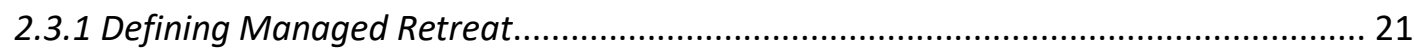

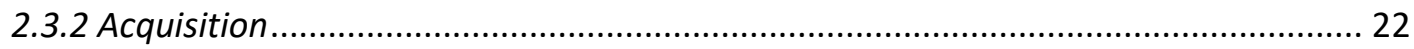

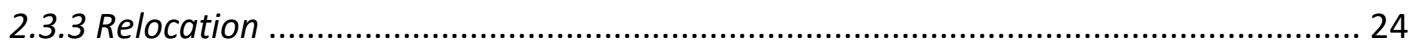

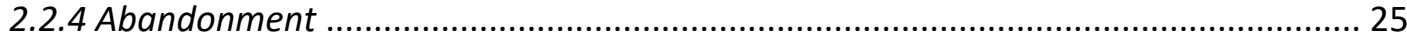

2.3.5 Development and Rebuilding Restrictions .......................................................... 26

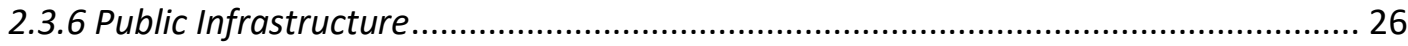

2.4 Climate Change Adaptation Costing …....................................................................... 28

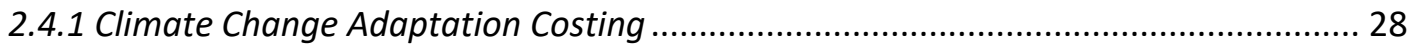

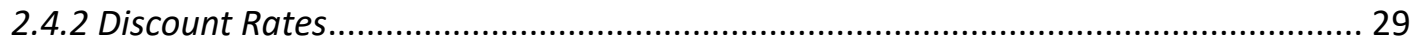

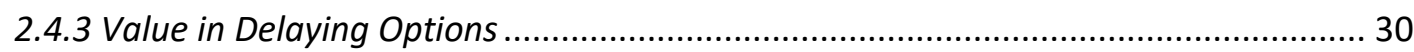

2.4.4 Approaches to Climate Change Adaptation Costing .................................................. 31

2.5 Methodologies Relevant to the Costing of Managed Retreat Components .................... 32

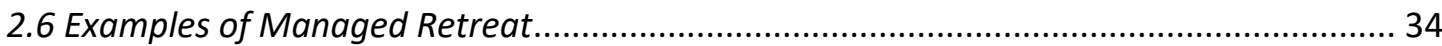




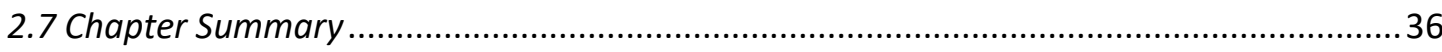

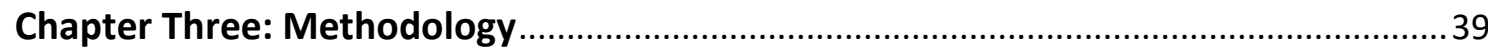

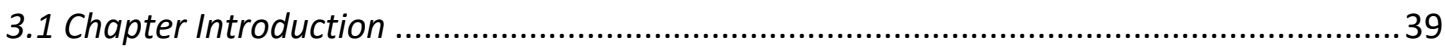

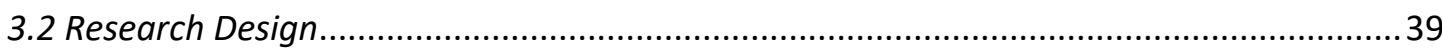

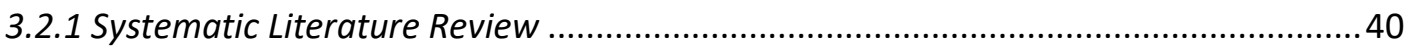

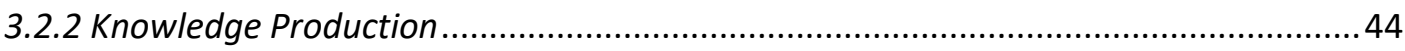

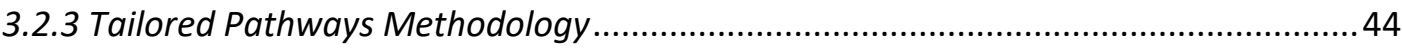

3.2.4 Testing of Typology and Framework …................................................................ 48

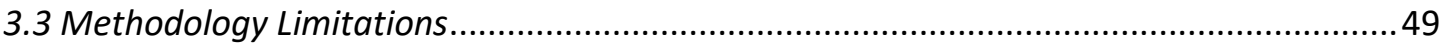

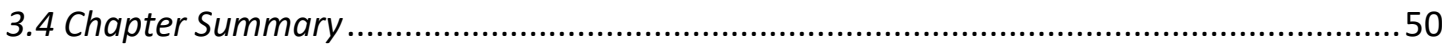

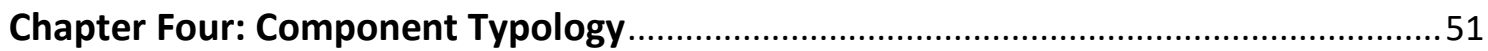

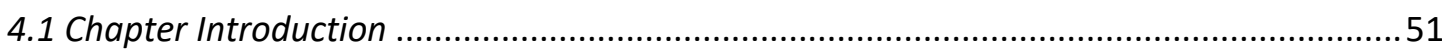

4.2 Identification of Managed Retreat Components ................................................................51

4.3 Grouping of Managed Retreat Components ...............................................................5

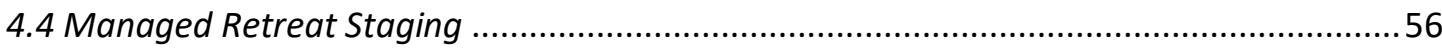

4.4.1 Managed Retreat Using the DAPP Framework …...................................................57

4.4.2 The Staging of Hypothetical Managed Retreat Strategies .......................................58

4.4.3 Staging of Managed Retreat in the Real World .....................................................62

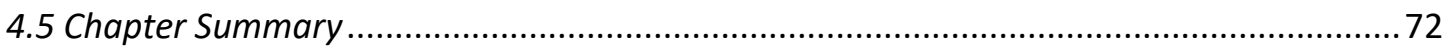

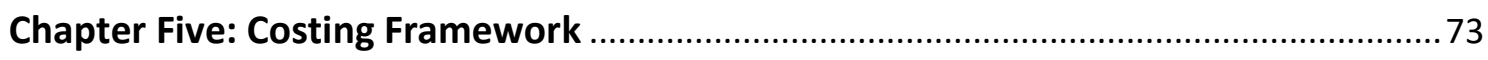

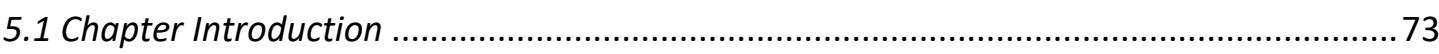

5.2 Valuation Methodologies for Managed Retreat Components ......................................... 74

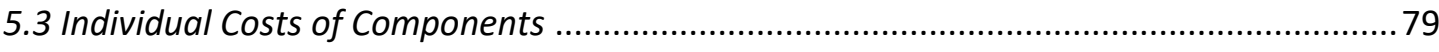

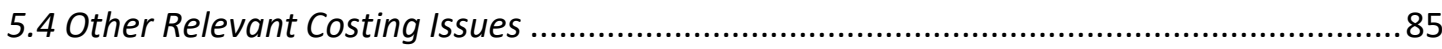

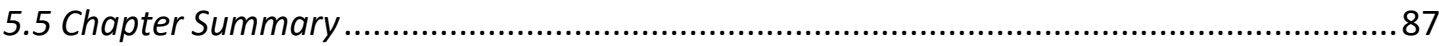

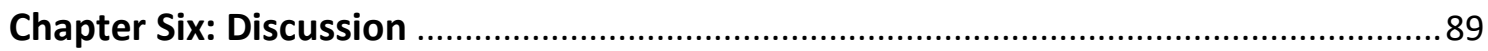

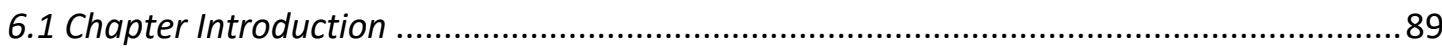

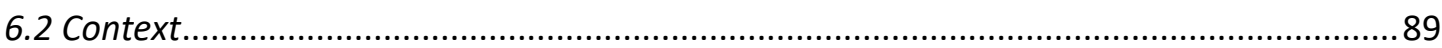

6.2.1 The Need for Understanding Climate Change Adaptation Options .............................89

6.2.2 The Uncertainty of Climate Change - Flexibility of Adaptation Options .....................90

6.2.3 Avoiding Policy Path Dependency and Safety Paradox ..........................................91

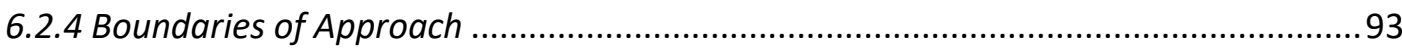

6.3 Steps for the use of the Typology and Framework ............................................................93

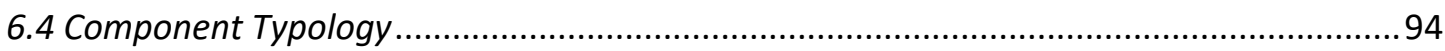

6.4.1 Identification of Managed Retreat Components ........................................................94 
6.4.2 Staging of Managed Retreat.................................................................. 95

6.4.3 Summary of the Component Typology Section ............................................... 96

6.4.4 Implementation Issues Related to the Component Typology ................................. 96

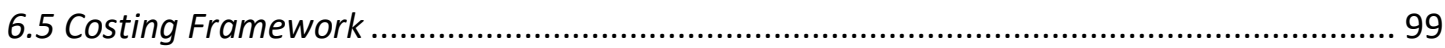

6.5.1 Costing Methodologies for Managed Retreat ................................................. 99

6.5.2 Application of Costing Methodologies to Components.......................................... 99

6.5.3 Identification of Individual Costs of Components .............................................. 100

6.5.4 Summary of the Costing Framework Section ................................................... 100

6.5.5 Implementation Issues Related to the Costing Framework ................................ 100

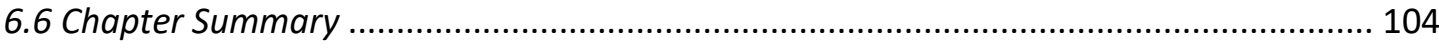

Chapter Seven: Conclusions.......................................................................... 107

7.1 Research Objectives and Approach ..................................................................... 107

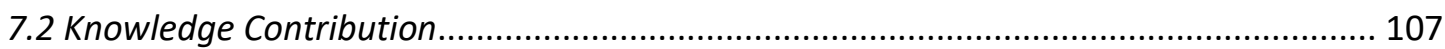

7.3 Future Research Opportunities ................................................................. 108

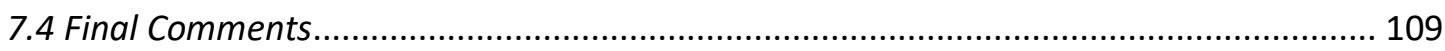

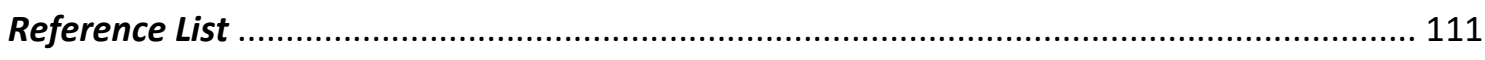

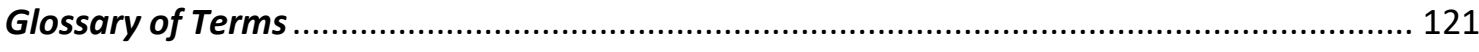

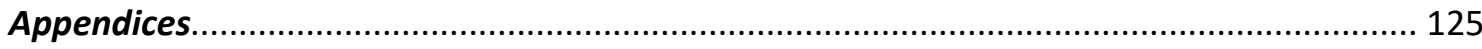

Appendix A: Managed Retreat and Coastal Hazard Management Context ....................... 125

Appendix B: Search Terms Used for the Literature Review .......................................... 133

Appendix C: Rationale for Table 5.2 ................................................................... 135

Appendix D: Information Sheet Provided For Discussions............................................ 139

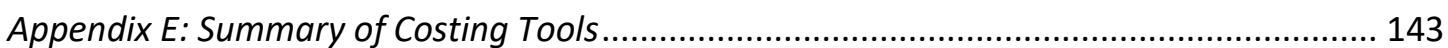




\section{List of Figures}

Figure 1.1: Projections of average global mean sea-level rise from the Intergovernmental Panel on Climate Change Fifth Assessment Report.

Figure 1.2: Sea-level rise projections for New Zealand. 5

Figure 3.1: Methodological steps followed in this thesis. 39

Figure 3.2: The tailored pathways methodology. 46

Figure 3.3: DAPP approach which includes the use of signals and trigger/decision points. 47

Figure 4.1: Example of a DAPP pathway showing many options, including managed retreat... 57

Figure 4.2: Possible staging of components for retreating an entire community to another location. 59

Figure 4.3: Possible staging of components under a managed retreat strategy that focuses on local government buyouts.

Figure 4.4: Possible staging of components under a managed retreat strategy that focuses on the signalling of intentions to reduce government investment in the area.

Figure 4.5: Timeline of component staging for the Mapua/Ruby Bay example 64

Figure 4.6: Timeline of component staging for the Grantham managed retreat example. 66

Figure 4.7: Timeline of component staging for the Newtok managed retreat example. 67

Figure 4.8: Timeline of component staging for the Medmerry example. 69

Figure 6.1: Outline of steps for the use of the component typology and costing framework... 93 


\section{List of Tables}

Table 2.1: Acquisition components summary.

Table 2.2: Relocation components summary.

Table 2.3: Abandonment components summary.

Table 2.4: Rebuilding/development restrictions components summary

Table 2.5: Reduction of public infrastructure service levels components summary. 28

Table 3.1: Search terms applied to databases. 42

Table 3.2: Search terms used in search for grey literature that addressed the research questions.

Table 3.3: Inclusion and exclusion criteria. 43

Table 4.1: Managed retreat components and responsibilities for managed retreat strategies. 52

Table 4.2: Grouping of managed retreat components...... 55

Table 5.1: Descriptions of valuation methods relevant for the costing of managed retreat components.

Table 5.2: Valuation methodologies and their applicability for different managed retreat components.

Table 5.3: Rationale behind attributing valuation methodologies to managed retreat components.

Table 5.4: Managed retreat components, their associated costs and types of costs. 80

Table 5.5: Cost grouping and classification. 84 



\section{Chapter One: Introduction}

\subsection{Background}

Climate change is significantly impacting the climate-ocean system, with coastal communities around the word already being affected by the associated impacts of sealevel rise (Freudenberg, Calvin, Tolkoff \& Brawly, 2016; Bell, Lawrence, Allan, Blackett \& Stephens, 2017). Sea-level rise is expected to accelerate through the current century and beyond, resulting in an increase in the rate and magnitude of coastal hazard impacts (Stephens, Bell \& Lawrence, 2017). Expected sea-level rise of 0.5-2.0m could potentially displace and affect between 72 and 187 million people globally (Nicholls et al., 2011), with many low-lying areas becoming uninhabitable. This will result in the eventual withdrawal or abandonment of coastal settlements in anticipation of harm (Lawrence, Bell, Blackett, Stephens \& Allan, 2018).

Substantial reductions in global greenhouse gas emissions may lead to a reduction in the rate and magnitude of sea-level rise. A long-term rise in sea level is, however, already unavoidable (Bell et al., 2017). While much of the current global focus is on the reduction of greenhouse gas emissions, adaptation to the effects of climate change is becoming an integral part of global climate change policy (Intergovernmental Panel on Climate Change (IPCC), 2018). It is therefore important that coastal adaptation options are developed, studied, and understood to ensure effective and appropriate implementation of these options when they are required. Managed retreat is one such adaptation option.

\subsubsection{Climate Change}

Global warming is caused by the trapping of heat due to increases in greenhouse gas concentrations in the earth's atmosphere (e.g. carbon dioxide, nitrous oxide and methane) (IPCC, 2014). Anthropogenic greenhouse gas emissions have increased since the pre-industrial era driven by economic and population growth, which has resulted in current concentrations being higher currently than ever experienced in human existence (IPCC 2014). The effect of greenhouse gas emissions is the dominant cause of observed global warming since the mid-20th century (IPCC, 2014). 
By 2012, global mean temperature had already increased on pre-industrial levels by $0.85^{\circ} \mathrm{C}$ (Bell et al., 2017). As part of the 2015 Paris Agreement ${ }^{1}, 185$ countries, which represented 97 percent of the global population and 94 percent of global greenhouse emissions, submitted emissions pledges under which they would reduce their national emissions prior to 2030 (Magnan et al., 2016). The Paris Agreement established a goal of limiting global mean surface temperature to well below $2^{\circ} \mathrm{C}$ above pre-industrial levels, while taking measures to try and limit the overall increase to $1.5^{\circ} \mathrm{C}$ above preindustrial levels. While many countries have agreed to limit emissions, warming will continue over at least the next few decades to centuries. Higher temperatures cannot be ruled out if emissions targets are not achieved. Even if emissions were to completely cease today, cumulative emissions already in the atmosphere and oceans would continue to have an impact on climate processes ad their impacts due to the lag time between emissions reductions and their impact (Bell et al., 2017).

\subsubsection{Sea-Level Rise}

The climate-ocean system has responded to global warming, with one of the major, and most certain consequences being sea-level rise (Parliamentary Commissioner for the Environment, 2015). Sea-level changes as the Earth's temperature changes with a lag in response. Two main processes drive this interaction - a volume increase that becomes a water-height increase, as oceans are constrained by coastlines; and a mass increase as ice stored on land melts and adds to the mass of water in the oceans.

There are three types of sea-level rise:

- Absolute, or eustatic sea-level rise expressed as a global mean and used for most sea-level projections

- Offsets or departures from the (eustatic) mean sea-level rise. For example the sea surrounding New Zealand. Significant variations can result in response to wind and warming patterns between different regional seas.

\footnotetext{
${ }^{1}$ The Paris Agreement was opened for signature on the April 22, 2016 and was entered into force on the November 4, 2016.
} 
- Local or relative sea-level rise which is net sea-level rise from absolute, regional-sea offsets and local vertical land movements relative to the local land mass. This is the sea-level rise relevant for country scale adaptation.

(Bell et al., 2017)

\section{Global Sea-Level Rise}

Globally, sea levels had been relatively stable over much of the past 2000-3000 years, with small rates of change of up to $\pm 0.2 \mathrm{~mm}$ per year (Kopp et al., 2016). They began to rise globally in the late 1800 s, mainly in response to increasing anthropogenic greenhouse gas emissions following the Industrial Revolution. It is very likely, according to the IPCC (see Glossary) that the mean rate of global sea-level rise was $1.7 \pm 0.2$ millimetres per year between 1901 and 2010. Between 1971 and 2010, a higher annual rise in sea-level occurred at 2.0 \pm 0.3 millimetres per year (Church et al., 2013).

Greenhouse gas emissions already present in the atmosphere ensure an eventual 1.61.7 metres of continued sea-level rise beyond current levels, even if global emissions were reduced to zero today (Strauss, Kulp \& Levermann 2015; Clark et al., 2016; Bell et al., 2017). With emissions expected to continue over this century, the full extent of sealevel rise is uncertain. Figure 1.1 outlines published projections of sea-level rise from the IPCC Fifth Assessment Report illustrating sea-level projections for a range of representative concentration pathway (RCP) scenarios (see Glossary) - RCP2.6, RCP4.5, RCP6.0, and RCP8.5. Solid lines represent median projections, shaded areas represent the likely range of RCP 2.6 and 8.5, and dotted lines represent the likely ranges of RCP 4.5 and 6.0. The bars to the right of the figure indicate the likely range for all four RCPs averaged over the final 20 years of this century (Church et al., 2013).

Figure 1.1 illustrates that global sea-level rise will continue during the $21^{\text {st }}$ Century and that this will likely occur at a faster rate than the 1971-2010 period. Figure 1.1 also illustrates that by 2100 , global sea-level rise will likely be in the range of $0.28-0.98$ metres. There is, however, uncertainty around how much sea-level rise will accelerate during this century, with the onset of melting of the Antarctic ice sheets potentially causing global mean sea-level to rise substantially above the likely range illustrated in Figure 1.1 (Church et al., 2013). 


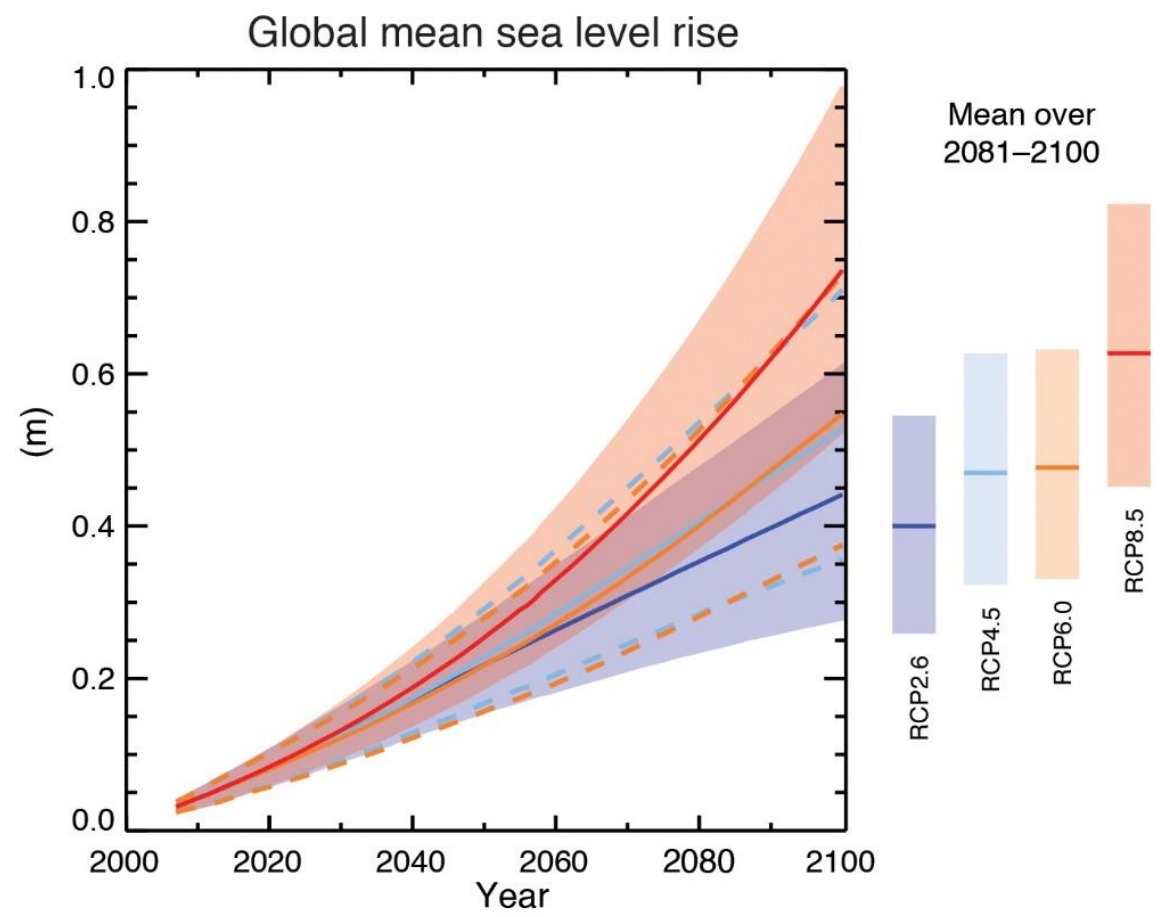

Figure 1.1: Projections of average global mean sea-level rise from the Intergovernmental Panel on Climate Change Fifth Assessment Report. Source: (Church et al., 2013).

\section{New Zealand Sea-Level Rise}

Acceleration of sea-level rise in New Zealand began around 1900 based on sediment analyses from Otago marsh sediments (Gehrels, Hayward, Newnham \& Southall, 2008; Bell et al., 2017). The average trend for New Zealand's sea-level rise between 1900 and 2008, averaged for the four main ports (Auckland Wellington, Lyttelton and Dunedin), was 1.7 \pm 0.1 millimetres per year (Hannah \& Bell, 2012). Figure 1.2 below is taken from Bell et al. (2017) and shows the four sea-level rise scenarios that they suggest should be used when developing and testing adaptation plans for New Zealand. These projections include a New Zealand wide offset as a small additional rise above the projections for global sea-level rise (Bell et al., 2017). Three of the four scenarios in Figure 1.2 (NZ RCP2.6, NZ RCP4.5, and NZ RCP8.5) are based on median global sea-level rise projections for the RCPs presented in the Fifth IPCC Assessment Report (Church et al., 2013) and are extended to 2120 to meet the New Zealand Coastal Policy Statement (NZCPS) (Minister of Conservation, 2010), which requires risk to be assessed over at least 100 years (Bell

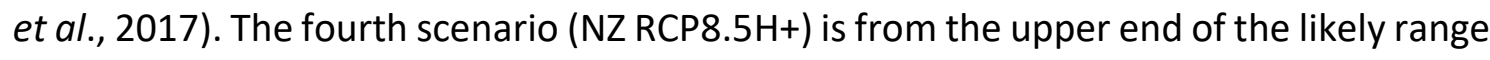
of possibilities presented by Kopp et al. (2016). Sea levels will continue to rise in New Zealand over at least the next 100 years, with the magnitude depending on which scenario eventuates. 


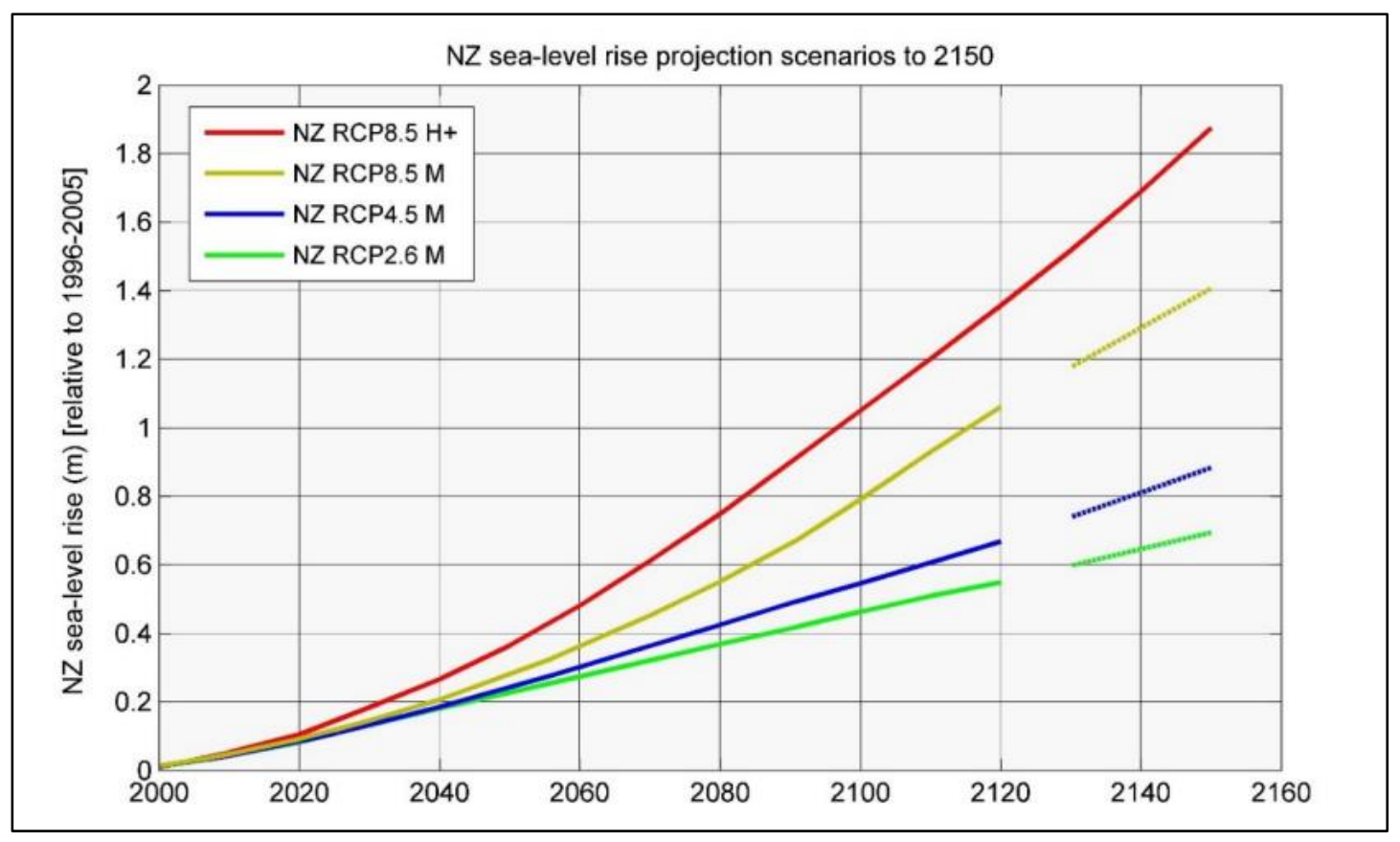

Figure 1.2: Sea-level rise projections for New Zealand. Source: (Bell et al., 2017).

\section{Sea-Level Rise Issues}

Rising sea-levels are already having impacts on human activities and infrastructure in coastal areas through greater inundation during extreme sea-level events, and increased nuisance flooding during high tides (Stephens et al., 2017). Rising seas will result in the permanent inundation of low-lying coastal areas and will increase the frequency and consequences of flooding events (Stephens et al., 2017; Stephens, Bell \& Lawrence, 2018; Lawrence et al., 2018). Sea-level rise will also result in the following consequences: (1) the gradual inundation of low-lying and estuarine margins and adjoining dry land during spring tides, (2) increased incursion of saltwater into rivers and coastal groundwater which will raise water tables in tidally influenced systems, and (3) increased geomorphic adjustment of the coastline through erosion of sand and gravel coastlines and unconsolidated cliffs (Bell et al., 2017; Stephens et al., 2017; Stephens et al., 2018).

These impacts will have increasing relevance for many coastal communities and the services which they depend on. Local government provided services, such as roads and 'three-waters' infrastructure (see Glossary) will be increasingly impacted (Bell et al., 2017). There will be implications for wastewater treatment plants and piped systems, potable water supplies, and capacity implications for drainage infrastructure (both storm water and overland drainage systems) (Bell et al., 2017). 


\section{Other Issues}

Additional to rising seas, weather-related coastal-hazard drivers such as storm surges, winds, waves, and the intensification of storms will affect coastal areas (Freudenberg et al., 2016; Bell et al., 2017). The impacts of these drivers are likely to cause an escalation in the frequency of nuisance and damaging coastal inundation events and will have implications for the management of coastal erosion, coastal inundation, groundwater and drainage (Bell et al., 2017).

\section{Why Is Sea-Level Rise an Issue?}

Human development of the coastal zone occurred under the assumption that sea levels would remain relatively stable (Bell et al., 2017; Stephens et al., 2017). However, sea level is rising, accelerating, and is expected to do so for the foreseeable future (PCE, 2015). Permanent inundation of coastal areas will become the dominant coastal issue by the end of the current century (Le Cozannet et al., 2015) with many structural protection measures eventually requiring abandonment (PCE, 2015). As a result, the long-term impacts of sea-level rise on coastal populations is potentially large (Bell et al., 2017). It is therefore important that options for managing and adapting to these increased risks at the coast are developed and understood. This is especially the case for options that remove the risks completely, such as managed retreat. Building understanding of these options is therefore important to ensure their effective implementation when required.

\subsubsection{Managed Retreat}

Managed retreat is a coastal management option that aims to entirely remove risk from coastal communities. The option provides an alternative to the protective and accommodative options traditionally taken for coastal hazard risk adaptation (Hino, Field \& Mach, 2017), which will become increasingly ineffective or expensive as oceans rise (Lawrence et al., 2015).

Alexander, Ryan \& Measham (2012) describe managed retreat as "one of the few policy options available for coastal communities facing long-term risks from accelerated sealevel rise" (p.409). Despite this, managed retreat currently is scarcely used despite 
broader economic benefits (Hino et al., 2017) due to the social and psychological implications of displacing people from their homes (Freudenberg et al., 2016) and the perceived costs. Therefore, it is important that managed retreat is thoroughly understood, especially in terms of what it might involve and how it can be costed. Doing so will enable the option to be implemented more readily for the management of coastal risk.

The current managed retreat literature tends to focus on a few key themes which include stakeholder opinions and community engagement/acceptance, governance issues, managed retreat case studies and managed realignment (discussed in Section 2.2). The literature, however, does not comprehensively identify all managed retreat components, nor does it address how to cost managed retreat as a strategy (see Glossary). This presents a significant gap in our knowledge and an opportunity to provide a better understanding of what managed retreat involves. This includes the planning for, and the staging and costing of managed retreat.

\subsection{New Zealand Context}

The following section discusses the legislative context within which coastal hazards are managed, and managed retreat implemented in New Zealand. Coastal hazards and climate change impacts are managed primarily by local government through the Resource Management Act 1991 (RMA), the Local Government Act 2002 (LGA), the Local Government Official Information and Meetings Act 1987 (Land Information Memoranda), the Building Act 2004, the Soil Conservation and Rivers Control Act 1941 and the Civil Defence Emergency Management (CDEM) Act 2002. These statutes are supported by national policies, including the statutory New Zealand Coastal Policy Statement 2010 and National CDEM Strategy and National CDEM Plan.

The avoidance, reduction and mitigation of natural hazards, disaster risk and the effects of climate change are regulated by policies, plans and rules by both regional and territorial local governments, through Regional Policy Statements, Regional Coastal Plans, and District Plans. The New Zealand National Coastal Policy Statement discourages the construction of coastal defences as a first option for coastal risk management as they interfere with the dynamic physical processes, and public amenity 
values, and can result in increased erosion in other areas of the coast. Local government also uses non-statutory planning instruments, such as Asset Management Plans and Hazard Mitigation Plans. There is a statutory requirement for community consultation set out in the RMA and LGA. The RMA also sets out Māori values, traditions and culture for the management of natural and physical resources that guide council decisionmaking with Māori.

Each of these statutes and plans have different timeframes and are applied in a static manner (across both time and space) which creates barriers to the implementation of staged retreat over time and space as an adaptation option at the coast. For example RMA plans are usually for 10 years before review, Long Term Plans under the LGA are for 10 years with rolling reviews every 3 years, Infrastructure Plans are for 30 years under the LGA, the Building Act has a 50 year life for buildings, and the NZCPS requires at least a 100 year planning horizon.

A cascade of statutory provisions are outlined in Appendix A, which seek to sustainably manage and preserve the natural character of the coastal environment, manage significant natural hazards, encourage a precautionary approach to coastal management for the foreseeable needs of future generations, acknowledge kaitiakitanga, ${ }^{2}$ preserve amenity, and give consideration to the effects of climate change which avoids increasing coastal hazards and the risk associated with them. These provisions anticipate sea-level rise by discouraging hard protection measures and the increasing of risk at the coast (through new development), and encouraging consideration of the managed retreat option.

\subsection{Research Objectives}

The purpose of this thesis is to identify what managed retreat comprises and to develop a framework for its costing. This thesis aims to build the understanding of, and provide guidance for managed retreat as a coastal hazard risk adaptation option in the face of

\footnotetext{
${ }^{2}$ Kaitiakitanga: means protection, guardianship, or preservation. Is a way of managing the natural environment, based on the traditional Maori view of nature and the world.
} 
uncertainty and changing risk associated with future climate change and the extent of sea-level rise. Three primary research questions shape this research:

1. What are the issues related to the implementation of managed retreat as an adaptation strategy in coastal areas, now and moving into the future?

2. What are the components of managed retreat that enable a better understanding of managed retreat as an adaptation option to be considered now, and for its implementation over time?

3. What framework could be built for planning and costing managed retreat as an adaptation option within a coastal risk management strategy?

The aim of research question one is to identify the issues faced by communities developing options for the changing risks associated with sea-level rise at the coast, and to provide a baseline of issues that would need to be considered when implementing managed retreat.

The aim of research question two is to identify the components of a managed retreat. Currently, there is little understanding in the literature or in decision practice about what managed retreat comprises and how it might be implemented in decision making today and in the future as sea-levels rise. Breaking down the components of managed retreat and reconstructing them in a typology will build the understanding of what managed retreat could involve in practice, and what needs to be considered when using its different components as part of a wider coastal risk management strategy.

The aim of research question three is to build a framework for costing the managed retreat components identified in response to research question two. Such a framework could support economic assessments of adaptation options that address the changing risk profiles associated with sea-level rise.

This thesis focusses on identifying what managed retreat comprises, how it could be implemented over time, and developing a framework which addresses how the option could be costed. There are several significant aspects of managed retreat (for implementing and costing the option) that have been ruled 'out of the scope' as they 
require more in depth analysis and go beyond the focus of the thesis. They include: distributional impacts, discounting of costs and benefits over time, equity and fairness, social costs and impacts. These issues have, however, been noted for completeness and for further research as in realty, when managed retreat is being developed as an adaptation option, the listed issues become significant considerations.

Although the terms 'costing' and 'valuation' are largely interchangeable, 'costing' is generally used in the thesis to mean the process of determining the cost of an action or component of managed retreat (e.g. the cost of moving or rebuilding a house). Determining the cost of an action may involve the 'valuation' of an asset (e.g. a water treatment plant) or an activity (e.g. access to a beach).

\subsection{Thesis Structure}

This opening chapter has described the rationale for developing the understanding of options for adapting to increasing risks to coastal communities as a result of climate change. This chapter has also outlined the issues surrounding the understanding and implementation of managed retreat currently which provides the context in which this research occurs.

Chapter Two presents a literature review which discusses the issues relevant to addressing the research objectives and questions. The chapter begins by analysing the literature for background context to managed retreat, including what the climate change issues are, and how managed retreat has been addressed in the past. This analysis informs the production of the component typology which is then presented with a focus on the components of managed retreat strategies. The chapter then presents and analyses the literature on costing methods relevant to the production of a managed retreat costing framework, with a focus on what methodologies and steps have been used to cost climate adaptation measures.

Chapter Three outlines and discusses the various methods used in this thesis for the collection, analysis, and presentation of the findings. The chapter commences by discussing the research design with a focus on the steps taken to produce the component typology and costing framework. These steps include a systematic literature 
review, a tailored pathways (see Glossary) methodology and the testing/validation of findings. Following this, the limitations of the methodology are discussed.

Chapters Four and Five present the findings of this thesis. These findings are presented in response to the research questions (Section 1.2) and are in the form of a managed retreat component typology (Chapter Four), and a costing framework (Chapter Five). Chapter Four focusses on identifying potential managed retreat components, responsible agencies, and the staging of managed retreat across time. Examples of the use of the typology are then provided to illustrate that the typology can be used in different coastal risk situations.

Chapter Five provides a framework which examines the various methodologies for costing managed retreat. It also provides indications of which costs will require valuation for the use of different components. This is done to provide guidance for costing managed retreat as an adaptation option.

Chapter Six discusses the findings of this thesis from Chapters Four and Five (component typology and costing framework). This includes what has been produced and how they could be used within a managed retreat strategy. Chapter Six also discusses issues associated with the implementation of managed retreat and how the findings contribute to the body of managed retreat knowledge.

Chapter Seven concludes this thesis by discussing and summarising the key findings and relates the component typology and costing framework back to the research questions and objectives (Section 1.2). Chapter Seven concludes by discussing the directions for future research that can build upon the findings of this thesis. 


\section{Chapter Two: Literature Review}

\subsection{Chapter Introduction}

Chapter Two presents a literature review of how managed retreat is currently understood, identifies information gaps that need to be addressed, and discusses how the literature informs the development of the component typology and costing framework. This chapter is structured into three sections labelled as managed retreat 'context', 'components', and 'costing'. Each section has a short paragraph outlining what is included followed by a series of subsections that identify and analyse the literature relevant to the development of the component typology and costing framework.

\subsection{Managed Retreat Context}

The 'context' section of this literature review begins by outlining the issues and impacts for coastal areas that are associated with global warming (e.g. rising seas, permanent coastal inundation and groundwater issues). The definitions of managed retreat included within the literature are then identified. This is then followed by a discussion of how managed retreat has been studied to date, and how this may aid in the understanding of managed retreat as an option. Identifying the issues that climate change impacts present for coastal communities, and how managed retreat has been studied, allows for the better understanding of why options like managed retreat are required, and assists in the identification of knowledge gaps.

\subsubsection{Sea-Level Rise}

Climate change is considered to be a serious and ongoing process which results in an increase in hazard risk to coastal communities. While many countries around the world have agreed to act to help limit global warming to $2^{\circ} \mathrm{C}$ above pre-industrial levels, warming will continue over at least the next few decades (Bell et al., 2017). Even if global emissions were to completely cease effective immediately, current emissions in the atmosphere will continue to have an impact on climate and ocean processes due to the 
time lag between emissions reduction and their impacts. Sea-levels will continue to rise at least well into the next century (Bell et al., 2017).

Sea-level rise occurs predominantly due to glacial melting and the thermal expansion of oceans as the atmosphere warms (Church et al., 2013). Sea-level rise will not be uniform around the globe and could be quite different depending on local geophysical characteristics, such as topography and the rate of uplift/subsidence. Meltwater is not distributed evenly around the world, and while the eustatic volume of water in the oceans may increase, relative sea level may be very different (Bell et al., 2017). Relative sea level relates to the combined movement of both sea and land. If land is subsiding, effective sea levels are higher and the opposite occurs for uplifting land. Because rising seas will have different impacts on different coastal areas, different adaptation options need to be understood and available, depending on the local situation.

Rising sea levels, which occur as a result of climate change, also have major impacts on coastal groundwater tables. Groundwater tables will rise in coastal areas where they are connected to the sea. This increases the likelihood of coastal flooding in storm events due to heavy rainfall as the holding capacity of the ground is reduced (Pattle Delamore Partners (PDP), 2011). In addition to drainage issues, saltwater intrusion and liquefaction are associated with rising coastal groundwater levels (PDP, 2011). As a result of these groundwater impacts, existing and planned development in areas of the coast may become too risky, and managed retreat of such communities becomes an option.

\subsubsection{The Human Element}

Increasing development of human settlements at the coast increases the risks associated with climate change impacts and magnifies the damages when climaterelated events occur. The rapid global development of cities is making more people vulnerable to climate change and its associated impacts (Abel et al., 2011; Song, Fu, Wang, Peng \& Gu, 2018; World Economic Forum, 2019). An estimated 800 million people live in coastal cities which will be vulnerable to sea-level rise by 2050 (World Economic Forum, 2019). This suggests that globally, coastal risk from climate change is increasing due to both mounting greenhouse gas emissions, and the growing number of 
people and assets placed in vulnerable coastal areas. Managed retreat provides an alternative option to the more commonly taken protective and accommodative measures, and should be considered because it entirely removes risks to coastal communities as the seas rise (Hino et al., 2017).

Rising sea-levels is one of the top climate change risks to New Zealand due to the threat posed to low-lying coastal infrastructure, communities and ecosystems (Rouse et al., 2017; Owen, Turner, Ryan \& Kench, 2017). Warming climates will also affect waves, storms, sediment supply, wind regimes and ocean temperatures leading to the exacerbation of coastline erosion, an increase of coastline inundation and the potential salinization of coastal aquifers, estuaries and wetlands (Rouse et al., 2017). Drainage issues will become increasingly significant with a rising coastal groundwater table. This suggests that different options for the management of and adaptation to these distinct coastal risks are required in New Zealand, bearing in mind that sea levels will continue to rise for the foreseeable future.

\subsubsection{Managed Retreat as an Adaptation Option}

Alexander et al. (2012) state that managed retreat "is one of the few policy options available for coastal communities facing long-term risks from accelerated sea-level rise" (p.409). Neal, Bush \& Pilkey (2005) argue that it is unrealistic to 'hold the line' through the use of protective measures for every developed coastline. Neal et al. (2005) also state that managed retreat may provide the best management tools for reducing coastal risk exposure and for the mitigation of future losses. Therefore, with current projections of sea-level rise, it is important that managed retreat is well defined and understood.

Managed retreat is defined in the literature as a coastal management method that aims to remove hazard risk from coastal communities, through the abandonment of land and relocation of structures (Alexander et al., 2012; Niven \& Bardsley, 2013; Esteves, 2014; Koraim \& Negm, 2016; Koslov, 2016; Hanna, White \& Glavovic, 2017; Hino et al., 2017; Owen et al., 2017; Rulleau, Rey-Valette \& Clément 2017; Elkin \& Keenan, 2018; Matthew \& Potts, 2018; Rangel-Buitrago, de Jonge, \& Neal 2018; Tadgell, Doberstein \& Mortsch, 2018; Williams, Rangel-Buitrago, Pranzini \& Anfuso, 2018). Neal et al. (2005) describe 
managed retreat as a term for the application of management tools at the coast, which are designed to shift existing and planned development away from coastal hazards.

An important consideration for changes in land-use and hazard management options is the land-use, or safety, paradox. This paradox reflects that the adoption of some hazard risk management measures can stimulate further development in hazardous areas (e.g. coastal areas at risk of inundation) (Burby \& French, 1981). Tobin (1995) describes this as the levee effect, where the use of protective structures provides a false sense of security in at-risk communities, which encourages the further development in these locations. This increased development results in a higher value of assets at-risk (which increases the residual risk when protective structures eventually fail), an increased reliance on protective structures, and can result in the expectation of ongoing protection (Tobin, 1995; Lawrence, Quade \& Becker, 2014). It is therefore important that adaptation options which recognise the risks, communicate those risks to the community, and discourage or restrict further development of hazard prone areas (or those that will become hazardous as a result of sea-level rise), are understood and used effectively. Managed retreat is an option that can facilitate local governments to communicate risk to communities and help prevent placing higher values at risk ahead of future actions being taken.

\subsubsection{Elements of Managed Retreat}

The literature on managed retreat has to date focussed on a few consistent themes. These include: community perceptions, governance, managed retreat methods, and managed realignment.

Community acceptance of managed retreat is regarded as a significant hurdle for the implementation of the option (Binder, Baker \& Barile, 2015; Freudenberg et al., 2016; Hino et al., 2017). This is due to the social and psychological issues that occur from displacing people from their homes and communities (Fullilove, 1996; Hino et al., 2017). These issues occur because of the effects on displaced people due to attachment to community and location, described as place attachment. As Fullilove (1996) explains, a sense of belonging is necessary for psychological wellbeing, and the loss of this feeling of place is a source of mental distress. Therefore, consideration of the social impacts 
that managed retreat will have, is significant in the development of components of managed retreat as an adaptation option.

Hino et al. (2017) review how different managed retreat strategies have been implemented around the world. The thesis analyses community perceptions of managed retreat depending on who initiates the option and who ultimately benefits. This enabled them to identify four groups: the 'greater good' (where broader society benefits from the retreat, but residents do not initiate it); the 'hunkered down' (where only residents benefit from a retreat, but they do not initiate it); 'self-reliance' (where resident initiate the retreat and are the only ones who benefit from it); and the 'mutual agreement' (where residents initiate the retreat and broader society benefits from it). This has implications for the governance of managed retreat.

Abel et al. (2011) identify five common governance themes which have an influence on the implementation of retreat: (1) state governments promote population increase and can override local government zoning; (2) sea-level rise is slow and development pressures are high; (3) local governments that rezone land for coastal ecosystems may be liable for declining property values; (4) development control is incremental and does not take into account threshold changes, meaning that development continues in areas where they will eventually become vulnerable - once buildings are in place, they attract further development; and (5) political pressure for local governments to provide protective coastal structures will grow as more assets are threatened.

Kousky (2014) considers how society can undertake managed retreat proactively, suggesting that reducing new development in high-risk areas, and adopting policies that allow for expected and orderly removal/modification of development as it is inundated. This will enable proactive management of shoreline retreat of a community. It is also suggested that, if planned for in advance, damaging coastal events can be used as opportunities for rebuilding to occur in accordance with managed retreat (Kousky, 2014). This pre-disaster planning could take the form of decision-making about where to rebuild and where to abandon, or buyouts of affected property. While damage causing events can be windows of opportunity for change, Abel et al. (2011) and Kousky (2014) both explain that decisions about such changes should not be taken in the immediate aftermath of damaging events as lengthy negotiations may lead to affected 
residents being left "in an unacceptable limbo" (Kousky, 2014, p.16). This indicates that proactively developing plans and engaging with communities is essential.

A third theme in the literature involves consideration of different methods for implementing managed retreat, for example Neal et al. (2005), Turbott (2006) and Siders (2013). There are many 'management tools' that can be utilized for managed retreat, including abandonment, relocation, the use of set-back lines, property acquisition, and land use planning, to avoid development in areas where coastal hazards are expected to worsen in the future. The identification of these methods is relevant for this thesis, as it suggests what managed retreat might comprise in practice, and therefore provides an indication of what would require costing within a managed retreat strategy.

In the United Kingdom, the equivalent of managed retreat is called managed realignment (see Glossary). The word 'retreat' is not used due to the negative connotations associated with 'retreating' from the coast. Managed realignment is however, slightly different to managed retreat as it is usually undertaken in sparsely populated areas (e.g. agricultural land), and involves the inland relocation of coastal defences, which allows the coastline to naturally readjust and to allow for the regrowth of salt flats and wetlands. The Abbotts Hall Managed Realignment Scheme in Essex, United Kingdom, involved the breaching of sea wall defences to provide a soft engineering defence for high value, agricultural land, while encouraging the regeneration of mud flats (National Climate Change Adaptation Research Facility (NCCARF), 2017). ${ }^{3}$ There were many benefits of this approach which can be applied to managed retreat as an option, including the development of a new intertidal zone which provides a natural, sustainable defence, while also reducing the impacts of coastal squeeze (see Glossary) (NCCARF, 2017).

\subsubsection{Managed Retreat in New Zealand}

Managed retreat studies have been undertaken at a regional level in New Zealand. The

Waikato Regional Council, Thames-Coromandel District Council and the Auckland

\footnotetext{
${ }^{3}$ Information retrieved from https://coastadapt.com.au/sites/default/files/case studies/SS46 UK Coastal Realignment.pdf
} 
Regional Council examined what managed retreat might involve (Turbott, 2006), identifying issues that are likely to be faced, as well as different methods of retreat. These methods included changes to district plans, local government property purchases, changing property rights to public ownership, and adding covenants to coastal properties, while also discussing the issues associated with public infrastructure and its maintenance.

Vandenbeld \& McDonald (2013) investigated community acceptance of managed retreat in New Zealand, focussing on the incentives or disincentives for acceptance of making room for a river, which included the purchase of at least 156 properties in the Twin Streams area in Auckland's Waitakere Ranges. The study identified the following factors useful for achieving community acceptance of managed retreat: the use of a voluntary approach, fairness in negotiations, consistent and open communication, providing personalised information about risk, employing people with a mixture of skills, recognising and responding to individual circumstances and emotions, and accommodating those who chose not to take up offers of acquisition. These factors are considered to be an important part of the community engagement phase of a managed retreat project and will have impacts on the overall cost of the option.

Hanna et al. (2017) consider the use of managed retreat as a coastal risk adaptation strategy in New Zealand. Their study focusses on governance issues related to two examples, Matata and Kaeo, affected by debris flows and successive floods respectively. They found a lack of attention to 'infrastructure retreat' in the application of the New Zealand Resource Management Act, in Long Term Plans under the Local Government Act, and in asset management plans. They concluded that managed retreat has the potential to avoid harm to coastal infrastructure assets and the services that they support. This suggests that managed retreat is also an important adaptation strategy for New Zealand's coastal communities given expected sea-level rise. In a subsequent paper, Hanna, White \& Glavovic (2018) examined the role of environmental planning in enabling managed retreat, concluding that there is no guiding policy framework for all hazard planning in relation to managed retreat, and that legislative tools for managing existing land use are largely absent. 
Furthermore, how to cost managed retreat emerged from another example of managed retreat outside a coastal context in New Zealand. Major subsidence and liquefaction after the 2010 and 2011 Canterbury earthquakes resulted in increased risk of flooding to a number of areas in Christchurch, and led to uninhabitable land being red-zoned. Property owners within red zones received offers of purchase from the Government based on $2007 / 2008$ rateable values. This decision to compensate property owners is bound to increase public expectations that people facing unavoidable losses due to climate-related impacts should also receive some form of government compensation (Boston \& Lawrence, 2018). This suggests that understanding the nature of the costs involved across New Zealand will be necessary. An understanding of what components might be compensated and who will, or should, bear the costs, will be required to achieve this. This thesis examines what categories of cost might be included, by developing a typology of the components of managed retreat and a framework for costing those components.

Reisinger et al. (2015) discuss managed retreat as an option to enable coastal communities to adjust to climate change impacts. They provide overviews of policies that can support and are involved in the implementation of managed retreat in different socioeconomic contexts, timescales and community preferences. Table 13.2 (p.295) in this study includes many of the options for managed retreat and discusses how they could be implemented, who bears the costs of the different options, key barriers to option implementation, timeframe for implementation and limitations. While many of these issues focus on implementing managed retreat, and are thus 'out of scope' for this thesis, the study discusses the relocation/removal/dismantling, rezoning, and council purchase (acquisition) options. The study concludes that the development of policy tools and the information base for managed retreat is important and will contribute to the ability of coastal communities to adjust to sea-level rise. This thesis aims to address these points by building the understanding around what managed retreat comprises, and how it could be costed.

\subsection{Managed Retreat Components}

The 'components' section of this literature review focuses on the components of managed retreat identified in the literature that require costing. Existing literature 
analysed for this section focusses on the different management strategies that can assist the implementation of managed retreat (e.g. planning and funding mechanisms) or on how the physical processes of relocation or abandonment are undertaken, and the social consequences of such actions. While the literature does not specifically address the components of managed retreat, it helps to inform the identification of components for the typology (Chapter Four). This section of the literature review informs the identification of managed retreat components and assists in the development of a component typology.

\subsubsection{Defining Managed Retreat}

In order to avoid expensive adaptation to rising seas, especially in the second half of the 21st century, plans for managed retreat need to be put in place now (Dawson et al., 2009). Neal et al. (2005) suggest a 10/100-year relocation concept in which a relocation strategy is developed in a ten year planning window and implemented as needed over a one hundred year time period. This suggests that a planning process be managed to allow planning and preparation for managed retreat to be implemented as needed, and that this planning process should begin early.

The 'managed' part of coastal retreat planning involves the establishment of a set of thresholds or triggers, such as sea-level encroachment within a predetermined distance of development or the number of days access is disrupted, which activate policies, procedures, and actions as part of the retreat processes (Koraim \& Negm, 2016; Fletcher et al., 2013). Such thresholds/triggers can be established now with existing information which can inform the timing of activation (Yohe, 1991). Research that characterises such triggers for sea-level rise is underway, including for New Zealand (Stephens et al., 2018; Kwakkel, Haasnoot \& Walker, 2016). Establishing trigger points and initial planning procedures are components of managed retreat. They have human resource costs (labour and expertise) to develop and implement.

Many different 'management tools' for climate change adaptation have been described in the literature for use in addressing its uncertainty and adaptation over time, such as: Lempert, Scheffran, \& Sprinz (2009); Kalra et al. (2014); Dittrich, Wreford \& Moran. (2016); Lawrence \& Haasnoot (2017); and Marchau, Walker, Bloemen \& Popper (2019). 
There is also literature that addresses managed retreat and its management tools directly, such as Neal et al. (2005), Turbott (2006), and Siders (2013), all of which have associated costs. All of these management tools have associated components and costs, which are discussed in the following section.

\subsubsection{Acquisition}

The use of property acquisition as a management tool to enable managed retreat features widely in the literature. Property acquisition, in the context of managed retreat, principally refers to the transfer of property from private to public ownership, or in some cases, to intermediary organisations. Different methods of property acquisition have been identified. Neal et al. (2005), Turbott (2006), and Freudenberg et al. (2016) describe acquisition whereby local governments acquire land and have it maintained as public greenspace. Turbott (2006) and Song et al. (2018) discuss 'buy and lease' acquisition, under which local government acquires property and leases it back to the original owner until retreat is required, thus allowing for some of the acquisition cost to be offset through the lease. Turbott (2006) also suggests that local governments could acquire property and then covenant it before reselling, thus establishing what the new owner is required to do, and not to do, with the property. Covenants in this case could include: prohibiting the development of protection works, prohibiting the making of complaints about erosion, or that the buildings must be removed once sea level reaches a certain position in relation to the buildings.

Henderson (2018) discusses the use of sea-level purchase options (SLPOs). A SPLO is a real estate option which does not come into effect "until sea-level rise imposes tangible effects on a given property" (Henderson, 2018, p.644). Henderson (2018) suggests SLPOs on threatened coastal properties could be purchased by non-profit, conservationfocused organisations, like land trusts. They argue that the real value of SLPOs is that they delay abandonment until it is absolutely necessary. When sea-level rise reaches a pre-determined point, property purchases are undertaken. Maintenance of the newly acquired land as public greenspace can then be the next step.

Each of the options for acquisition have associated costs. Neal et al. (2005) and Scarano (2018) suggest that it is possible for property acquisition to be achieved through 
condemnation proceedings, however compensation at market value is more commonly provided for property owners (Freudenberg et al., 2016; Kousky, 2014; Vandenbeld \& McDonald, 2013). Rulleau et al., (2017) found that compensation criteria based on market prices have significant positive influence on community acceptability of managed realignment options. Freudenberg et al. (2016) suggests that no property owner should ever be forced to sell, and that taking part in an agreement should be entirely voluntary. Freudenberg et al. (2016), Siders (2013), and Neal et al. (2005) discuss the use of incentives to encourage property owners to accept acquisition offers. This means that the total cost of property acquisition would be market value and any incentives would be on top.

After acquiring properties, there may be the need to demolish existing structures, rehabilitate the land to avoid marine pollution, and maintain the land as a publicly available space (Turbott, 2006; Linham \& Nicholls, 2010; Freudenberg et al., 2016). Scarano (2018) expands on this by suggesting that property acquisition involves a costly 'triple hit' to local governments, because coastal properties are expensive, the acquired land will require maintenance, and there is a possible loss to the tax base. Siders (2013), Kousky (2014), and Freudenberg et al. (2016) agree that acquisition could lead to the diminishment of the local tax base if people relocate elsewhere. Siders (2013) suggests that providing incentives to relocate nearby, could address the tax base issue by encouraging people to relocate within a specific council's jurisdiction. It must be stated, however, that relocation out of this jurisdiction into that of another council means that tax/rate payments will be collected by the new council and not that from which relocation has occurred from. The costs identified above (loss of tax base, cost of incentives, demolition, land rehabilitation and land maintenance) are those additional to the cost of purchasing the property, and require valuation where acquisition is used as a component of managed retreat.

The New Zealand Twin Streams case study (Vandenbeld \& McDonald, 2013) illustrates some of the components of managed retreat that incurred costs. Here, the local council acquired properties at-risk of flooding at market value, but also paid for costs associated with moving the houses, including legal fees and hiring movers. In response to the 2005 Matata debris slide, acquisition is a one-off offer based on independent valuations alongside the extinguishment of the existing use rights. Due to the potential risk to life 
(Whakatane District Council (WDC), 2017) in this location, structural protection is not feasible. Hanna et al. (2018) adds to this by suggesting that while not legally required to provide compensation, "WDC considers it has a moral obligation to 'invest in the retreat from high risk natural hazard situations that satisfy certain risk criteria'" (p.18). This signifies that while compensation does not need to be provided, it will be considered equitable to do so.

There are wider fairness and equity issues for ratepayers elsewhere who contribute to any acquisition costs through their Council rates. This is because these rates are the main source of council funds used for any acquisition undertaken within a managed retreat strategy.

Table 2.1: Acquisition components summary.

\begin{tabular}{|ll|}
\hline \multicolumn{1}{|c|}{ Components } \\
\hline$-\quad$ Property Acquisition (compensation \& \\
incentives). \\
- $\quad$ Demolition. \\
- $\quad$ Land rehabilitation. \\
- $\quad$ Land maintenance. \\
- $\quad$ Diminishing tax base (localised). \\
\hline
\end{tabular}

\subsubsection{Relocation}

Relocation as a component of managed retreat reduces inundation risk to coastal structures by moving them to another location, away from the hazard. Neal et al. (2005) explain that active relocation involves the movement of a structure away from the coast either before it is threatened, or if already threatened, before it is damaged. Relocation can occur at different scales: it could involve moving structures within property boundaries, to another site, or the staged relocation of entire communities (Turbott, 2006) and if relocation is not economically viable, demolition could occur. Each of these different scales/types of relocation have different associated costs.

Providing land to which relocated structures can be moved is another component to be considered, referred to by Matthews \& Potts (2018), Scarano (2018), Esteves (2014), Linham \& Nicholls (2010), Turbott (2006), and Neal et al. (2005). Providing alternative 
land would have additional costs, including provision of temporary housing and the development of new public facilities (Matthews \& Potts, 2018; Correa, Ramirez \& Sanahuja, 2011). After structures are removed from a coastal site, the remaining land will require rehabilitation and maintenance until it is lost to the sea (Henderson, 2018).

Table 2.2: Relocation components summary.

\begin{tabular}{|cl|}
\hline \multicolumn{1}{|c|}{ Components } \\
\hline- & Relocation (assisted or not). \\
- & Temporary housing. \\
- & Demolition (if relocation is not viable). \\
- & New land. \\
- & Land rehabilitation. \\
- & Land maintenance.
\end{tabular}

\subsubsection{Abandonment}

Abandonment as a managed retreat outcome is included in many definitions of managed retreat. There are however few studies that investigate what active abandonment of coastal development involves as an adaptation option. Neal et al. (2005) describe abandonment as either unplanned, or part of a planned retreat strategy. Planned abandonment involves regarding buildings as having a fixed life-span, and when the sea becomes a threat, no protection effort is made (Neal et al., 2005). Buildings could be demolished either after they are damaged by the sea, or just prior to damage, to avoid pollution (Linham \& Nicholls, 2010). Again, the abandoned land would require some form of rehabilitation and ongoing maintenance.

Abandonment in the managed retreat context could also include the abandonment of land. Requiring rebuilding to occur behind a setback line is essentially land abandonment (Neal et al., 2005). Abandonment as part of managed retreat would likely involve the cost of demolition, land rehabilitation and land maintenance, and potentially some form of compensation, noting that abandonment would need to sit within the legal requirements of councils for health and safety, risk reduction, and the avoidance of natural hazards if mitigation is not feasible. 
Table 2.3: Abandonment components summary.

\begin{tabular}{|ll|}
\hline \multicolumn{1}{|c|}{ Components } \\
\hline - & Demolition. \\
- & Land rehabilitation. \\
- & Potential compensation. \\
- & Land maintenance. \\
- & Removal of marine structures. \\
\hline
\end{tabular}

\subsubsection{Development and Rebuilding Restrictions}

Another way of facilitating managed retreat for existing development is to restrict rebuilding after the occurrence of damage, using planning provisions. A similar approach could be taken for new developments. Any rebuilding or new development would be completed behind a setback line, a certain distance from the coastline (Neal et al., 2005; Siders, 2013). Siders (2013) suggests that restrictions could include how many times a building can be rebuilt/repaired following damage before requiring removal, which would be a way of avoiding costly expenses involved with repetitive damages. These avoided damages could be costed for managed retreat.

While rebuilding restrictions are discussed in the literature, the costs involved are not. It is likely, however, that the cost of demolition, or relocation and compensation, land rehabilitation and maintenance would follow.

Table 2.4: Rebuilding/development restrictions components summary

\begin{tabular}{|c|}
\hline Components \\
\hline $\begin{array}{ll}\text { - } & \text { Possible compensation. } \\
\text { - } & \text { Loss of 'abandoned land' as a result. } \\
\text { - } & \text { Avoided damage. }\end{array}$ \\
\hline
\end{tabular}

\subsubsection{Public Infrastructure}

Public infrastructure (roads, water pipes, etc.), private infrastructure (e.g. telecommunications and power networks), and community assets (including police and fire stations, hospitals, libraries, community halls, and reserves) are vital for the viability of communities (Turbott et al., 2006). They cost local government and private 
companies to maintain, repair and 'relocate' as the sea advances. This means that when and how this infrastructure is abandoned, or moved or rebuilt somewhere else, influences costs that are part of a managed retreat strategy.

Scarano (2018) argues that withholding municipal services (see Glossary) may be a way of reducing public investment in high risk coastal areas while encouraging property owners to retreat. Local government could discontinue maintaining public infrastructure, such as roads and sewerage systems, meaning that those who choose to stay, would internalize the maintenance costs while freeing up local government investments to be used elsewhere (Scarano, 2018). Doing so would allow the redistribution of funds that may otherwise have been allocated to the repairing and maintaining of services, in an area of increasing coastal hazard. There are, however, some limitations to adopting this strategy, such as legal obligations of councils, and equity and fairness considerations which also would have financial cost implications for councils, in the form of potential legal challenges and compensation.

Kousky (2014), when discussing relocation of infrastructure, highlights that managed retreat would enable local governments to avoid costly maintenance and repair costs, as damaging coastal events become more frequent with rising seas. Compensation, land rehabilitation and land maintenance are recurring costs that are relevant for most of the management techniques identified in the literature. The avoidance of maintenance and repair costs, as coastal hazard increases, are significant avoided damage costs that can be identified as benefits of managed retreat. Other important avoided costs from adopting managed retreat include the reduction in loss of human life and costs associated with emergency responses (Correa et al., 2011; Freudenberg et al., 2016). Such costs and avoided damages will increase over time so identifying them creates benefits for managed retreat as an adaptation option. 
Table 2.5: Reduction of public infrastructure service levels components summary.

\begin{tabular}{|c|}
\hline Components \\
\hline $\begin{array}{ll}\text { - } & \text { Possible compensation. } \\
\text { - } & \text { Legal costs. } \\
\text { - } & \text { Avoided damage and repair. } \\
\text { - } & \text { Avoided maintenance. }\end{array}$ \\
\hline
\end{tabular}

\subsection{Climate Change Adaptation Costing}

This 'costing' section of the literature review identifies issues that inform the costing framework of this thesis (Chapter Five). The section outlines what is identified in the literature as being relevant to the costing of climate change adaptation options and discusses different valuation techniques that inform the development of the costing framework for managed retreat.

\subsubsection{Climate Change Adaptation Costing}

The valuation and costing of possible climate change adaptation actions have been sparsely documented within climate change adaptation literature (e.g. Haasnoot et al. (2019), and Kind et al. (2014). While not explicitly focussed on managed retreat, the following discussion sets out what the literature shows as being important for costing climate adaptation. This will inform what requires consideration when costing and valuing the components of managed retreat.

According to Chambwera et al. (2014), the cost of climate adaptation is the cost of any additional investment required to adapt to climate change with benefits, including the reduction in damages plus any gains in climate-related welfare that occurs after an adaptation action. Adaptation costs and benefits are established as a way of deriving a price for different adaptation options (Chambwera et al., 2014). It is suggested by Chambwera et al. (2014), that adaptation options should be investigated at a local level through the calculation of localized impacts. This is because cost estimates are often very different for local scale estimations, when compared to global or even national estimations. This suggests that enhancing local government understanding of the 
current and future impacts of sea-level rise, their costs and the costs of potential adaptation options is necessary before making coastal adaptation decisions.

Yohe (1991) identifies some of the issues that should be considered when costing climate change adaptations. These include; further economic development before inundation occurs and the response to true economic depreciation, when inundation is anticipated. Yohe (1991) also states that the benefit side of protection schemes should be valued as the "true economic cost avoided through its enactment" (p.256), and that the value of coastal structures can be expected to depreciate as the threat of sea-level inundation increases.

Yohe \& Schlesinger (1998) suggest that land and structures should be considered separately, and that procedures that account for the economic loss of one would not necessarily be the same for the other. According to Yohe \& Schlesinger (1998), the value of land lost to the sea should be estimated on the basis of land value from far inland, away from the ocean. This is because as land and property is inundated at the coast, values placed on a parcels of land close to the coast shift inland.

\subsubsection{Discount Rates}

Discount rates (see Glossary) are an important part of the costing of any climate change adaptation option. There is however conflict when it comes to what rate should be used. This is generally due to ethical concerns around how much 'better off' future generations might be, and how able they will be to bear costs in the future. Chambwera et al. (2014) discuss rates used for climate adaptation costing, which could fall between $0.1 \%$ and $2.5 \%$.

The United Kingdom Treasury currently mandates the use of declining discount rates for adaptation actions costing (Turner, Burgess, Hadley, Coombes \& Jackson, 2007; Luisetti

et al., 2011; Chambwera et al., 2014). Turner et al. (2007) explain that "the standard CBA practice of positive, fixed and short term (<25 years) discounting" (p.399) does not work well with longer term climate change adaptations such as managed retreat. Discount rates are important for the cost benefit analysis of managed retreat and its comparison to other adaptation actions. 
It is important to recognise that discount rates used to value individuals investments over time are likely to be very different to those used for societal investments. From an individual perspective, a higher discount rate is likely to be used when valuing investment (or divestment) over time. From a societal perspective, however, a lower discount rate may be more relevant as benefits extend beyond those that are purely private.

\subsubsection{Value in Delaying Options}

Yohe (1991) introduces a process which involves determining when response actions are optimal within the context of waiting for new information. Yohe explains that many management actions will be triggered in the future only when certain state variables cross specified thresholds. This allows communities to "correct any error in anticipating exactly when a given response may be required" (Yohe, 1991, p.266). Doing so allows for the possibility of new information becoming available, which could help differentiate future states of nature prior to the need to respond (Yohe, 1991). Yohe goes further to state that societies will learn more about the future and what global climate is heading towards as it unfolds, with this information likely leading to better management decisions. This could delay actions until the point they are actually necessary (with lead in time for implementation taken into account (Bell et al., 2017)), avoiding costly investments when they may not yet be required. The approach described by Yohe is very similar to the real options analysis (ROA) (see Glossary) approach taken by the Greater Wellington Regional Council (GWRC) (2015) in their analysis of flood protection options for the Hutt Valley, and by Infometrics (2017) in their analysis of flood and coastal adaptation options in Hawke's Bay.

Yohe \& Schlesinger (1998), Chambwera et al. (2014) and Tsvetanov \& Shah (2013) also refer to the value of delaying adaptation actions until new information is available. Delaying adaptation actions allows the opportunity for new information to become available which may affect the timing of actions. By delaying different actions until they are necessary, land and structures can deliver value while they are still in place. By timing the action using signals and triggers (Stephens et al., 2018), investment in managed retreat is not undertaken too early. Nevertheless, if actions are taken too late, there is the risk of damage resulting in expensive maintenance and repair costs and emergency 
removal of buildings and people. Yohe \& Schlesinger (1998) explain that if the timing of climate change adaptations is too late, the remaining value of the properties is lost. As such, allowing for market values to adjust with the imminent threat of inundation is important. The value of delaying actions can be estimated through real options analysis.

Twigger-Ross et al. (2015) in the United Kingdom undertook a review of the Pathfinder scheme which provided funding to local governments in the UK to implement flood management actions that improve community resilience (Twigger-Ross et al., 2015). The review assessed the benefits and put monetary values on the outcomes of the different management actions, which enables comparisons of their costs and benefits. The main benefits were described, then their scale was estimated along with the variation in scale depending on flooding events of varying sizes and return periods, and an indication of how soon the benefits would be expected. This process was important for making transparent the value of the benefits which would offset the costs.

The Pathfinder review also examined a counterfactual scenario if the Pathfinder Scheme was not in place - in other words, the 'do nothing' strategy. Establishing the counterfactual scenario is another part of understanding the impacts of proposed managed retreat actions. Including the counterfactual alongside the analysis of costs and benefits of managed retreat should be part of the component typology and costing framework in this thesis.

\subsubsection{Approaches to Climate Change Adaptation Costing}

There are many approaches to the valuing and costing of potential climate change adaptation actions (Watkiss, Hunt, Blyth \& Dyszynski, 2015). There are, however, very few that have been applied to managed retreat options, specifically. The Clifton to Tangoio Coastal Hazards Strategy 2120 (Hawkes Bay) (Bendall, 2018), and The Hutt River Protection Scheme (Lower Hutt) (Lawrence et al., 2019b) are two examples that assessed managed retreat options. Costing approaches that are relevant to answering the question of how to value the different components of managed retreat include those from Turner et al. (2007), Lu, Peng \& Du (2012), Fletcher, Rambaldi, Lipkin \& McAlister (2016), Fu, Song, Sun \& Peng (2016), Fu \& Song (2017), and Lin et al. (2014). 
Turner et al. (2007) undertook a cost-benefit analysis (see Glossary) for many managed realignment strategies for the Humber Estuary in England, and compared these scenarios to the current 'hold the line' strategy. The study involved an extensive GISbased study of the selected sites for realignment to establish what would be lost (of both land and property) under each realignment strategy. The study then compared the net discounted costs of each realignment strategy to the 'hold the line' strategy. The valuation of costs took into account the capital costs of realignment and the opportunity costs (e.g. grades/standards of agricultural land), along with the costs of maintaining defences, replacement costs and costs associated with habitat creation. As managed realignment is a similar approach to managed retreat, these costs (capital, opportunity, maintenance, and replacement) are relevant for the costing of a managed retreat strategy.

\subsection{Methodologies Relevant to the Costing of Managed Retreat}

\section{Components}

The following section outlines the various costing and valuation methodologies that are useful for the costing of managed retreat components.

Fletcher et al. (2016) and Fu et al. (2016) use hedonic regression (see Glossary) to estimate the cost of sea-level rise resulting in property damage or loss. Hedonic regression is a process where individual components of an asset are assessed for their impact on the overall value of the asset. This costing method could be applied to the value that public assets (such as parks, community halls, libraries and perhaps some critical facilities like hospitals) have to the community.

Optimised deprival values (ODV) are relevant for the valuation of managed retreat. The ODV of a group of assets is the smaller value of either: the lowest cost of replacing them with assets that would provide the same flow of services (optimised depreciated replacement cost (ODRC)), or the economic value of the assets (New Zealand Institute of Economic Research (NZIER), 2000). The economic value of assets is the higher of their disposal value (DV) and their value to users (UV). The UV of the assets is equivalent to what customers would pay for an equivalent service using the least cost practical solution. 
Birol, Karousakis \& Koundouri (2006) defined the role of many economic valuation techniques in designing water resource management policies; the methods could be applied to the valuation of managed retreat. The valuation methods explored include the replacement cost, market prices, and hedonic pricing methods as outlined above. They also introduce the use of travel cost, net factor income/production approach, and contingent valuation/choice experiment methods. The travel cost method is generally used to estimate values associated with sites used for recreation such as parks and reserves. The travel time and expenses that people incur in order to visit these sites represents a lower bound to the value placed on access to those sites. People's 'willingness to pay' to visit a site can be estimated based on the number of trips these people would make, at different prices (Birol et al., 2006). As managed retreat involves the moving of public assets away from the coast, the travel cost method could be useful for costing those aspects of the option which include the relocation of assets that have value to the affected community (e.g. town halls, fishing jetties). This is because these public assets will have value to the community and the travel cost method is a way of estimating that value. Lu et al. (2012) used the differences in travel time, to value the loss of services when a road is inundated and projected this out to 2060 . Adaptation options investigated include protecting the road or building it in another location.

Net factor income is a method used to estimate the value of ecosystem services that contribute to commercially marketed goods or services. This method estimates changes in producer surplus (in terms of the monetary benefit of producing a good or service) by subtracting the costs of other production inputs, including a normal rate of profit, from total revenue, with the remaining surplus indicating the value of the ecosystem service (Birol et al., 2006). An example of this in the case of managed retreat could be the reduction in income for a camping ground as a result of the business being relocated inland from the coast. This loss of earning potential could be used to compare the benefit of relocating this business with the benefit of providing on-site protection. The production function approach is similar, as it can be used to value non-market goods and services that act as an input to the production of marketed goods and services (Birol et al., 2006). The production function approach relates the output of goods and services to the inputs that are necessary for their production, usually by using econometric methods. 
Contingent valuation and choice modelling are 'stated preference' methods used to determine individuals' preferences in monetary terms for changes in the quantity or quality of non-market resources (such as reserves or jetties) (Birol et al., 2006). Individuals are asked to state their maximum willingness to pay or minimum willingness to accept, for an increase or decrease in the quality or quantity of the resource/asset. The main difference between contingent valuation and choice modelling is that the latter is used to quantify the trade-offs people make between different attributes of a good or service. As is the case with the travel cost method, contingent valuation and choice experiment methods are useful for estimating the value that public assets have to the community, assets that could be lost and might need to be replaced under managed retreat (e.g. the amenity of a beach, or a wetland created, respectively).

An alternative to stated preference methods are revealed preference methods. They impute values attached to non-market goods and services by asking people to choose between hypothetical scenarios that differ in the mix of goods and services on offer. For example an individual may be asked to choose between two or more travel routes that have different travel times and different safety levels. Given a value on time, an implied value on safety can be determined. Although this methodology may reveal values, it still relies on preferences being stated. In other cases, revealed preference can be based entirely on observed decisions in the market. For example, peoples preferences for living at the coast despite safety considerations.

With regard to managed retreat, either stated preference or revealed preference techniques could be used to value the trade-off between access to a beach coupled with relocation of structures, and a sea wall that protects structures but reduces beach access and, arguably, amenity.

\subsection{Examples of Managed Retreat}

The following section outlines some examples of managed retreat from New Zealand and overseas. Boxes 1-5 discuss managed retreat projects undertaken at Nags Head (North Carolina, United States), Kaeo (Northland, New Zealand), Twin Streams (Auckland, New Zealand), Muriwai (Auckland, New Zealand), and Matata (Bay of Plenty, New Zealand). 
A managed retreat strategy was implemented by the Nags Head community in North Carolina in response to a desire to protect the family beach atmosphere. The community recognised that the town would continue to be exposed to hurricanes and decided on a range of measures to adapt to this threat. Incentives were introduced to encourage new development to be located at a distance from the coastline through the use of strict setback lines. The town adopted much more restrictive building standards than those required by FEMA or the North Carolina Coastal Management Act (Neal et al., 2005). Future development of oceanfront hotels and condominiums was limited in Nags Head as smaller, single-family structures are easier to relocate/move when required (Neal et al., 2005). The different policy actions taken in this example (e.g. restricting building permissions and future relocation of buildings) are necessary components of managed retreat strategies.

Box 2: Kaeo (Northland, New Zealand)

The Kaeo flood risk reduction project was undertaken in a community which had experienced repeated flooding events (Hanna et al., 2017). The project provided funding assistance for the relocation of people from high risk homes through subsidies for retreat from the floodplain. As of April 2016, works were completed on eight of fourteen properties. This work included the demolition of two dwellings, the raising of four, removal of one and the registration of an encumbrance on the legal title of one dwelling to prevent it being used for accommodation. These actions are components of a managed retreat strategy that would require costing and funding, demolition, accommodation (raising houses), building removal, and legal matters.

Box 3: Twin Streams Project (Auckland, New Zealand)

The Twin Streams project was carried out in Waitakere, Auckland, as a community project designed to restore the stream environment which had deteriorated through pollution and neglect, and to manage storm water and river flooding (Vandenbeld \& McDonald, 2013). This project involved the purchase of at least 156 properties that were within the 1 in 100 year event floodplain (Vandenbeld \& McDonald, 2013). Following the acquisition of properties by the Waitakere City Council, using a fund for community development purposes, houses were removed in order for storm water reserves and management parks to be created. Twentyfive million New Zealand dollars was allocated for the acquisition process, with half of the properties being fully purchased and the other half part purchased (e.g. land only) (Vandenbeld \& McDonald, 2013). Properties were purchased at market value after a long process of discussion with the property owners. In addition to purchasing property, the council assisted people to move house, paying for legal costs and movers. These elements of the managed retreat process could all form part of a costing typology. 
A managed retreat process was undertaken at Muriwai beach in Auckland (Turbott, 2006; Bell et al., 2017) following significant erosion of about one metre per year since the $1960 \mathrm{~s}$, with the landward retreat of the shoreline putting infrastructure (including a carpark, the surf club tower and roads) at-risk. In response, the Auckland Regional Council used the services of an independent facilitator to work with the community to establish an agreed solution. While no private property was at stake, a process was developed through which all voices could be heard. The outcome of the community consultation was the establishment of a negotiated and staged plan that included decision making 'trigger points'. In addition to this, the carpark, surf club tower and a road were relocated landwards, providing space for the natural fluctuations in the coastline. The engagement process with the interested parties, the removal of the defensive coastal structures and relocation of assets all have costs relevant to a managed retreat strategy. What is significant in this example, is that while none of the affected assets was privately owned, the community placed significant value on them.

\section{Box 5: Matata (Bay of Plenty, New Zealand)}

In the aftermath of a damaging debris flow in 2005 at Matata, after finding no feasible protection options for the avoidance of future similar events, the Whakatane District Council have investigated other options. In 2015, council staff worked with a Consensus Development Group investigating different risk adaptation options (Hanna et al., 2017). This group came to the conclusion that voluntary managed retreat through council property acquisition presented the best option moving forward. The council is currently progressing with a retreat package for properties exposed to high yearly risk of loss of life from debris flows (Hanna et al., 2017; Whakatane District Council, 2017). A voluntary property purchase package has been offered to owners of at-risk properties in Matata on a one-off basis, the value of which is based on independent valuations at 'current market values' as of 1/07/2016 - excluding constraints associated with the event (Whakatane District Council, 2017). The regional council has the statutory authority to extinguish existing use rights without providing compensation. However, the councils have decided, under the particular circumstances, on a property buyout package and the extinguishing of existing use rights. The Matata example illustrates the potential elements to be costed for managed retreat, including compensation and acquisition.

\subsection{Chapter Summary}

This literature review has discussed the issues that climate change presents to coastal communities that are relevant to managed retreat as an option for coastal adaptation and how managed retreat has been defined in the literature. The various components identified in the literature of different types of managed retreat that require costing or valuation have been identified. There is, however, no literature found that brings the elements of managed retreat and their costing together. The aim of this thesis is to address this gap through answering the second research question - "what are the components of managed retreat that enable a better understanding of managed retreat as an adaptation option to be considered now and for its implementation over time?" 
The third section of this chapter examined the research surrounding the costing and valuation of managed retreat. There is little literature that covers the costing and valuation of managed retreat specifically, in any depth. This chapter forms an important foundation for the identification of managed retreat components and for the development of a costing framework set out in Chapters Four and Five. 


\section{Chapter Three: Methodology}

\subsection{Chapter Introduction}

Chapter Three outlines the methodology used in this thesis - the approach, design, and limitations of the research. The different methods used to develop the component typology and costing framework (Chapters Four \& Five) are also discussed.

\subsection{Research Design}

This thesis uses a qualitative 'desk-top' approach with deductive and inductive elements to generate new knowledge and build understanding of managed retreat as an adaptation option for addressing sea-level rise. This approach involved deconstructing managed retreat as a strategy across space and time, and presenting it in a way that decision makers, planners and at-risk coastal communities can better understand what it comprises and how managed retreat can be costed. As the literature lacked specific details of the components of managed retreat and how to cost it, a scaffolding approach, as described by Crotty (1998), has been used. A 'scaffolding approach' involves the building of a research process (involving different methods or steps) that best suits the purpose of the specific research. Figure 3.1 sets out the steps taken.

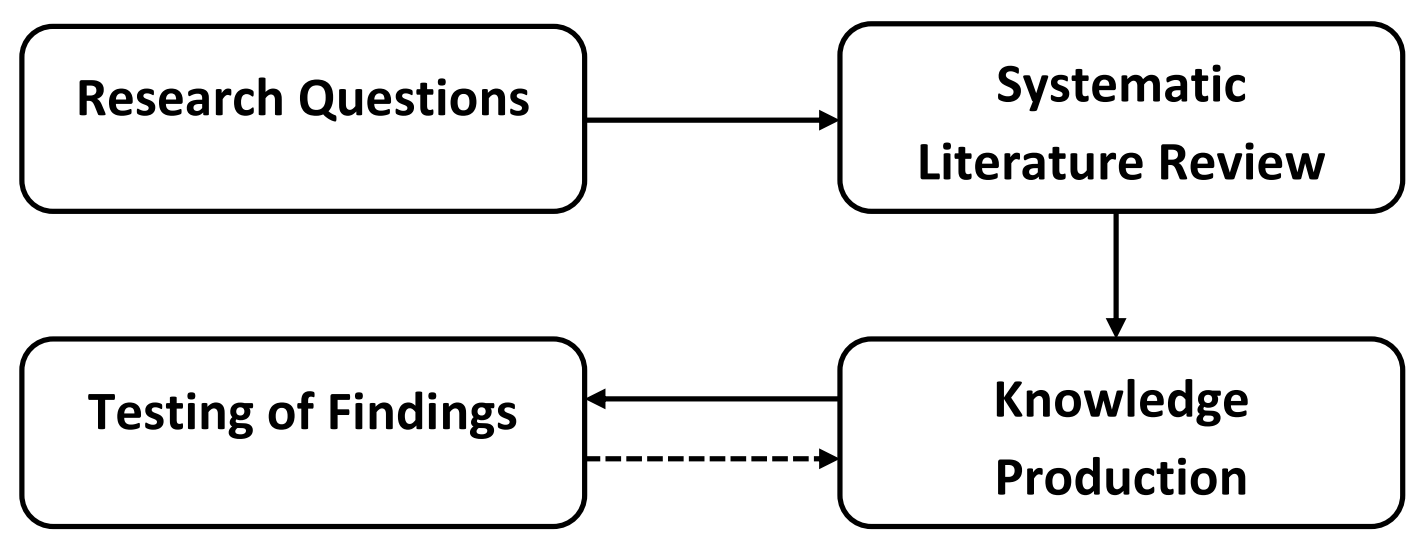

Figure 3.1: Methodological steps followed in this thesis. 
The research questions in Chapter One were developed based on the knowledge gaps in the literature surrounding managed retreat, and were designed to contribute and build upon the current understanding of managed retreat as an adaptation option. $A$ systematic literature review was undertaken to gain an understanding of how managed retreat had been studied and was understood in the literature. This helped to identify the focus of the thesis, as well as informing the development of the component typology and costing framework. A tailored pathways methodology (see Section 3.2.3) was developed and applied through this development phase of the thesis to help address the staging of components and the changing time and risk elements of managed retreat strategies.

The managed retreat component typology and costing framework were then 'tested' using a number of semi-structured discussions with key practitioners (including other researchers, regional councils, infrastructure managers, and an asset funder). They were taken through the component and costing typologies to get feedback on their robustness and usefulness in practice.

\subsubsection{Systematic Literature Review}

A detailed review of published literature relevant to the research questions (Chapter One) was conducted using a systematic literature review approach broadly following methodologies used by climate change adaptation researchers (Gough, Thomas \& Oliver, 2012; Berrang-Ford, Pearce \& Ford., 2015). The systematic literature review process is designed to make sure that literature is searched for using a set of clear and defensible criteria to avoid ad-hoc selection and possible undisclosed research bias (Berrang-Ford et al., 2015). The systematic review process followed the five steps: (1) the defining of research questions; (2) document selection (using specific inclusion and exclusion criteria); (3) critical appraisal of study quality; (4) analysis and synthesising of evidence/information; and (5) the presentation of results.

The process used started with the development of research questions (documented in Chapter One), followed by a refined literature search (including the selection of documents), and then the collection, synthesising and analysis of the insights from the relevant literature. Tables 3.1, 3.2 and 3.3 outline the search terms applied for both peer 
reviewed and grey (non-peer reviewed) literature, and the inclusion/exclusion criteria used for the selection of relevant documents.

Key words, outlined in Table 3.1, were applied to four academic databases (Springerlink, Web of Science, Scopus and Google Scholar) and to IPCC assessment reports, in different combinations, to search for peer reviewed literature relevant to the research questions. Titles and abstracts (or executive summaries) were analysed against the inclusion/exclusion criteria (Table 3.3) to screen information sources for those relevant to the thesis. The literature search was an open search across time with the relevance to the research questions being the primary factor. A similar approach was used in the search for grey publication sources, with search terms from Table 3.2 applied to the publications databases of Envirolink, NCCARF (see Glossary), local government websites, government department websites and Google searches. Again, sources were analysed using the inclusion/exclusion criteria. Following this, relevant insights were analysed and synthesised using thematic analysis which organised literature either into 'context', 'components', or 'costing' categories before further classification occurred within these categories. 
Table 3.1: Search terms applied to databases.

\begin{tabular}{|c|c|}
\hline Group & Key Words \\
\hline Natural Process & $\begin{array}{l}\text { Sea-Level Rise } \\
\text { Storm Tide } \\
\text { Coastal Flooding } \\
\text { Coastal Hazards } \\
\text { Flooding } \\
\text { Coastal Inundation }\end{array}$ \\
\hline Managed Retreat Terms & $\begin{array}{l}\text { Managed Retreat } \\
\text { Planned Coastal Retreat } \\
\text { Community Relocation } \\
\text { Community Abandonment } \\
\text { Managed Realignment }\end{array}$ \\
\hline Costing/Component Terms & $\begin{array}{l}\text { Costs } \\
\text { Costing } \\
\text { Economic Cost } \\
\text { Compensation } \\
\text { Adaptation } \\
\text { Components }\end{array}$ \\
\hline
\end{tabular}

(Full list of combinations of key words searched for within academic databases is included in Appendix C).

Table 3.2: Search terms used in search for grey literature that addressed the research questions.

\begin{tabular}{|c|c|}
\hline Managed Retreat & Managed Retreat Costing \\
\hline Sea-Level Rise Adaptation & Sea-Level Rise Adaptation Cost \\
\hline Coastal Retreat & Coastal Adaptation Costing \\
\hline
\end{tabular}


Table 3.3: Inclusion and exclusion criteria.

\begin{tabular}{|l|l|}
\hline \multicolumn{1}{|c|}{ Inclusion } & \multicolumn{1}{c|}{ Exclusion } \\
\hline Texts written (or available) in English & Texts in other Languages \\
\hline $\begin{array}{l}\text { Texts relating to one or more of the research } \\
\text { questions }\end{array}$ & $\begin{array}{l}\text { Texts not relating to any of the research } \\
\text { questions }\end{array}$ \\
\hline $\begin{array}{l}\text { Peer reviewed literature available through } \\
\text { Scopus, Web of Science, SpringerLink or Google }\end{array}$ & $\begin{array}{l}\text { Peer reviewed literature not available through } \\
\text { these databases }\end{array}$ \\
\hline $\begin{array}{l}\text { Grey literature easily available online through } \\
\text { Google searches, Envirolink, NCCARF, local } \\
\text { council websites and government department } \\
\text { websites }\end{array}$ & $\begin{array}{l}\text { Grey literature not easily accessible through } \\
\text { these databases }\end{array}$ \\
\hline
\end{tabular}

There were three objectives for the review. These were

1. To develop an understanding of how managed retreat had been discussed in the literature to date, and how this information helps to answer the research questions

2. To identify knowledge gaps about managed retreat that can inform the three research questions

3. To gather information for developing the component typology and costing framework

The search terms outlined in Tables 3.1 and 3.2 were developed in order to capture the full range of available information that addressed the relevant literature for answering the research questions. Document screening was completed using the inclusion/exclusion criteria outlined in Table 3.3, an approach that enabled a quick analysis of the search results and the selection of documents that aligned with the targeted scope of the review.

Through the review, it was noted that while the challenges around implementing managed retreat were widely covered in the literature, the components and costing of 
the option were not. In response to this knowledge gap, the managed retreat component typology and costing framework presented in this thesis were built.

\subsubsection{Knowledge Production}

The information and insights gathered through the literature review process were applied to the development of the component typology and costing framework presented in Chapters Four and Five.

The component typology was developed from knowledge about management tools relevant to a managed retreat strategy, or from knowledge about processes undertaken in different examples of managed retreat. Careful analysis of what different managed retreat strategies had comprised, enabled the identification of possible managed retreat components. These components were listed alongside the agency responsibilities (e.g. central government, local government, and private owners) for each of them (Table 4.1, p.52). These components were then organised into groups with shared characteristics and into stages that indicated their sequencing within a managed retreat strategy. A tailored pathways approach (Section 3.2.3) was then used to help illustrate the component staging aspect within each managed retreat strategy.

The costing framework (Chapter Five) was developed using a similar approach to the typology. The framework was developed using insights gained from the analysis of the literature that examined the costing of climate change adaptation strategies. The costing methodologies identified within the literature were matched to the components in the component typology. Those components that would require costing were identified from literature distinctly describing the costing of adaptation options, general literature on costing, and through discussions with practitioners (see Section 2.2.4).

\subsubsection{Tailored Pathways Methodology}

A tailored pathways methodology was developed for the staging of managed retreat components. This methodology is based on the principles of the Dynamic Adaptive Policy Pathways (DAPP) approach (Haasnoot, Kwakkel, Walker \& ter Maat, 2013) but is tailored to illustrate the staging of components of managed retreat for implementing a managed retreat strategy. Box 7 (p.47) provides an outline of the DAPP approach and 
illustrates how signals and trigger points are used to determine when discussions need to be had, as well as decisions made about which option to shift to as the physical world changes and before impacts of climate change are experienced. Under distinct climatechange scenarios, different options will be more appropriate and can therefore be activated and different pathways followed. This enables the overall strategy to retain flexibility and be applied in whatever physical and societal conditions emerge over time.

Section 4.4 discusses the staging of managed retreat components and identifies that there will be differences in when and which managed retreat components are activated, depending on the sea-level situation and what and who is exposed to the changes at any specific coastal location.

Figure 3.2 illustrates the tailored pathways approach. The activation of components is prompted once a pre-determined trigger point is reached with signals ahead of time indicating that a trigger point is approaching. Specific times have been excluded from the $x$-axis and replaced with 'conditional time' to suggest that the timing of component activation is dependent on the magnitude and rate of sea-level rise, including how this is exacerbated by the rate of subsidence/uplift, and the assets and people at-risk. Under one set of conditions, the activation of certain components may be brought forward, whereas under other sets of conditions, they may be pushed back. Components may also be substituted for others if it is decided that they are more appropriate in the climate and sea-level situations that develop. The basic principles of the DAPP approach are still followed; they are, however, applied in a slightly different way to show the components and their staging in one adaptation strategy - managed retreat. 


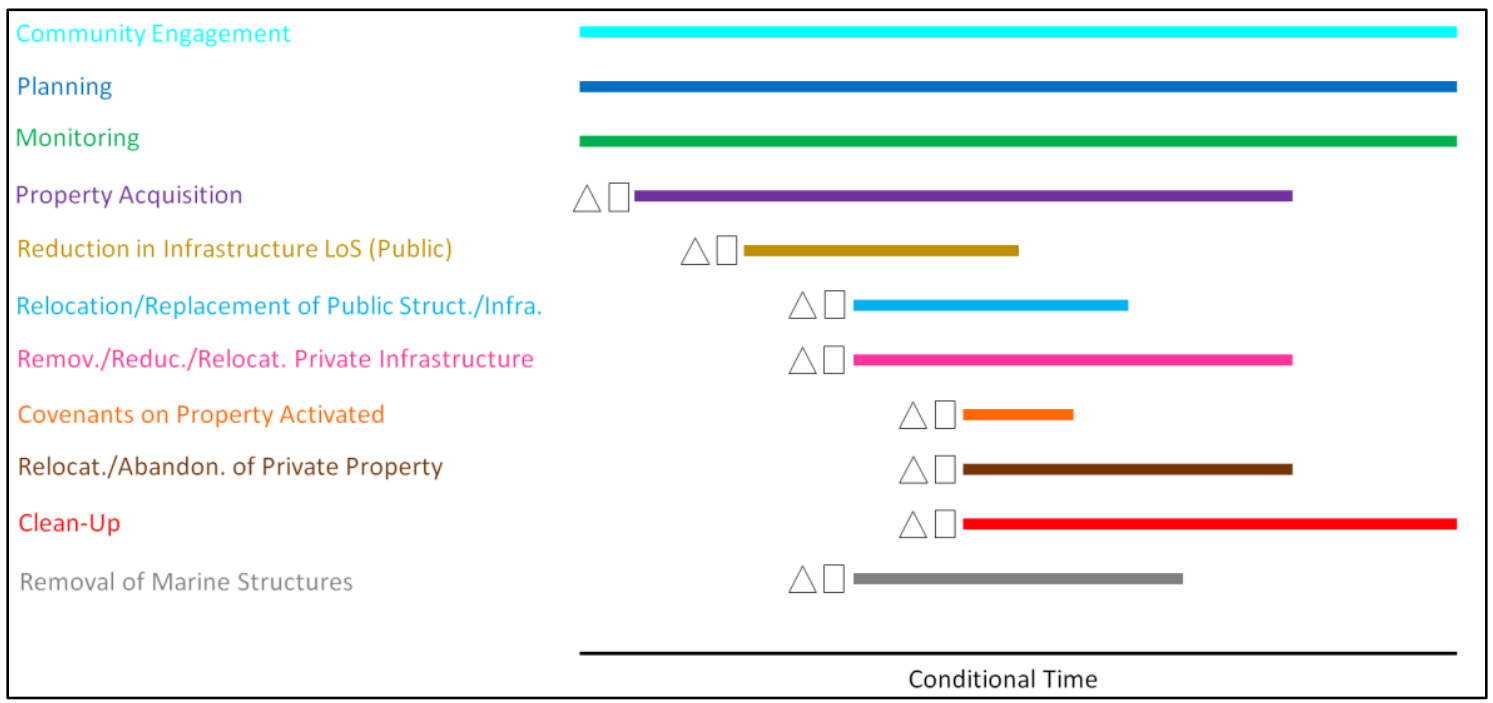

Figure 3.2: The tailored pathways methodology.

This DAPP-like approach (Figure 3.2) has been used in this thesis to illustrate the staging of components under a managed retreat strategy. This approach allows for the staging of component groups to be discussed while addressing the changing time and risk characteristics of managed retreat. In this way, indicators (signals - triangles; trigger points - rectangles) are used to alert when decisions need to be made to change to another component, while allowing for a flexible managed retreat strategy. This approach helps deal with uncertainties around future conditions. Figures 4.2-4.8 (Chapter Four, p.59-p.69), as part of the component typology use this tailored pathways approach to illustrate the staging of managed retreat components over time in different situations. 
Implementing flexible strategies under conditions of deep uncertainty is a challenge. The Dynamic Adaptive Policy Pathways (DAPP) approach is one approach designed to allow decision makers to plan for long term climate adaptation, while facing fundamental (deep) uncertainties associated with climate change and the consequences of impacts (Kwakkel et al., 2016; Lawrence \& Haasnoot, 2017; Bloemen, Reeder, Zevenbergen, Rijke \& Kingsborough, 2018).

Due to climate change uncertainties, there is a risk of making inappropriate strategy decisions (whether that be too little, too much, too soon or too late) (Kwakkel et al., 2016). Therefore, approaches are needed that assist planners and decision makers in making long-term, informed adaptation and management plans. The DAPP approach is a proactive planning approach which allows for flexible adaptation depending on how a situation unfolds over time (Kwakkel et al., 2016; Lawrence \& Haasnoot, 2017). A DAPP approach allows for the appropriate sequencing of a set of actions based on external developments (e.g. the extent and rate of sea-level rise). Given the uncertainties surrounding the rate and extent of sealevel rise now emerging, the DAPP approach is relevant for the planning of managed retreat strategies.

Adaptation pathways are decision strategies that work towards appropriate adaptation to climate change impacts through a sequence of manageable steps over time. The DAPP approach works on the premise that each action/decision/policy has a design life and may eventually fail to meet the management objectives (Lawrence \& Haasnoot, 2017). Once actions/decisions/policies fail, additional or other actions are required to continue to meet these objectives. Shifts to other actions are made at pre-determined trigger points (when physical or societal conditions reach a defined state) (Bloemen et al., 2018). By exploring different pathways and considering the path dependency of possible actions, adaptive plans can be built which include both short and long-term actions. The plan is then monitored for the signals that indicate when the next step within a plan should be implemented or the plan reassessed (Lawrence \& Haasnoot, 2017). Figure 3.3 illustrates how a typical DAPP would occur. Different options are considered with signals and trigger points providing warning for upcoming decision points and indicating when decisions to move to another option are required.

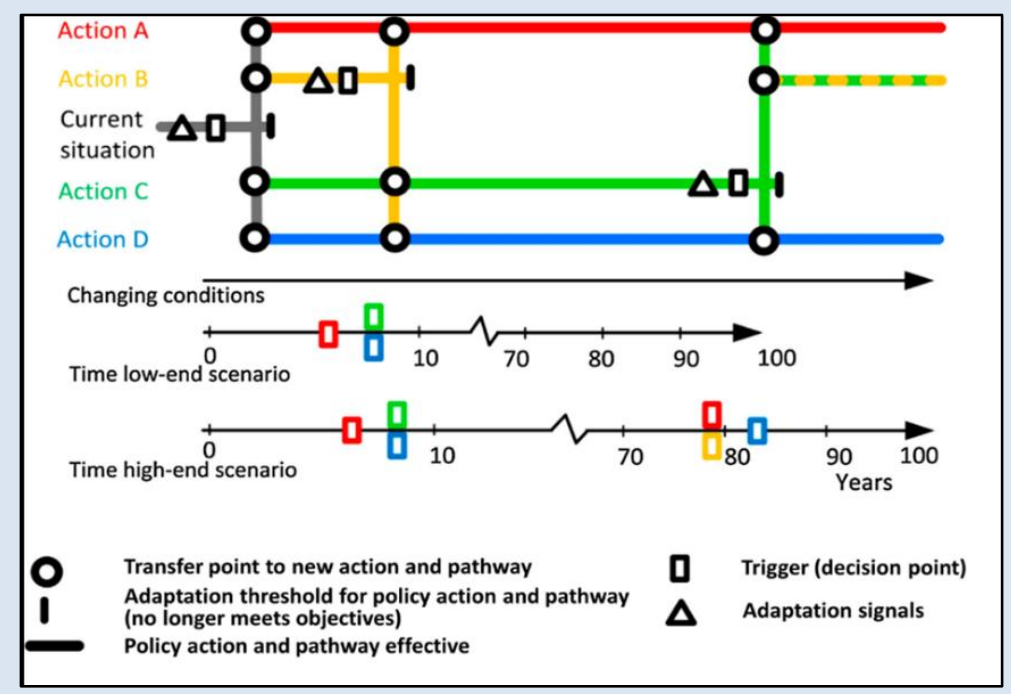

Figure 3.3: DAPP approach which includes the use of signals and trigger/decision points. Source: (Haasnoot et al., 2013; Hermans, Haasnoot, ter Maat \& Kwakkel, 2017). 


\subsubsection{Testing of Typology and Framework}

Scientific method requires that when new knowledge is produced, some form of validation is necessary. As Silverman (2011) explains, validity of scientific findings is an important consideration no matter what theoretical orientation from which they are produced, and irrespective of whether they are produced using quantitative or qualitative data. Validation processes help provide confidence in findings of their replicability and applicability across other locations or situations. New knowledge was developed in this thesis through the development of the tailored pathways methodology, the component typology, and the costing framework. These required validation. The validation process was undertaken through a series of six discussions with practitioners currently working in the climate change adaptation and policy/planning sectors.

Practitioners were selected according to their experiences of working with managed retreat (e.g. mitigating flood risk), those who had implemented strategic and planning stages of a managed retreat (e.g. for managing coastal inundation by halting further development in an exposed, low-lying area, and providing alternative development areas in various districts), in planning major long-term local government infrastructure (e.g. agencies servicing local government), in managing local government finances (e.g. a financial officer at a New Zealand regional council), and those planning the implementation of coastal adaptation. These discussions were used to test whether the typology and framework were useful, relevant and appropriate for those who may apply them in the future. This provided the opportunity to test whether anything else might be considered from their professional perspective and practice for application to a managed retreat strategy.

The practitioners were provided with an information sheet (see Appendix D), a copy of the typology and framework, had the approaches introduced to them, and were given the opportunity to make comments on the typology and framework. The following questions were used for the discussions: 
1. What are your impressions/thoughts on the typology and framework?

2. Is the thinking behind the typology and framework useful/relevant to those who may use them?

3. Do you believe that there is anything missing from the approaches? Or is there anything that can be expanded upon?

4. Is the way the typology and framework are presented useful/relevant for those who may use them?

5. Do you have any other suggestions for improving the approaches?

Comments made and responses given throughout these discussions were used to make changes to the component typology and costing framework. This process enabled the typology and framework to be effectively tailored for use by those who would apply them in practice.

The validation process followed corresponds to a 'respondent validation' discussed by Silverman (2011). Respondent validation is a method that can be used to test the validity of scientific findings by taking them back to those who are being studied. By doing so, it can be tested to see whether the findings conform to the lived experiences and gained knowledge of those being studied. Where these people verify the findings, it can be argued that one can be confident in their validity.

This thesis is part of the 'Living at the Edge' project under the Resilience National Science Challenge for which ethics approval was gained. Ethics approval was held by the primary supervisor within this programme through the University of Auckland Ethics Approval \#018448.

\subsection{Methodology Limitations}

As is the case with any piece of research, there are a number of limitations to the research methods. The timeframe within which this thesis was completed meant that the depth and breadth of the research was constrained. This was addressed by focussing solely on the issues, components and the possible costing approaches for managed retreat, while recognising the wider context for implementation (Sections 6.4.4 and 
6.5.5). Thus, the thesis was only able to address one part of the issues around implementation of managed retreat as an adaptation option. 'Who pays' for managed retreat, and how planning rules can enable managed retreat to be implemented, were out of scope, but are significant to those using managed retreat as an adaptation option and will require further research to resolve.

Another limitation is that the testing phase of this thesis was limited to New Zealand participants, albeit some key individuals who have had experience addressing the problems associated with managed retreat. Only issues in a New Zealand governance context were discussed with participants, although many of the issues are common across the world, but their implementation enablers may be locally specific. This means that the applicability of the typology and framework developed in this thesis, for other areas of the world where managed retreat is being considered or planned, has not been tested. The contribution of this thesis could be built on by gaining perspectives from others in similar sectors in different parts of the world to develop its application further.

\subsection{Chapter Summary}

This chapter has outlined the mixed methods, qualitative approach used in this thesis to address the research questions described in Chapter One. It has identified that taking a qualitative approach through the use of a systematic literature review to inform the development of new knowledge is an appropriate methodology for exploring the elements of managed retreat and building a costing framework. Chapter Three has outlined the methodologies followed to develop and test the approaches (component typology and costing framework). This chapter has also discussed the limitations of this research including the restrictions on the depth and breadth of the research as well as the potential for wider applicability of the research. 


\section{Chapter Four: Component Typology}

\subsection{Chapter Introduction}

Chapter Four focuses on answering the second research question: 'what are the components of managed retreat that enable a better understanding of managed retreat as an adaptation option now, and for its implementation over time?' This question is answered through the development of a managed retreat component typology, which identifies possible component parts of managed retreat strategies. Components have been identified through a systematic review of the managed retreat literature. The typology also illustrates component staging in differing physical and community conditions that exist in different locations.

The chapter begins by identifying both the managed retreat components, as well as agency responsibilities. Components are then organised into groups of similar actions and stages are identified. A tailored pathways method is then used to illustrate the changing time and risk elements surrounding sea-level rise for which a managed retreat strategy is designed. Hypothetical and real-world examples are used to illustrate the use of many of the components. This component typology and how it is presented also illustrates that managed retreat strategies will look different (components used and their timing) in every location, due to differences in the prevailing physical, environmental, economic, and societal conditions. The component typology can be adapted to accommodate these differences upon their implementation.

\subsection{Identification of Managed Retreat Components}

The component identification process has been undertaken to outline what activities and management processes/actions could be considered by coastal planners, decisionmakers and communities when forming a managed retreat strategy. These are set out in Table 4.1 (column 1). Table 4.1 (column 2) identifies who is currently responsible for each of the components. Identifying where responsibilities fall for each component, illustrates where funding consequences may fall in the first instance and informs the discussion for the costing framework (Chapter Five), and for a wider managed retreat plan. 
Table 4.1: Managed retreat components and responsibilities for managed retreat strategies. (Continued on following page).

\begin{tabular}{|c|c|}
\hline Components & Responsible Agencies \\
\hline $\begin{array}{l}\text { Community engagement/consultation on adaptation } \\
\text { options and implementation of managed retreat. }\end{array}$ & $\begin{array}{l}\text { Local government, central government } \\
\text { (state highways) }\end{array}$ \\
\hline $\begin{array}{l}\text { Local government plan/rule changes. Central } \\
\text { government legislation changes }\end{array}$ & Local government, central government \\
\hline Planning/consulting for the reduction in level of service & $\begin{array}{l}\text { Local government, central government } \\
\text { (state highways) }\end{array}$ \\
\hline $\begin{array}{l}\text { Monitoring of conditions (including the establishment of } \\
\text { trigger points for future actions) }\end{array}$ & Local government \\
\hline $\begin{array}{l}\text { Acquisition offers (including buy and lease back, } \\
\text { covenant and sell, buy and demolish and sea-level } \\
\text { purchase options (SLPOs)) }\end{array}$ & Local government \\
\hline Acquisition of alternate land & Local government \\
\hline $\begin{array}{l}\text { Development of new community facilities (town centre, } \\
\text { infrastructure etc.) }\end{array}$ & Local government \\
\hline Reduction of service levels of public infrastructure & $\begin{array}{l}\text { Local government, central government } \\
\text { (state highways) }\end{array}$ \\
\hline $\begin{array}{l}\text { Replacement/relocation of public infrastructure } \\
\text { elsewhere }\end{array}$ & $\begin{array}{l}\text { Local government, central government } \\
\text { (state highways) }\end{array}$ \\
\hline $\begin{array}{l}\text { Private companies relocate/reduce/remove investment } \\
\text { in privately owned infrastructure (to the extent } \\
\text { permitted by law) - including telecommunications, } \\
\text { power, ports etc. }\end{array}$ & $\begin{array}{l}\text { Private companies, local government } \\
\text { (some ports and national power grid } \\
\text { (Transpower) }\end{array}$ \\
\hline Activation of covenants on property & Local government, property owners \\
\hline Rebuilding and development restrictions & Local government \\
\hline $\begin{array}{l}\text { Relocation/abandonment of privately owned residential } \\
\text { and commercial property }\end{array}$ & Property owners, local government \\
\hline Providing of temporary housing & Local government \\
\hline
\end{tabular}


Table 4.1 (cont.): Managed retreat components and responsibilities for managed retreat strategies.

\begin{tabular}{|c|c|}
\hline Components & Responsible Agencies \\
\hline $\begin{array}{c}\text { Relocation/replacement of 'critical-facility' structures } \\
\text { (including hospitals, schools, police \& fire stations, } \\
\text { government buildings etc.) }\end{array}$ & Local government, central government \\
\hline $\begin{array}{c}\text { Relocation/replacement of community facilities/assets } \\
\text { (community halls, parks \& reserves etc.) }\end{array}$ & Local government \\
\hline Demolition & Local government \\
\hline Land rehabilitation & Local government \\
\hline Land maintenance & Local government, private companies, \\
& central government (DoC) \\
\hline Removal of marine structures & Lovent \\
\hline
\end{tabular}

The components are listed in a notional order according to their staging as part of a managed retreat strategy (e.g. planning and monitoring components are listed first, with demolition and land maintenance listed at the bottom). This has been done to enable those using the typology to better understand the range of components, and to visualise at what stage each component (and their associated costs) may become relevant in a managed retreat plan.

Identifying who is responsible for components is an important part of planning a managed retreat strategy. Doing so helps establish who will be required to manage different aspects of the strategy, and who may bear the associated costs. The agencies identified in Table 4.1 (column 2), include local government (both district and regional councils), central government (e.g. Department of Conservation and New Zealand Transport Agency), property owners (residential, commercial and agricultural) and private companies (e.g. telecommunication, ports, airports). Identifying where responsibilities may fall allows planners and policy-makers to understand the agencies involved and who may bear the costs of various aspects of the managed retreat strategy. 
As noted, managed retreat strategies will be made up of different components in different sequences in different locations. This is due to the varying conditions present in different locations. These conditions may include geophysical aspects, such as topography and rate of uplift/subsidence, and community aspects such as the assets atrisk, current management strategies, and existing legacy decisions/commitments made (some of which will have created lock-in and policy path dependency). Section 4.3, below, addresses these differences and outlines how the component typology may be used (components used and their staging): through the use of three hypothetical managed retreat strategies and four real-world examples that illustrate the application of the components identified in Table 4.1, in different locations with different physical and community characteristics.

\subsection{Grouping of Managed Retreat Components}

Table 4.2 organises managed retreat components from Table 4.1 into groups of similar actions at each stage of managed retreat. These groupings include planning and monitoring components, investment related components (including property acquisition, investment in new community facilities, and the reduction in public infrastructure or the loss of service (LOS)), active retreat components (including the relocation of public infrastructure and structures, the relocation or abandonment of private property, the reduction, removal or relocation of private infrastructure, and the activation of covenants) and clean-up components (including clean-up, removal of debris and developing the site for amenity, recreation and parks).

Stages of managed retreat are also included as part of Table 4.2. These stages include the 'Planning and Preparing', 'Enabling Investment', 'Active Retreat' stages; and a 'Clean-Up' stage. Table 4.2 is organised in chronological order according to when the components associated with each grouping occur within a managed retreat strategy. 
Table 4.2: Grouping of managed retreat components.

\begin{tabular}{|c|c|c|}
\hline & Grouping & Components \\
\hline 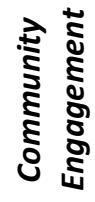 & Community Engagement & $\begin{array}{l}\text { - Community engagement/consultation on } \\
\text { adaptation options and implementation of } \\
\text { managed retreat. }\end{array}$ \\
\hline \multirow{2}{*}{ 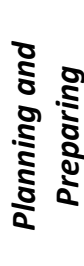 } & Planning & $\begin{array}{ll}\text { - } & \text { Plan/rule changes } \\
\text { - } & \text { Planning for a reduction in infrastructure LoS } \\
\text { - } & \text { Rebuilding and development restrictions }\end{array}$ \\
\hline & Monitoring & $\begin{array}{ll}- & \text { Monitoring } \\
\text { - } & \text { Establishing trigger points }\end{array}$ \\
\hline \multirow{3}{*}{ 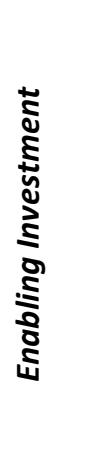 } & Property Acquisition & $\begin{array}{l}\text { - } \quad \text { Property acquisition offers and negotiations } \\
\text { - } \quad \text { Development of covenants on property. }\end{array}$ \\
\hline & New Community Investment & $\begin{array}{l}\text { - Acquisition of alternative land for relocation } \\
\text { to occur to } \\
\text { - } \quad \text { Development of new community facilities }\end{array}$ \\
\hline & $\begin{array}{l}\text { Public Infrastructure LoS } \\
\text { reduction }\end{array}$ & $\begin{array}{l}\text { - Reduction in maintenance (LoS) of public } \\
\text { infrastructure }\end{array}$ \\
\hline \multirow{5}{*}{ 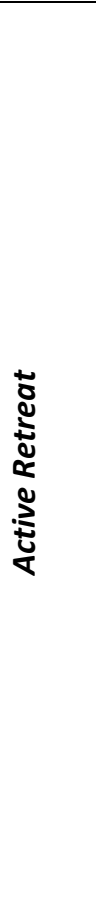 } & $\begin{array}{l}\text { Public Infrastructure and } \\
\text { Structures Relocation }\end{array}$ & $\begin{array}{ll}\text { - } & \text { Replacement/redevelopment of public } \\
\text { infrastructure elsewhere } \\
\text { - } & \text { Relocation of critical-facility structures } \\
\text { (schools, hospitals etc.) } \\
\text { - } \quad \text { Relocation/replacement of community } \\
\text { facilities (community halls, parks etc.) }\end{array}$ \\
\hline & Privately Owned Infrastructure & $\begin{array}{l}\text { - Private companies begin to } \\
\text { reduce/remove/relocate their infrastructure }\end{array}$ \\
\hline & Covenants on Property Activated & - Covenants on property activated \\
\hline & $\begin{array}{c}\text { Private Property } \\
\text { Relocation/Abandonment }\end{array}$ & $\begin{array}{l}\text { - } \quad \text { Relocation/abandonment of residential and } \\
\text { commercial property } \\
\text { - } \quad \text { Providing temporary housing }\end{array}$ \\
\hline & Removal of Marine Structures & - $\quad$ Removal of marine structures \\
\hline 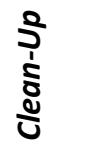 & Clean Up & $\begin{array}{ll}\text { - } & \text { Demolition } \\
\text { - } & \text { Land Rehabilitation } \\
\text { - } & \text { Land Maintenance }\end{array}$ \\
\hline
\end{tabular}


By organising the components into these groupings, planners and policy-makers using the typology can understand which actions might be considered together when forming a managed retreat strategy. When combined with the managed retreat stages (Table 4.2 , column 1), the groupings provide an indication of when components might become relevant, along with their staging within a managed retreat strategy. By illustrating such relative staging of components, users will have a better idea of which costs (of components) will need to be considered at different stages of managed retreat.

\subsection{Managed Retreat Staging}

Managed retreat is an ongoing risk management strategy that contains many components that occur at different stages. It is thus important that the overall process begins early to ensure that communities and those coordinating the strategy are aware and prepared for the 'Active Retreat' stage components before they are required. The following section uses a tailored pathways method to address the staging and timing of managed retreat components.

First, a dynamic adaptive policy pathways map that includes managed retreat (Figure 4.1) is presented to illustrate how the process of managed retreat develops. The other short-term actions will occur in parallel and only buy time while the early stages of managed retreat ('Planning and Preparing' and 'Enabling Investment') occur ahead of the later stages ('Active Retreat' and 'Clean-Up'). Following this, hypothetical strategies and real-life examples that involve the use of components from the typology, are presented to illustrate the staging aspect of managed retreat. These examples all occur under different circumstances and help to illustrate that the typology can be used and adapted to plan for the use of managed retreat in all coastal locations, regardless of their specific prevailing conditions (physical, environmental, social and economic). 


\subsubsection{Managed Retreat Using the DAPP Framework}

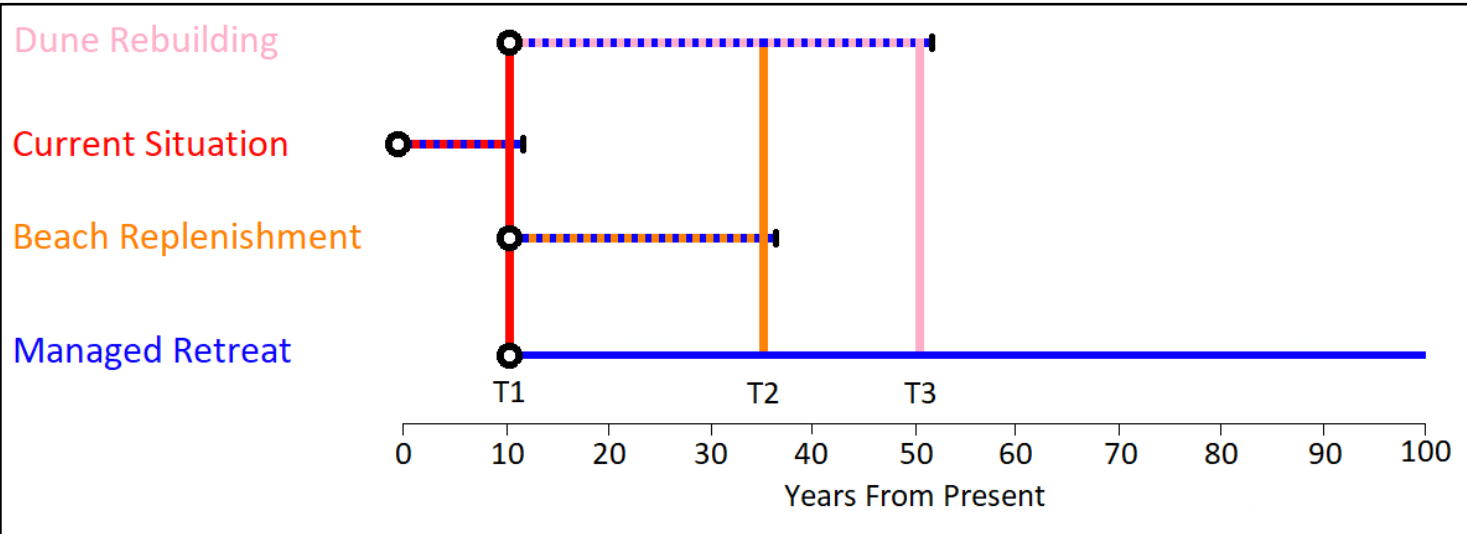

Figure 4.1: Example of a DAPP pathway showing many options, including managed retreat.

Figure 4.1 shows many options, including managed retreat, for the management of coastal hazard risk in a coastal location. In this hypothetical location, it has been identified that an eventual policy shift to managed retreat is inevitable. The current policies/actions being utilised at this location will fail to meet the risk management objectives for much longer. This means that alternative or additional policies/actions are required to meet these objectives before the current ones fail and the community faces coastal damage. Therefore, there is a policy shift at trigger point 1 (T1), where the management strategy can move to either beach replenishment, dune rebuilding or to the 'Active Retreat' stage of a managed retreat.

Following this first policy shift, there are two others (T2 and T3) that can be made to continue meeting risk management objectives, while avoiding the failure of current management policies/actions. If beach replenishment was the chosen strategy to follow at T1, it would continue until T2 where there would be the option to shift to either dune rebuilding or managed retreat. If dune rebuilding was the original chosen strategy (at T1), there is an option to change to managed retreat at either T2 or T3. In this example, managed retreat is the only option which can be shifted to at T3.

Managed retreat could be activated as the chosen risk management strategy at any of the decision/trigger points in this example (Figure 4.1). Managed retreat is shown to begin at present in Figure 4.1 as time is needed for the initial stages of managed retreat ('Community Engagement', 'Planning and Preparing' and 'Enabling Investment') to occur in advance of the activation of 'Active Retreat' stage components. These initial stages of 
managed retreat ahead of the 'Active Retreat' stage are illustrated by the dotted blue lines as part of the current situation, beach replenishment, and dune rebuilding options. These dashed lines signify that the early stages of managed retreat occur concurrently with the other options, with a shift to 'Active Retreat' components occurring at either $\mathrm{T} 1, \mathrm{~T} 2$ or $\mathrm{T} 3$. If managed retreat was activated at $\mathrm{T} 1$, there would only be a short lead time to prepare with the 'Active Retreat' components activated at T1. The use of shorter-term management options, such as dune rebuilding and beach replenishment may buy some time for the 'Community Engagement', 'Planning and Preparing' and 'Enabling Investment' components to be completed ahead of the activation of 'Active Retreat' components at either T2 or T3.

Managed retreat at the coast in many low-lying areas will be required as sea-level rise is ongoing, and the extent and acceleration of sea-level rise is uncertain past midcentury in New Zealand. Managed retreat may be required within the next 10 years in some locations, or around the middle of this century for others, depending on what is at stake (e.g. community and private assets) and the adaptive capacity of communities, including their coping capacity for storm events on top of the rising sea. Figure 4.1 illustrates this by suggesting that a shift to managed retreat could occur at T1, T2 or T3, depending on what conditions emerge in the future. Actions taken today need to consider how they can be transferred to a managed retreat strategy without locking in higher asset exposure to inundation and extreme storm events. Such notions include avoiding putting in place options such as sea walls which may create a feeling of false security, encouraging further development of at-risk locations, and that increase the value at-risk. This will involve signalling that managed retreat is inevitable for some locations, and that some locations will have greater or lesser time within which to plan and adjust.

\subsubsection{The Staging of Hypothetical Managed Retreat Strategies}

The following time-lines illustrate that there are many ways of undertaking managed retreat, with the component typology applied slightly differently in terms of the components used and their staging. Each of the following figures (4.2-4.8) use the component groupings from Table 4.2 and illustrate how the components might be staged in different situations. Again, it is important to note that definite times have not 
been used on the X-axis for the following figures. This is because the components shown could all occur within 10 years in some locations, over 50 in others, or may not end up occurring in some locations until next century. Conditions experienced in different locations will differ, as will the urgency for components to be used and activated due to the social and economic context in each location.

\section{Retreat of an Entire At-Risk Coastal Community to Another Site}

The first hypothetical managed retreat strategy involves the relocation of an entire coastal community away from the hazard over a distinct time period, thus removing the risk altogether. The staging of this managed retreat strategy is illustrated in Figure 4.2.

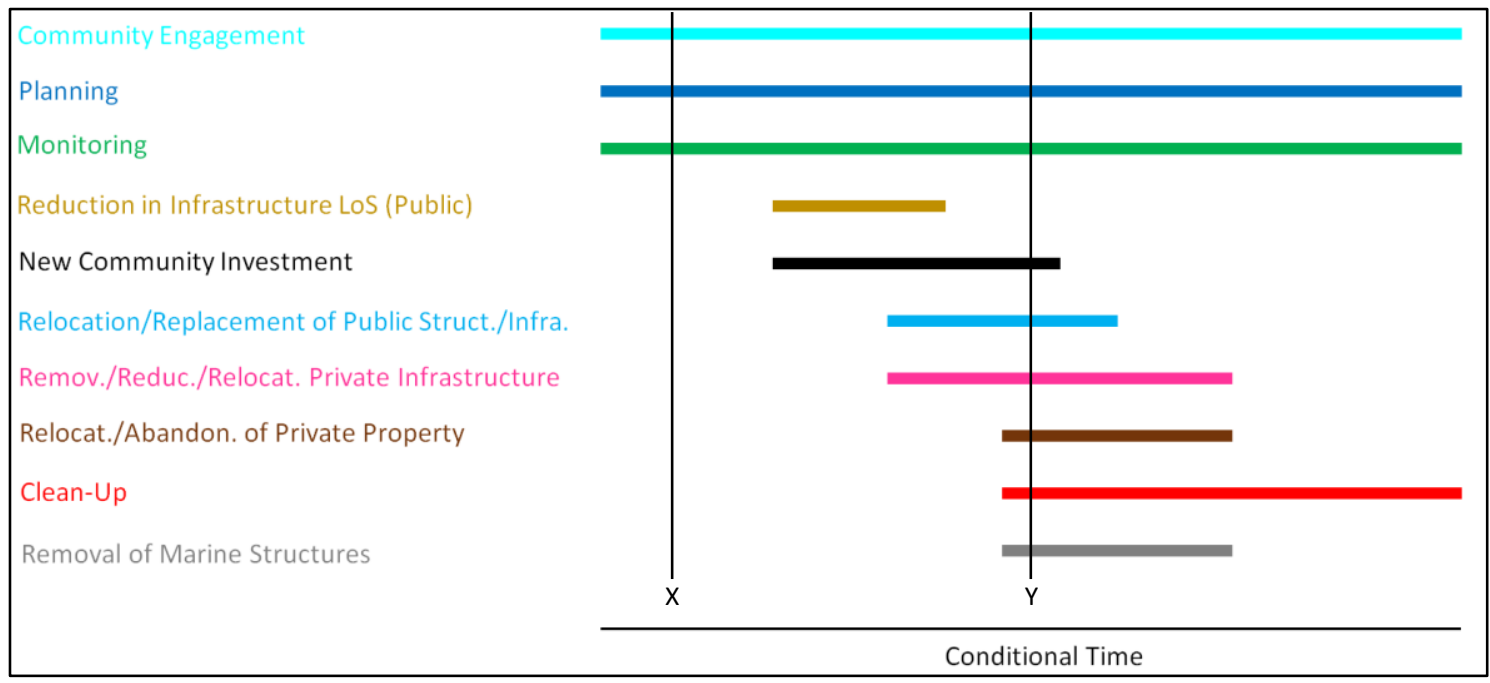

Figure 4.2: Possible staging of components for retreating an entire community to another location.

This strategy begins with a 'Planning and Preparing' and 'Community Engagement' phase, within which plans are made for which actions will be used. Decisions around what triggers will activate future actions are also made during this stage. The 'Planning and Preparing' stage may also include planning for the reduction of public infrastructure and introduction of supporting planning measures (or changes to district plans) to allow the active relocation in the future.

'Enabling Investment' could act as a stage that supersedes the initial 'Planning and Preparing' stage. This second stage could include reductions in the level of service provided by local and central government for public assets, the acquisition of a new site for relocation, and the development of new roading and storm-water drainage services for the relocated community. 
This could then be followed by an 'Active Retreat' stage, which could include the relocation or removal of publicly owned infrastructure and utilities (such as main roads, telecommunications, electricity, and ports) and community facilities (e.g. schools and hospitals). Local government-led relocation of privately-owned property and structures (residential and commercial) may occur alongside the relocation of public assets. Associated 'Clean-Up' stage components, including demolition, land rehabilitation, and land maintenance ensue. The removal of marine structures, such as wharves and seawalls, is included towards the end of this strategy as they may need to be left in place until the relocation process is completed in case of intervening storm events.

The value of Figure 4.2 being presented as staged actions is that coastal planners, decision-makers, and communities can see the different components of managed retreat and the staging that could be relevant to their situation. This also allows the different costs of their managed retreat strategy to be transparent over time. The two vertical lines in Figure $4.2($ Time $(X)$ and Time $(Y))$ are examples of this. Time $(X)$ occurs sooner in the managed retreat option and only intersects the community engagement, planning and monitoring components. This means that at Time $(\mathrm{X})$, only community engagement, planning and monitoring-related costs would be implemented. Time (Y), however, intersects the timelines of many components, including: new community investment, the relocation of public assets, reduced investment in private infrastructure, the relocation of private property, clean-up, and the removal of marine structures. This suggests that at Time $(\mathrm{Y})$, there are more components occurring simultaneously with costs and responsibilities falling on many different agencies or individuals. This process can be replicated at any point along the time-line to show which components and their associated costs might be relevant at any given point in time for a proposed managed retreat strategy. 


\section{Local Government Acquisition of Coastal Property}

This strategy (Figure 4.3) relates to a managed retreat strategy that focusses on local government acquisition of property in an at-risk coastal location.

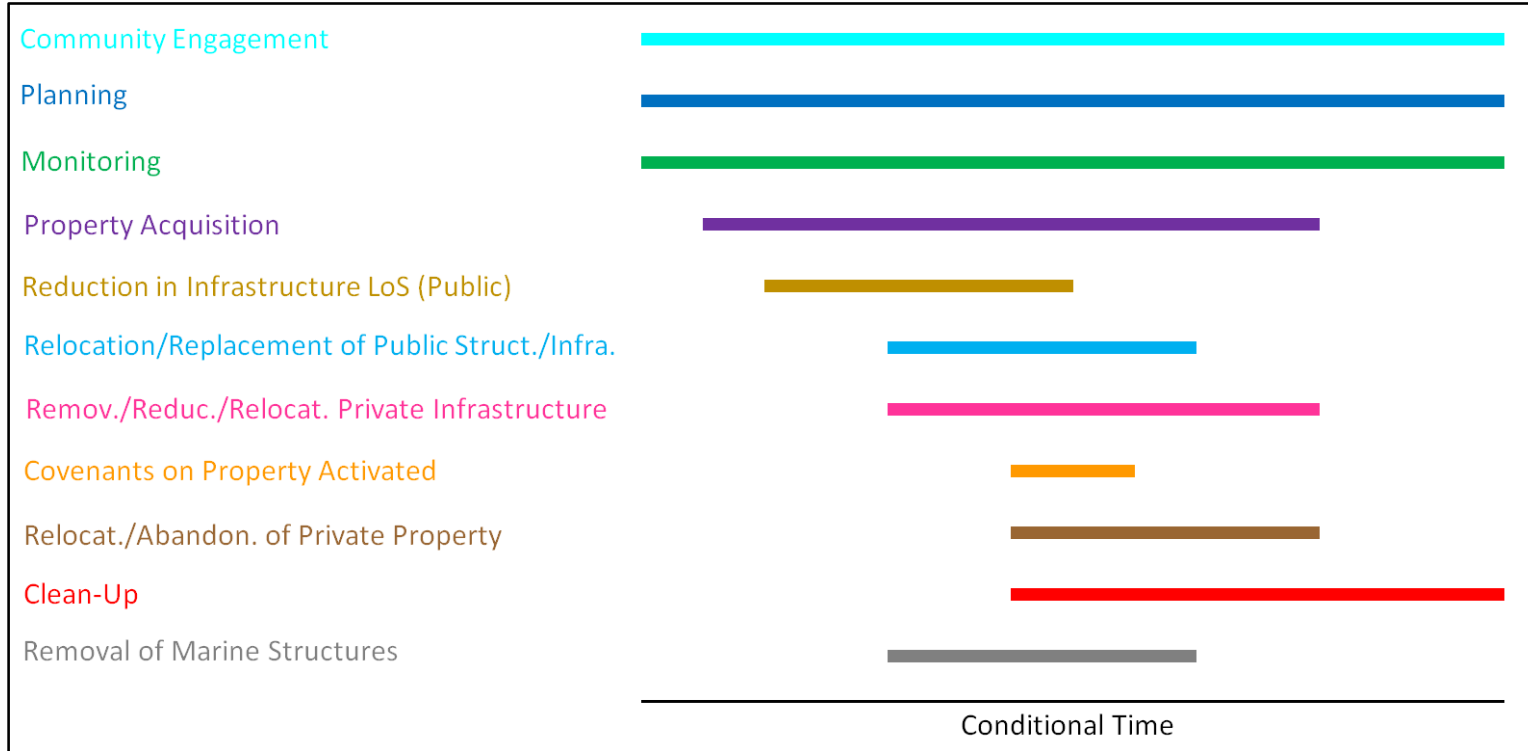

Figure 4.3: Possible staging of components under a managed retreat strategy that focuses on local government buyouts.

Local government property acquisition offers begin early in this strategy with local government having options regarding the outcome of the property. These options are: 'purchase-and-lease-back', where the acquired property is leased back to the original owner; 'purchase-covenant-sell', where coastal hazard provisions are added to the property before it is sold on; and 'purchase-demolish', where acquired property is demolished and the land is subsequently maintained as public space. By using one of these three options, local government gains more control over abandonments/relocation arrangements, while gaining the opportunity to recover part of the acquisition cost.

Reductions in infrastructure levels of service are another possible option under this strategy ('local government acquisition of coastal property'), which may encourage property owners to accept offers of acquisition, although this could create equity issues due to differential payment abilities. Once the conditions of a predetermined trigger point are met, the covenants added to properties are activated and the process of relocation/abandonment begins, with subsequent clean-up components activated. The removal of marine structures, such as sea walls and other recreational structures, may 
occur earlier in this strategy to encourage resident and business owners to accept acquisition offers.

\section{Signalling Approach}

The signalling approach strategy (Figure 4.4) involves local government signalling to the residents/business owners in the area their intentions to reduce their investment in an area (e.g. maintenance of public facilities).

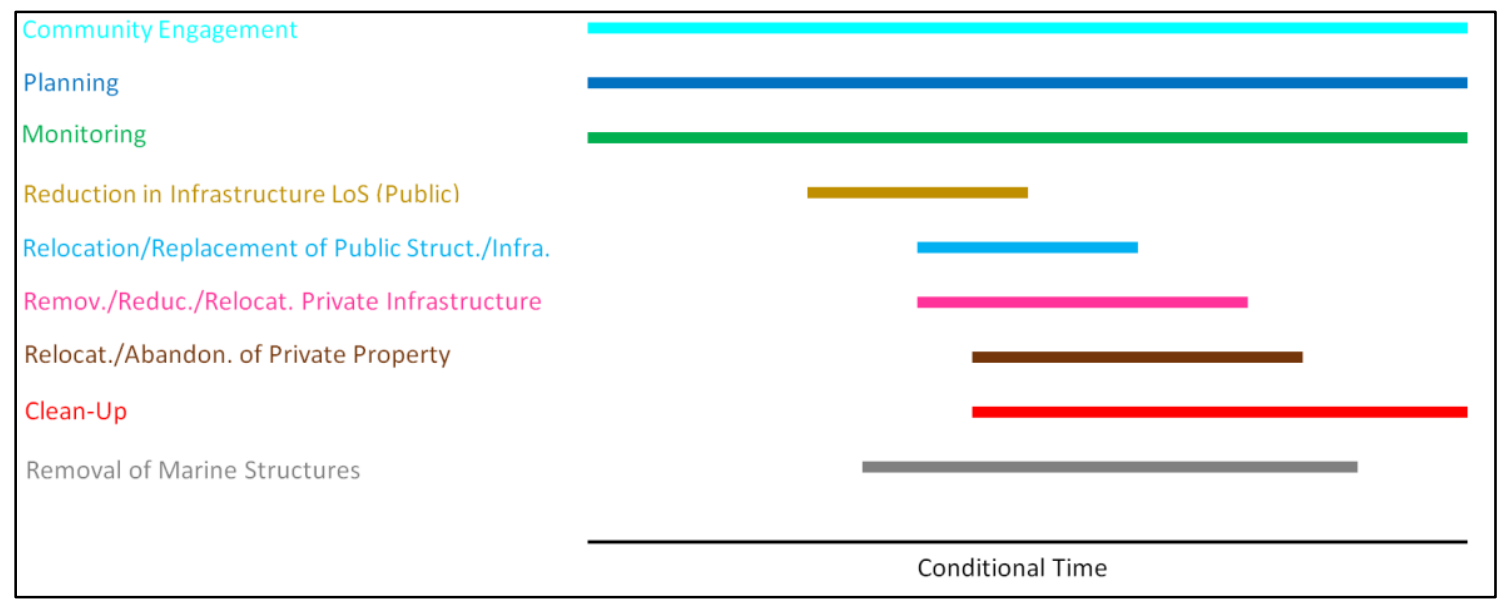

Figure 4.4: Possible staging of components under a managed retreat strategy that focuses on the signalling of intentions to reduce government investment in the area.

This strategy would involve a period of planning and monitoring, followed by a reduction in local government investments and a reduction in the level of services provided. The relocation of other public facilities, such as hospitals and schools, may also occur. The decision on whether and when to relocate or abandon property would be left to those residing in the area. It is likely that some form of compensation would need to be provided to those affected. 'Clean-Up' components, such as the demolition of remaining structures, and rehabilitation and maintenance of the land would occur as the community 'relocates'.

\subsubsection{Staging of Managed Retreat in the Real World}

Real-world applications of managed retreat components identified in the typology are presented in the following examples from around the world; Mapua/Ruby Bay (New Zealand), Grantham (Australia), Newtok (USA), and the Medmerry Estuary (UK). These examples illustrate that the typology can be used in a variety of situations to address 
coastal risk to communities, and different combinations of components, as well as different staging of components. Each example is illustrated with different characteristics to help illustrate that the typology can be used in these distinct situations.

\section{Mapua/Ruby Bay (New Zealand):}

- Low-lying coastal settlement currently experiencing coastal hazards which are expected to worsen as sea level rises

- Provides an example of how the early stages of managed retreat ('Community Engagement', 'Planning and Preparing' and 'Enabling Investment') may be implemented/undertaken

\section{Grantham (Australia):}

- Inland location, retreat in response to flash flooding

- Provides an example of a completed managed retreat strategy which uses many components from the typology

- Illustrates that components can be staged quickly and in response to inland flooding (not only retreating from coastal areas)

\section{Newtok (United States):}

- Retreat undertaken in response to increased erosion and inundation risks as a result of melting permafrost and ice sheets

- Provides an example of how aspects of the typology could be applied at a much smaller, resident-led (rather than local government led) retreat

\section{Medmerry (United Kingdom):}

- An example of adaptation within an estuarine environment which is becoming very relevant in New Zealand as sea levels continue to rise

- Provides an example of how undertaking managed retreat (or similar strategies) has the potential to result in the addition of increased amenity value in a community 


\section{Mapua/Ruby Bay, Tasman (New Zealand)}

Mapua/Ruby Bay in the Tasman region of New Zealand provides an excellent example of how the first few stages ('Community Engagement', 'Planning and Preparing' and 'Enabling Investment') may be implemented for a managed retreat strategy. Mapua/Ruby Bay is a low-lying section of the New Zealand coastline already affected by coastal inundation and it will become increasingly exposed to coastal hazards as sea levels continue to rise. The Tasman District Council follows an approach which provides a useful example of how local councils could provide signals to the community ahead of what could develop into a managed retreat strategy. The process in this region has evolved over more than a decade, and includes some of the components from the typology. Figure 4.5 illustrates how managed retreat groupings (as outlined in Table 4.2) have been used in the Mapua/Ruby Bay example.

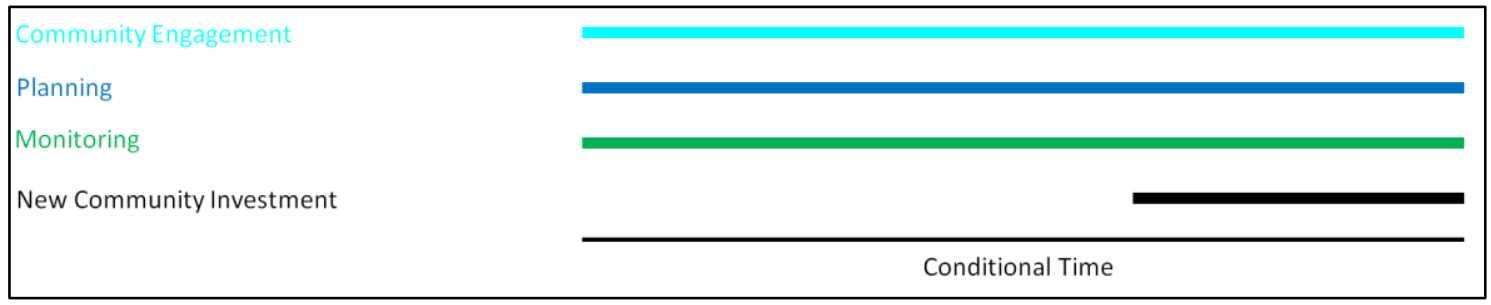

Figure 4.5: Timeline of component staging for the Mapua/Ruby Bay example.

\section{Context:}

The Ministry for the Environment coastal hazards and climate change guidance (Bell et al., 2017) use Mapua/Ruby Bay as a case study showing that the process of management of the coastal risks took over ten years beginning with information collection and assessment and the development of a 'structure plan'. The purpose of the structure plan was to provide alternative areas for future expansion of development away from lowlying areas and those prone to inundation and erosion at Mapua/Ruby Bay. This 'structure plan' involved extensive community input including extensive public debate. To achieve objectives of the structure plan, the Tasman District Council revised its District Plan with new rules prohibiting further subdivision and habitable building within the at-risk coastal zone, while also allowing new subdivisions on higher land, away from the coast.

The Council sought, and was granted, a declaration from the Environment Court for the new rules to have an immediate effect upon public notification of the Plan change. This 
was done to avoid a rush of development applications under the old rules in an area of known hazard risk from coastal processes which would have undermined the objective of the Plan change. Additional monitoring of coastal conditions in the area had been occurring before the planning process began and is currently ongoing. While there has not been any active relocation of dwellings/structures from the Mapua/Ruby Bay coastline, the Council strategy signals that it will not allow an increase in the assets and people at-risk. This strategy, while not yet a managed retreat one, could be the first priming stage of any managed retreat option. This is because it prevents an increase of assets in exposed areas and thus reduces the overall risk to the community and future costs of adjustment, whoever may be required to pay for them.

\section{Link to Typology:}

The Mapua/Ruby Bay example uses some of the components identified in the typology (Table 4.1). Here, the planning and plan changes fall under the 'local government plan/rule changes' and 'rebuilding and development restrictions' components from Table 4.1, and are grouped as 'Planning and Preparing' components (Table 4.2). The ongoing monitoring of conditions being carried out by the Tasman District Council relates to the 'monitoring of conditions' component identified in Table 4.1, and the 'Monitoring' grouping in Table 4.2. The zoning of a new, alternative area for development to occur relates to the 'local government acquisition of alternative land' component, and the development of the land relates to the 'development of new community facilities' components identified in Table 4.1. Both of these components ('land acquisition' and 'development of new facilities') fall into the 'New Community Investment' grouping of components (Table 4.1). There is also an element of 'Community Engagement' in this example.

'Active Retreat' stage components, such as the relocation of property, infrastructure, and other community facilities, have not yet occurred in the Mapua/Ruby Bay example. However, they could be activated in the future along with the removal of a sea wall structure that is currently in place along this stretch of coastline. This would allow the coast to be returned to a more natural state, as was done in the Medmerry example discussed later. 


\section{Grantham, Queensland (Australia)}

The risk management strategy undertaken in Grantham provides an example of a completed managed retreat strategy. This example also helps to illustrate that the component typology can be applied in a range of situations when responding to hazards, as the Grantham managed retreat occurred in response to inland flooding events which damaged the community. Inaction would have left the community at-risk of further damaging events. The following section investigates what was done in Grantham and how it relates to the component typology. Figure 4.6 (below) outlines the staging of managed retreat components for the Grantham example.

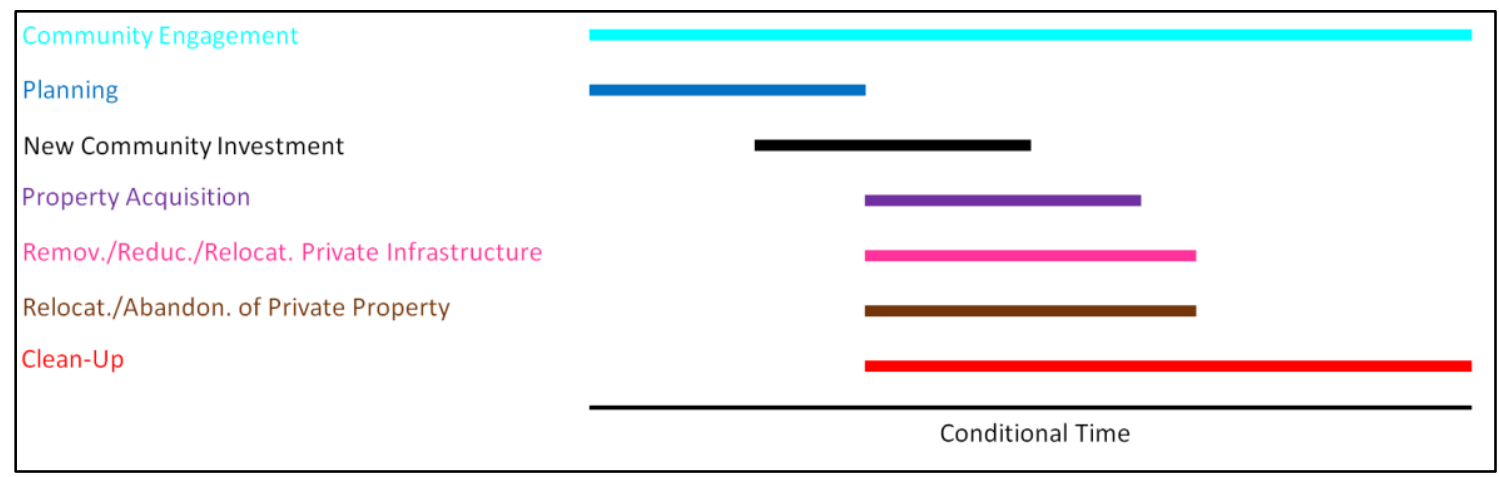

Figure 4.6: Timeline of component staging for the Grantham managed retreat example.

\section{Context:}

Grantham is a small, rural town in south-eastern Queensland, around 100 kilometres west of Brisbane. The Grantham community has been flooded many times over the last 150 years (Sipe \& Vella, 2014), the most significant event occurring on the $10^{\text {th }}$ of January 2011 when the community was hit by a flash flood resulting in major damage to houses and infrastructure which caused many fatalities. In response to this event, the Lockyer Valley Regional Council decided to relocate groups of the most at-risk residents to a safer location. This first involved extensive community consultations and "community visioning sessions on rebuilding Grantham" (Sipe \& Vella, 2014, p.406). Following this, the Lockyer Valley Regional Council entered negotiations to purchase a 377-hectare site near the town which was declared a State Reconstruction Area in order to fast track the regulatory processes enabling the land to be purchased. Within a month, essential infrastructure, such as roads and storm water drainage, were put in place for further development to occur. The land acquired by the Lockyer Valley Regional Council was used to enable voluntary land swaps of equivalently sized plots for property owners in 
the at-risk areas of Grantham. A lottery was considered to be the fairest way of deciding who would receive the original land swap offers (72 residents took part) with the construction of the first house completed at the new site within 11 months of the flood.

\section{Link to Typology:}

The Grantham managed retreat began with a short period of planning. The community information sessions and the regulatory process relates to the 'Community Engagement' and the 'Planning and Preparation' groupings (Table 4.2). The acquisition and development of the new site relate to the 'local government acquisition of alternative land' and 'development of new community facilities' components respectively (Table 4.1), with these all falling within the 'Enabling Investment' and 'Active Retreat' grouping of components from Table 4.2. The Lockyer Valley Regional Council essentially 'acquired' property through the land swap process. 'Demolition' of remaining structures on the acquired land and the rehabilitation and maintenance of it relates to the 'Clean-Up' grouping. The Grantham example is a managed retreat carried out in response to inland riverine flooding, but is an equally relevant example to a managed retreat in a coastal area at-risk from erosion and inundation, since it comprised many components from the typology.

\section{Newtok, Alaska (United States):}

Newtok in Alaska involves a small community which is retreating in response to increasing threats posed by the melting of permafrost and ice sheets. This example has a much smaller local government input compared to the other real-world examples presented here and helps to illustrate that the typology can be applied in a wide range of situations. Figure 4.7 indicates the staging of this retreat.

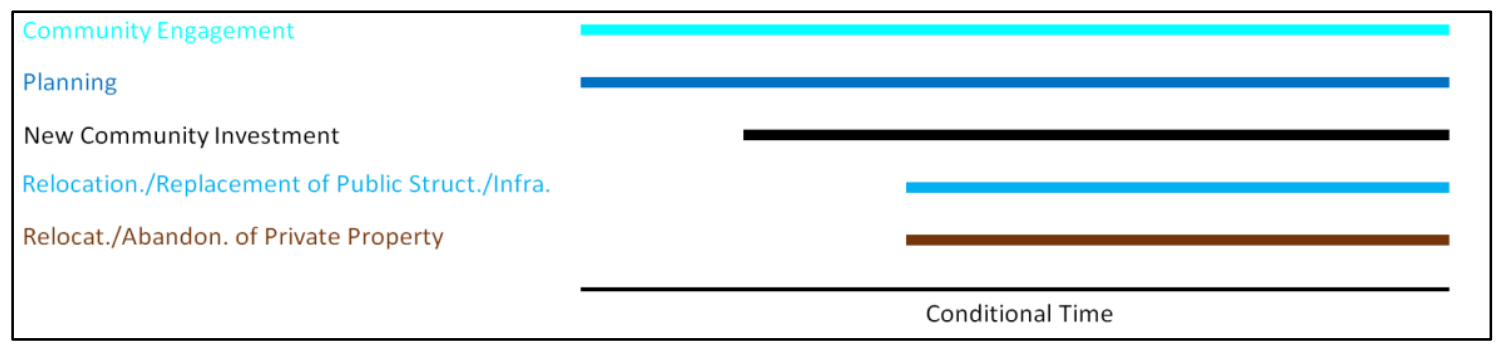

Figure 4.7: Timeline of component staging for the Newtok managed retreat example. 


\section{Context:}

Changing climatic conditions are affecting residents of small fishing villages in Alaska with major inundation and erosion issues arising as a result of melting ice sheets and the thawing of permafrost (Bronen and Chapin, 2013). One of these villages, Newtok, is located alongside the Ninglick River, close to the Bering Sea where a combination of rising local temperatures, thawing permafrost and wave action has shifted the river closer to the settlement. Six extreme weather events between 1989 and 2006 accelerated the erosion, caused flooding of the village's water supply, the spread of raw sewage throughout the town, and the displacement of people from their houses. These events have caused major damage to public infrastructure such as the village's landfill, sewage treatment facility, and to a barge landing which provides a significant service for the town, including the delivery of heating fuel and other supplies (Bronen \& Chapin, 2012). In order to avoid ongoing impacts, the village decided to relocate to another site nine miles from the current village, a process which has been ongoing since 2003.

Newtok's relocation process is very different from the other examples discussed in this section. The relocation is coordinated by the Newtok Planning Group, a multidisciplinary and multijurisdictional structure involving many federal, tribal, governmental, and nongovernmental agencies which voluntarily co-ordinate to facilitate the village's relocation (Bronen and Chapin, 2013). The relocation of Newtok first involved three votes, where local residents elected their preferred relocation site. Following this, the title to the preferred location (Mertavik) was acquired through a land-exchange agreement which was negotiated with the US Fish and Wildlife Service in 2003 (Bronen \& Chapin, 2013). Initially, no infrastructure existed at the new site, but residents built three houses at the site in 2006. The construction of 'pioneer infrastructure' including a new barge landing and multi-purpose evacuation centre began in 2009. As of December 2017, other key additions, such as a dining hall, bathrooms and electric generators, were in place at the new site (Trudeau, 2017). The relocation of key infrastructure from the old village to the new site was estimated to cost between US\$80 million and US\$130 million (Waldholz, 2017). 


\section{Link to Typology:}

Newtok's relocation uses many of the components outlined in the typology, however, it uses them in a very different way to the first two real-world examples (Mapua/Ruby Bay \& Grantham). Community engagement and consultation is a significant part of the Newtok managed retreat, with a ballot process instigated and the majority of the relocation being undertaken by those living within the community. The Newtok Planning Group conducted much of the engagement. The acquisition of alternative land in this example occurs under different circumstances as to what is outlined in the typology (Table 4.1), as land acquisition occurred through a negotiated land exchange, rather than a purchase. This acquisition relates to the 'acquisition of alternative land' component in the typology and together with the development of new community facilities (evacuation centre and barge landing) falling under the 'new community investment' grouping outlined in Table 4.2. While the Newtok managed retreat occurs under different circumstances and at different scales when compared to other the examples of managed retreat, many of the components identified in Table 4.1 are used, albeit applied in a slightly different way.

\section{Medmerry, Sussex (United Kingdom)}

The Medmerry coastline in southern England provides an example of managed realignment for the protection of the surrounding towns, as well as the development of salt flats to provide protection, habitat, and amenity for the surrounding community. While this example looks at a managed realignment strategy, the process undertaken and the resulting benefits are relevant to the typology. Figure 4.8 outlines the staging of components for the Medmerry example.

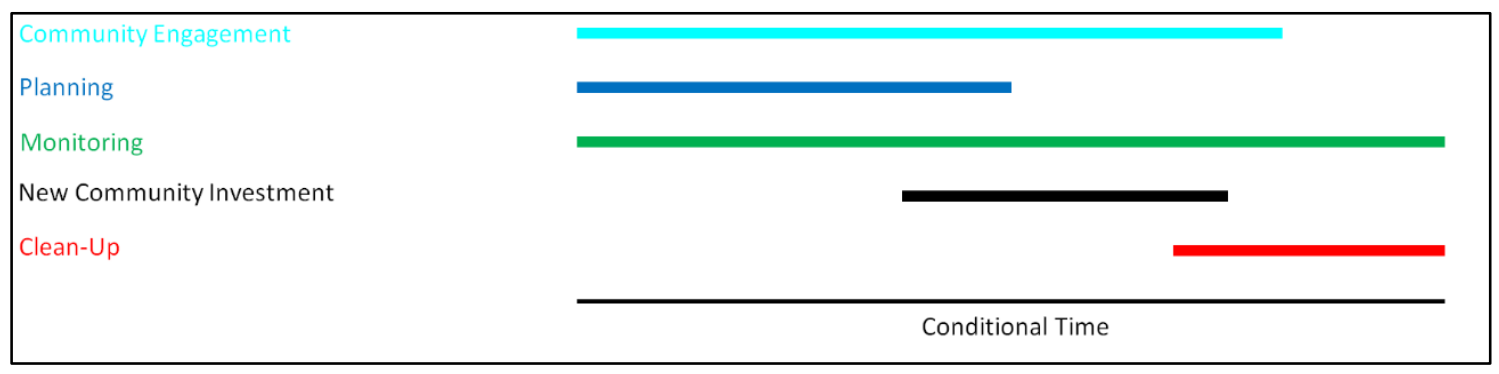

Figure 4.8: Timeline of component staging for the Medmerry example. 


\section{Context:}

Medmerry's coastline, in County Sussex, is one of the most at-risk areas from coastal flooding in southern England (Higuchi, Bruggemann, Obeahon, Gosden \& Elder, 2013). Coastal inundation has a long history at Medmerry and is a serious risk to the nearby towns of Selsey and Pagham (McAlinden, 2015). Prior to managed realignment, the protection for this coast was a three-kilometre shingle bank which was frequently breached. This did not provide adequate protection and the bank required re-profiling through winter months, costing the Environment Agency up to $£ 300,000$ each year in maintenance costs (McAlinden, 2015). In addition, the effect of rising seas was being felt due to coastal squeeze (McAlinden, 2015; Myatt, Scrimshaw \& Lester, 2003; Ledoux, Cornell, O’Riordan, Harvey \& Banyard, 2005; Rupp-Armstrong \& Nicholls, 2007). In response to a 2008 storm which caused $f 5$ million in damages, the managed realignment of defences was considered appropriate in this location (Higuchi et al., 2013; McAlinden, 2015).

The Environment Agency initiated a statutory Environmental Impact Assessment and obtained planning consent for the project (Landscape Institute, 2016). Community engagement was ongoing through this project as many residents and business owners believed it would damage the local community (McAlinden, 2015). The project team developed an engagement strategy which involved the Medmerry Stakeholder Group (2012; McAlinden, 2015). This group were involved in much of the decision making (McAlinden, 2015). This realignment included the construction of a new floodbank stretching two kilometres inland, and the construction of rock revetments which integrated with the remaining shingle barrier (Landscape Institute, 2016; McAlinden, 2015). A 110-metre breach in the shingle barrier allowed tidal waters to flow into the site, creating new intertidal habitat areas (Landscape Institute, 2016; McAlinden, 2015). Ongoing maintenance of the pathways, carparks and viewing facilities continues at the site.

Many benefits arose from this realignment. Three-hundred and forty-eight properties, the sewage works, caravan parks, and a main road now receive 1 in 100-year protection from coastal inundation events. Previously, this was only 1 in 1-year. Three hundred hectares of new habitat which is described as being of principal importance in the UK Biodiversity Action Plan (McAlinden, 2015) were formed, with 183 hectares of new 
intertidal habitat. Green tourism due to the new intertidal habitat has boosted the local economy (Landscape Institute, 2016; McAlinden, 2015). The scheme is estimated to have $£ 90$ million of direct economic benefits with maintenance costs, associated with protection, reduced significantly. Gained amenity value of the new coastline is beneficial to those situated in the surrounding community due to the strengthening of the economy as well as the amenity value the location now presents to the residents.

\section{Link to Typology:}

While the Medmerry example involved managed realignment as opposed to managed retreat, it contains actions that include components of the typology. There was a significant planning and consulting phase completed prior to the commencement of the construction phase, part of the 'Planning' grouping (Table 4.2). 'Community Engagement' was another significant component of this scheme. The Medmerry example includes action in the 'Clean-Up' grouping (including land rehabilitation and maintenance) as the land was 'rehabilitated' to form the new intertidal habitat with the accessible space and infrastructure put in place requiring ongoing maintenance. The 'Active Retreat' stage components for the Medmerry managed realignment relate more to the relocation of public structures and infrastructure, rather than the relocation of private property/public assets as only the defences were shifted and new ones developed, as opposed to the active relocation of an entire community.

The realignment process undertaken at Medmerry highlights the opportunity that managed retreat presents to gain amenity value. This could be through the addition of intertidal habitats/wetlands, which provide ecosystem services, or by the addition of publicly accessible coastal areas that were previously developed. Undertaking 'CleanUp' components can result in significant amenity value gains for communities. 


\subsection{Chapter Summary}

Managed retreat is an ongoing adaptation option that can comprise a number of actions, which, if thought about now, may help avoid further legacy decisions that can increase risk exposure, which would increase the costs of future adjustment. The process of managed retreat may take place over a long period of time, so steps along the way can begin as soon as possible in those locations where damages and losses are inevitable as identified by hazard and risk assessments.

This chapter has presented a range of hypothetical and real-world examples of managed retreat strategies. They illustrate both the short and long-term nature of managed retreat, and how managed retreat can advance in any particular location depending on the geophysical and community characteristics of the area, as well as the imminence of threat. Distinct circumstances in place and time can inform how the typology is used in a coastal risk management strategy. The typology presented in this chapter provides the essential components of managed retreat and identifies components that can be considered when costing the option. Accordingly, components can be chosen for a managed retreat strategy based on the location and community characteristics. 


\section{Chapter Five: Costing Framework}

\subsection{Chapter Introduction}

Chapter Five presents a methodology for the costing of managed retreat components. This is done to address the third research question: "What economic framework could be built for planning and costing managed retreat as an adaptation option within a coastal risk management strategy?" The costing methodology presented in this chapter has been developed through an analysis of literature relating to the valuation of management strategies in response to climate change issues. This analysis has allowed for the identification of various costing methodologies, with these methods being applied to the managed retreat components identified in the previous chapter. Chapter Five identifies what costs can be expected when using any of the identified components, provides an indication for those using the typology, as well as discussing other issues that require consideration when costing managed retreat.

Chapter Five commences by identifying which costing methodologies are applicable for costing different aspects of managed retreat components. Descriptions of what these methodologies are and what they involve are set out in Table 5.1 and are then applied to the managed retreat components set out in Table 4.1 (p.52). A discussion follows the specific costing methodologies. Subsequently, the chapter identifies both the individual types of costs for each component and the methodology that could be used to value them. The costs are then grouped and classified as either an economic costs, or simply a transfer of existing assets or property between different parties. Finally, Chapter Five outlines issues that will need to be considered when applying the costing methodology and is concluded with a short summary. 


\subsection{Valuation Methodologies for Managed Retreat Components}

Table 5.1 outlines valuation methods that have been identified as having the potential for estimating the individual costs of components. The descriptions in Table 5.1 have been included to provide an understanding of the different valuation methods, and whether they relate to the valuation of costs or benefits. Including these descriptions will increase the framework's practicality for those using it for the costing of managed retreat.

Table 5.2 identifies which of the valuation methodologies can be used to value the costs or benefits of different aspects of managed retreat components. The table uses the same components as those identified in the component typology (Table 4.1, p.52). Valuation methodologies are listed across the top of the table in abbreviated form with the components listed along the side. Tick marks symbolise whether a valuation methodology can be used to value an aspect of the different components.

Table 5.2 provides planners, policy makers and others working in the coastal risk adaptation space with a guide to find components relevant to their specific managed retreat strategy, and to gain an understanding as to which valuation methodologies are most applicable. As is the case with the component typology, different selections of components will be used for different managed retreat strategies. 
Table 5.1: Descriptions of valuation methods relevant for the costing of managed retreat components. (Continued on following page).

\begin{tabular}{|c|c|c|c|}
\hline \multicolumn{2}{|r|}{ Valuation Method } & Description & Cost or Benefit \\
\hline MP & Market Prices & $\begin{array}{l}\text { 'Market prices' refers to the } \\
\text { already available cost of marketed } \\
\text { good or services. For example, the } \\
\text { cost of labour or equipment hire } \\
\text { per hour, or quoted prices } \\
\text { provided by good/services } \\
\text { providers. }\end{array}$ & $\begin{array}{l}\text { Market prices are used to } \\
\text { estimate costs }\end{array}$ \\
\hline ODV & Optimal Deprival Value & $\begin{array}{l}\text { Optimised Deprival Value is the } \\
\text { value owners/uses would lose if } \\
\text { deprived of the asset or its } \\
\text { services. } \\
\text { ODV = Min (ODRC, Max (UV, DV)) } \\
\text { ODRC: Optimised Depreciated } \\
\text { Replacement Cost (optimised in } \\
\text { the sense of the best way to } \\
\text { deliver the existing services, not } \\
\text { whether the existing set of } \\
\text { services is itself optimal). } \\
\text { UV: Discounted Value of User } \\
\text { benefits, being what customers } \\
\text { would pay for an equivalent } \\
\text { service using a least cost practical } \\
\text { solution. } \\
\text { DV: Disposal Value, what the asset } \\
\text { could be sold for. } \\
\text { (NZIER, 2000) }\end{array}$ & $\begin{array}{l}\text { ODV is a measure of the } \\
\text { value of a benefit, or the } \\
\text { value of the loss of a benefit. } \\
\text { However, one way of valuing } \\
\text { the loss of a benefit is by } \\
\text { what it would cost to replace } \\
\text { it. Either with an equivalent } \\
\text { (depreciated) asset, or with a } \\
\text { different asset that delivers } \\
\text { equivalent services. For } \\
\text { example, a rainwater } \\
\text { collection tank may provide } \\
\text { as good a service as a } \\
\text { connection to a reticulation } \\
\text { system. }\end{array}$ \\
\hline HP & Hedonic Pricing & $\begin{array}{l}\text { Isolation of the value of an } \\
\text { individual characteristic of a } \\
\text { bundled good, usually valued } \\
\text { through econometric methods e.g. } \\
\text { valuing a sea view from data on } \\
\text { property prices. }\end{array}$ & $\begin{array}{l}\text { Used to impute the value of } \\
\text { a benefit that is not directly } \\
\text { traded in a market. }\end{array}$ \\
\hline TC & Travel Cost & $\begin{array}{l}\text { The cost, including time, of } \\
\text { traveling to an attraction is used } \\
\text { as a lower bound of the value } \\
\text { attributed to it by visitors. }\end{array}$ & $\begin{array}{l}\text { A cost used to value benefits, } \\
\text { usually environmental or } \\
\text { leisure, not traded in a } \\
\text { market (e.g. access to } \\
\text { wetlands). }\end{array}$ \\
\hline
\end{tabular}


Table 5.1 (cont.): Descriptions of valuation methods relevant for the costing of managed retreat components.

\begin{tabular}{|c|c|l|l|}
\hline $\mathbf{C E}$ & $\begin{array}{c}\text { Contingent } \\
\text { Valuation/Choice } \\
\text { Experiments }\end{array}$ & $\begin{array}{l}\text { Asking about 'willingness to } \\
\text { pay/accept' or imputing values } \\
\text { through a series of questions } \\
\text { about relative preferences. }\end{array}$ & $\begin{array}{l}\text { Used to value benefits, such } \\
\text { as protection provided by } \\
\text { sea walls versus having a } \\
\text { beach. }\end{array}$ \\
\hline $\mathbf{N F I}$ & $\begin{array}{c}\text { Net Factor } \\
\text { Income/Production } \\
\text { Function Approach }\end{array}$ & $\begin{array}{l}\text { Revenue less all costs of production } \\
\text { interpreted as the value of } \\
\text { unpriced (environmental) inputs. }\end{array}$ & $\begin{array}{l}\text { Used to value an input used } \\
\text { by businesses where that } \\
\text { input is not traded in a } \\
\text { market e.g. value of rapids to } \\
\text { anmunity that provides } \\
\text { comite water rafting. }\end{array}$ \\
\hline
\end{tabular}

Table 5.2: Valuation methodologies and their applicability for different managed retreat components. (Continued on following page).

\begin{tabular}{|c|c|c|c|c|c|c|}
\hline Managed Retreat Component & MP & ODV & HP & TC & CV & NFI \\
\hline $\begin{array}{l}\text { Community engagement/consultation on adaptation options } \\
\text { and implementation of managed retreat }\end{array}$ & $\checkmark$ & & & & & \\
\hline $\begin{array}{l}\text { Local government plan/rule changes. Central government } \\
\text { legislation changes }\end{array}$ & $\checkmark$ & & & & & \\
\hline $\begin{array}{c}\text { Planning/consulting for the reduction in infrastructure level of } \\
\text { service }\end{array}$ & $\checkmark$ & & & & & \\
\hline $\begin{array}{l}\text { Monitoring of conditions (including the establishment of trigger } \\
\text { points for future actions) }\end{array}$ & $\checkmark$ & & & & & \\
\hline $\begin{array}{l}\text { Acquisition offers (including buy and lease back, covenant and } \\
\text { sell, buy and demolish and sea-level purchase options (SLPO's)) }\end{array}$ & $\checkmark$ & $\begin{array}{l}\checkmark \\
\text { (b) }\end{array}$ & & & & \\
\hline Acquisition of alternative land for relocation & $\checkmark$ & & & & & \\
\hline $\begin{array}{c}\text { Development of new community facilities (town centre, } \\
\text { infrastructure etc.) }\end{array}$ & $\checkmark$ & & & & & \\
\hline Reduction of service levels of public infrastructure & & $\begin{array}{l}\checkmark \\
\text { (c) }\end{array}$ & & & & \\
\hline Replacement/relocation of public infrastructure elsewhere & $\checkmark$ & $\begin{array}{l}\checkmark \\
\text { (c) }\end{array}$ & & & & \\
\hline
\end{tabular}


Table 5.2 (cont.): Valuation methodologies and their appropriateness for different managed retreat components.

\begin{tabular}{|c|c|c|c|c|c|c|}
\hline Managed Retreat Component & MP & ODV & HP & TC & CV & NFI \\
\hline $\begin{array}{l}\text { Private companies relocate/reduce/remove investment in } \\
\text { privately owned infrastructure (to the extent permitted by law) } \\
\text { - including telecommunications, power, ports etc. }\end{array}$ & $\checkmark$ & $\begin{array}{c}\checkmark \\
(\mathrm{a})(\mathrm{c})\end{array}$ & & & & $\checkmark$ \\
\hline Activation of covenants on property & & $\begin{array}{l}\checkmark \\
\text { (c) }\end{array}$ & & & & \\
\hline Rebuilding and development restrictions & $\checkmark$ & & $\checkmark$ & & & \\
\hline $\begin{array}{l}\text { Relocation/abandonment of privately owned residential and } \\
\text { commercial property }\end{array}$ & $\checkmark$ & $\begin{array}{c}\checkmark \\
\text { (a)(b) }\end{array}$ & & & & $\checkmark$ \\
\hline $\begin{array}{l}\text { Relocation/abandonment of privately owned residential and } \\
\text { commercial property }\end{array}$ & $\checkmark$ & $\begin{array}{c}\checkmark \\
\text { (a)(b) }\end{array}$ & & & & $\checkmark$ \\
\hline Providing of temporary housing & $\checkmark$ & & & & & \\
\hline $\begin{array}{c}\text { Relocation/replacement of 'critical-facility' structures } \\
\text { (including hospitals, schools, police \& fire stations, government } \\
\text { buildings etc.) }\end{array}$ & $\checkmark$ & $\begin{array}{c}\checkmark \\
(\mathrm{a})(\mathrm{c})\end{array}$ & $\checkmark$ & & & \\
\hline $\begin{array}{l}\text { Relocation/replacement of community facilities/assets } \\
\text { (community halls, parks \& reserves etc.) }\end{array}$ & $\checkmark$ & $\begin{array}{c}\checkmark \\
\text { (a)(c) }\end{array}$ & $\checkmark$ & $\checkmark$ & $\checkmark$ & \\
\hline Demolition & $\checkmark$ & & & & & \\
\hline Land rehabilitation & $\checkmark$ & & $\checkmark$ & & $\checkmark$ & \\
\hline Land maintenance & $\checkmark$ & & $\checkmark$ & & $\checkmark$ & \\
\hline Removal of marine structures & $\checkmark$ & $\begin{array}{l}\checkmark \\
\text { (c) }\end{array}$ & & $\checkmark$ & $\checkmark$ & \\
\hline
\end{tabular}

(Letters in the ODV column relate to the reasons provided in the following table (Table 5.3)

Table 5.3 outlines the reasons why different components have had specific valuation techniques attributed to them in Table 5.2 (tick marks). This provides the thinking behind Table 5.2 so those using the framework can gain a stronger understanding of why different techniques might be useful for the costing of specific components. A full 
list of reasons for the costing methodologies attributed to each individual component is provided in Appendix C. Tables 5.2 and 5.3 make it clear that different aspects from within the same component can be costed using different techniques. An example of this is the 'relocation/replacement of public facilities' from Table 5.2, where six different costing methodologies (including MP, ODV-RC, ODV-UV, TC, HP, and CV) can be used to value different individual costs that occur within the one component. The decision over which of the methodologies is used for the costing of components is likely to be largely determined by what data is available, but not all methodologies can be applied to all items that might be listed under a given component. For example, ODV might be applied to community halls, but not to nature parks.

Generally speaking, all valuation methodologies are approximate, and so the more one can use multiple methods the better. Climate change brings additional uncertainty to the equation with many of its impacts (e.g. the rate of sea-level rise or the likelihood of a drought occurring) possibly impacting the robustness and applicability of different valuation methodologies. An example of this could be the use of a water storage facility under a changing climate scenario. Both the facility's ODRC and UV would be higher under climate change, but the respective increases may not be the same. If the ODRC is higher, it is implied that there is a better way to provide the same end service to the consumer. If, however, the UV is higher, it is implied that the current way of providing the service is optimal which provides an estimate of the cost of replacing the facility with essentially the same thing. 
Table 5.3: Rationale behind attributing valuation methodologies to managed retreat components.

\begin{tabular}{|c|c|}
\hline Valuation Method & Rationale \\
\hline MP & $\begin{array}{l}\text { Individual costs of the component can be costed by values already } \\
\text { available through the market. }\end{array}$ \\
\hline ODV & $\begin{array}{l}\text { (a) ODRC - The replacement cost of depreciated assets is relevant for } \\
\text { this component. } \\
\text { (b) DV - The value that an asset could be sold for is relevant for the } \\
\text { component. } \\
\text { (c) UV - Aspects of the component will have impacts on those using } \\
\text { the asset (infrastructure, houses etc.). }\end{array}$ \\
\hline HP & $\begin{array}{l}\text { There are aspects of the component that will have an effect on the } \\
\text { value of nearby property. }\end{array}$ \\
\hline TC & $\begin{array}{l}\text { There are aspects of the component which involve the removal of an } \\
\text { asset from the community. The travel cost method could be used to } \\
\text { estimate the value of the asset to the community (such as a town hall } \\
\text { or library). }\end{array}$ \\
\hline CE & $\begin{array}{l}\text { Aspects of the component (such as the value of an asset to the } \\
\text { community) can be valued through contingent valuation/choice } \\
\text { experiment methods. }\end{array}$ \\
\hline NFI & $\begin{array}{l}\text { Aspects of the component will have an impact/cost on/to business } \\
\text { income. NFI could be used to value this cost. }\end{array}$ \\
\hline
\end{tabular}

(A full list of reasons for the attribution of costing methodologies to each component is provided in Appendix C)

\subsection{Individual Costs of Components}

The following section outlines the various individual costs that occur within the different managed retreat components. These individual costs are presented in Table 5.4 along with an indication of which valuation methodology (Table 5.1) would be most appropriate for costing them. Table 5.4 also indicates whether the costs associated with each component are economic costs or are transfers of the ownership of existing assets. Following this, Table 5.5 outlines how various costs have been grouped for Table 5.4 (what they involve/include) and categorises them as either economic costs or transfers. This is done to allow for the explicit and transparent accounting for the different types of costs. 
Table 5.4: Managed retreat components, their associated costs and types of costs. (Continued on following page)

\begin{tabular}{|c|c|c|}
\hline Components & Costs Involved & Type of Cost \\
\hline $\begin{array}{l}\text { Community } \\
\text { engagement/consultation on } \\
\text { adaptation options and the } \\
\text { implementation of managed } \\
\text { retreat }\end{array}$ & $\begin{array}{l}\text { - Costs of running workshops } \\
\text { or discussion sessions. MP }\end{array}$ & Economic \\
\hline $\begin{array}{l}\text { Local government plan/rule } \\
\text { changes }\end{array}$ & - $\quad$ Human resources MP & Economic \\
\hline $\begin{array}{l}\text { Planning/consulting for the } \\
\text { reduction in infrastructure } \\
\text { level of service }\end{array}$ & - $\quad$ Human resources MP & Economic \\
\hline $\begin{array}{l}\text { Monitoring of conditions } \\
\text { (including the establishment } \\
\text { of trigger points for future } \\
\text { actions) }\end{array}$ & $\begin{array}{ll}\text { - } & \text { Human resources MP } \\
\text { - } & \text { Equipment MP }\end{array}$ & Economic \\
\hline $\begin{array}{l}\text { Acquisition offers (including } \\
\text { buy and lease back, covenant } \\
\text { and sell, buy and demolish } \\
\text { and sea-level purchase } \\
\text { options (SLPOs)) }\end{array}$ & $\begin{array}{ll}- & \text { Compensation payments } \\
\text { MP } \\
\text { - } & \text { Legal costs MP } \\
\text { - } & \text { Possible loss of capital } \\
& \text { stock. ODV } \\
\text { - } & \text { Development of covenants } \\
& \text { on property MP } \\
\end{array}$ & $\begin{array}{l}\text { Transfer of potential loss } \\
\text { from current owner to local } \\
\text { government. No economic } \\
\text { costs apart from transaction } \\
\text { costs }\end{array}$ \\
\hline Acquisition of alternate land & $\begin{array}{ll}- & \text { Land cost MP } \\
\text { - } & \text { Transactions costs MP }\end{array}$ & Land cost is a transfer \\
\hline $\begin{array}{l}\text { Development of new } \\
\text { community facilities (town } \\
\text { centre, infrastructure etc.) }\end{array}$ & $\begin{array}{ll}- & \text { Legal costs } \mathbf{M P} \\
\text { - } & \text { Development costs MP }\end{array}$ & Economic \\
\hline $\begin{array}{c}\text { Reduction of service levels of } \\
\text { public infrastructure }\end{array}$ & $\begin{array}{ll}\text { - } & \text { Reduction in capital stock* } \\
\text { ODV }\end{array}$ & Economic \\
\hline $\begin{array}{c}\text { Replacement/relocation of } \\
\text { public infrastructure } \\
\text { elsewhere }\end{array}$ & $\begin{array}{ll}- & \text { Relocation costs MP } \\
- & \text { Replacement cost of lost } \\
& \text { infrastructure ODV }\end{array}$ & Economic \\
\hline $\begin{array}{l}\text { Private companies } \\
\text { relocate/reduce investment } \\
\text { in privately owned } \\
\text { infrastructure networks (to } \\
\text { the extent permitted by law) } \\
\text { - including } \\
\text { telecommunications, power, } \\
\text { ports etc. }\end{array}$ & $\begin{array}{ll}- & \text { Infrastructure loss ODV } \\
- & \text { Relocation/replacement } \\
\text { costs MP } \\
\text { - } \quad \text { Value of abandoned/non- } \\
\text { maintained infrastructure } \\
\text { ODV } \\
\text { If activity limited by access } \\
\text { to eco-system services. NFI }\end{array}$ & Economic \\
\hline
\end{tabular}


Table 5.4 (cont.): Managed retreat components, their associated costs and types of costs.

\begin{tabular}{|c|c|c|}
\hline Components & Costs Involved & Type of Cost \\
\hline $\begin{array}{c}\text { Activation of covenants on } \\
\text { property }\end{array}$ & $\begin{array}{l}\text { - Cost is defined as the } \\
\text { incremental cost to the } \\
\text { affected party of having to } \\
\text { adopt a less preferred } \\
\text { option. There may be } \\
\text { offsetting benefits to other } \\
\text { parties. ODV }\end{array}$ & Economic \\
\hline $\begin{array}{l}\text { Restrictions on Rebuilding } \\
\text { and development }\end{array}$ & $\begin{array}{l}\text { - } \quad \text { Additional costs that } \\
\text { restrictions may cause. MP } \\
\text { - Valuation of the restrictions. } \\
\text { HP }\end{array}$ & Economic \\
\hline $\begin{array}{l}\text { Relocation/abandonment of } \\
\text { privately owned residential } \\
\text { and commercial property }\end{array}$ & $\begin{array}{ll}\text { - } & \text { Reduction in capital stock* } \\
& \text { ODV } \\
\text { - } & \text { Relocation costs MP } \\
\text { - } & \text { Compensation payments MP } \\
\text { - } & \text { Land to relocate to MP } \\
\text { - } & \text { Loss of housing services ODV } \\
\text { - } & \text { Loss of business income NFI } \\
\text { - } & \text { Social costs MP }\end{array}$ & $\begin{array}{c}\text { Economic except for asset } \\
\text { purchase costs }\end{array}$ \\
\hline $\begin{array}{l}\text { Providing of temporary } \\
\text { housing }\end{array}$ & $\begin{array}{l}\text { - Cost of temporary housing } \\
\text { MP }\end{array}$ & Economic \\
\hline $\begin{array}{l}\text { Relocation of 'critical-facility' } \\
\text { structures (including } \\
\text { hospitals, schools, police \& } \\
\text { fire stations, government } \\
\text { buildings etc.) }\end{array}$ & $\begin{array}{ll}\text { - } & \text { Relocation costs MP } \\
\text { - } & \text { Land cost MP } \\
\text { - } & \text { Cost to the community of } \\
\text { moving these facilities out of } \\
\text { the area HP } \\
\text { - } \quad \text { Value of lost facilities ODV } \\
\text { - } \quad \text { Social costs MP }\end{array}$ & $\begin{array}{c}\text { Economic except for land } \\
\text { purchase costs }\end{array}$ \\
\hline $\begin{array}{c}\text { Relocation of community } \\
\text { facilities/assets (community } \\
\text { halls, parks \& reserves etc.) }\end{array}$ & $\begin{array}{ll}\text { - } & \text { Relocation costs MP } \\
\text { - } & \text { Land cost MP } \\
\text { - } & \text { Cost to the community of } \\
\text { moving these facilities out of } \\
\text { the area HP TC CV } \\
\text { - } \quad \text { Loss of built assets ODV } \\
\text { - } \quad \text { Social costs MP }\end{array}$ & $\begin{array}{c}\text { Economic except for land } \\
\text { purchase costs }\end{array}$ \\
\hline Demolition & - $\quad$ Demolition costs MP & Economic \\
\hline
\end{tabular}


Table 5.4 (cont.): Managed retreat components, their associated costs and types of costs.

\begin{tabular}{|c|c|c|}
\hline Components & Costs Involved & Type of Cost \\
\hline Land rehabilitation & $\begin{array}{ll}\text { - } & \text { Removal of hazardous } \\
\text { - } & \text { materials MP } \\
& \text { semoval of remaining } \\
\text { structures including septic } & \text { tanks, driveways etc. MP } \\
\text { - } & \text { Treating of pollution MP } \\
\text { - } & \text { Gained amenity value } \\
\text { because of land } \\
\text { rehabilitation HP CV }\end{array}$ & Economic \\
\hline Land maintenance & $\begin{array}{ll}\text { - } & \text { Landscaping MP } \\
\text { - } & \text { Cleaning MP } \\
\text { - } & \text { Maintenance of gained } \\
& \text { amenity HP CV }\end{array}$ & Economic \\
\hline $\begin{array}{c}\text { Removal of marine } \\
\text { structures }\end{array}$ & $\begin{array}{l}\text { - } \quad \text { Loss of capital stock* ODV } \\
\text { - } \quad \text { Removal/demolition costs } \\
\text { MP } \\
\text { - } \quad \text { Cost to the community of } \\
\text { moving the asset out of the } \\
\text { community TC CV }\end{array}$ & Economic \\
\hline
\end{tabular}

The 'costs involved' column of Table 5.4 identifies individual costs associated with each of the managed retreat components. An indication as to which of the valuation methodologies could be used to value these individual costs are in bold print. Individual costs that require consideration within each component are an important part of planning for the use of managed retreat, and have therefore been included as part of this typology. Outlining particular costs to be considered and how they can be valued for each component enables a better understanding of financial considerations when costing a managed retreat strategy.

Column three of Table 5.4 describes what type of costs (in terms of economic or transfer) each of the managed retreat components are. Economic costs are those that cause a loss to the overall economy or require the use of resources that would otherwise be used elsewhere. Transfers, on the other hand, are transfers of property which are simply changes of ownership, responsibility, and risk in an asset from one party to another. While this transfer itself is not a cost, there are transactions costs (e.g. legal fees) that enable the transfer to occur. In terms of managed retreat, this transfer is generally from 
the property owner to local government or intermediary organisations. Money is not lost to the economy as such, however there is a cost for a local government to acquire the property, as money is being transferred to the property owner.

Table 5.5 describes how the individual costs have been grouped as used in Table 5.4. This has been done to simplify Table 5.4 while still providing an in-depth understanding of what costs make up the total costs of the different components. An example of this is that 'demolition costs' are included as part of Table 4.1 (p.52) (demolition component), while Table 5.5 presents the overall cost of demolition as an amalgamation of: human resource costs (e.g. labour and expertise), equipment costs and costs associated with gaining resource consents. Table 5.5 also identifies economic costs as distinguished from transfers of existing assets between parties. Providing this breakdown of cost groupings and what type of costs they fall under allows explicit and transparent accounting of the distinct costs and where they fall in the economy. 
Table 5.5: Cost grouping and classification.

\begin{tabular}{|c|c|c|}
\hline Costs Grouping & Economic Costs & Transfers \\
\hline Human Resources & $\begin{array}{ll}\text { - } & \text { Labour } \\
\text { - } & \text { Expertise } \\
\text { - } & \text { Legal fees (including } \\
& \text { resource consents) }\end{array}$ & \\
\hline Compensation Payments & $\begin{array}{l}\text { Relocation assistance } \\
\text { and transactions (e.g. } \\
\text { legal) costs }\end{array}$ & $\begin{array}{l}\text { - Compensation } \\
\text { payments for property } \\
\text { acquisition }\end{array}$ \\
\hline Social Costs & $\begin{array}{l}\text { - } \quad \text { Provided support for } \\
\text { those who require it }\end{array}$ & \\
\hline Land Costs & $\begin{array}{ll}\text { - } & \text { Land development } \\
\text { - } \quad \text { Transactions costs }\end{array}$ & $\begin{array}{l}\text { - } \\
\text { paymensation } \\
\text { transfer of land } \\
\text { ownership }\end{array}$ \\
\hline Development Costs & $\begin{array}{ll}\text { - } & \text { Human resources } \\
\text { - } & \text { Materials } \\
\text { - } & \text { Resource consents } \\
\text { - } & \text { Equipment }\end{array}$ & \\
\hline Relocation Costs & $\begin{array}{ll}\text { - } & \text { Human resources } \\
\text { - } & \text { Equipment } \\
\text { - } & \text { Associated legal costs }\end{array}$ & \\
\hline Demolition Costs & $\begin{array}{ll}\text { - } & \text { Resource consents } \\
- & \text { Human resources } \\
- & \text { Equipment }\end{array}$ & \\
\hline
\end{tabular}

It is important to mention that while some costs will be one-off investments (such as the relocation or demolition of a property), there are other costs that will be ongoing. One example of this will be the costs associated with local government monitoring of environmental conditions.

Social costs may have an economic cost associated with them (like the costs associated with counselling) as a result of managed retreat. There are however significant 'noneconomic' costs associated with managed retreat such as the psychological and health impacts that may occur as a result of moving people away from a location they call 
home. These impacts are signalled within the costing framework by the recognition of 'social costs' in Tables 5.4 and 5.5.

\subsection{Other Relevant Costing Issues}

There are a number of additional issues that are important to consider by those costing climate change adaptation options such as managed retreat. While these issues are out of scope for this thesis, their significance ought to be recognised.

\section{Discount Rates}

The use of a discount rate is important for the valuation of climate change adaptation strategies as discount rates are used to determine the present value of future costs (both positive and negative). As explained in GWRC (2015), discount rates have two fundamental hallmarks that are relevant to investment in adaptation to coastal inundation and erosion, including for adaptation by managed retreat. These are:

1. "If a project delivers returns that can be reinvested at the same rate and risk profile as the project itself, the cost of capital is an appropriate discount rate. The discount rate should incorporate a market-based premium.

2. However, the capital cost of the project must truly represent the opportunity cost of that capital used for other investment. A social discount rate is likely to be more appropriate if that condition is not met." (p.13)

The first of these hallmarks is a description of the Capital Asset Pricing Model (CAPM) ${ }^{4}$. The New Zealand Treasury's current standard discount rate for infrastructure projects is $6 \%{ }^{5}$ (GWRC, 2015). For adaptation to climate change impacts, however, this value is likely to be too high as the cost of capital is equal to the social opportunity cost of investment only if a particular project displaces investment elsewhere, which if in place, would have earned a rate of return (GWRC, 2015). In the case of local government investment in adaptation and managed retreat, this condition is unlikely to be met. This is especially the case if property values are higher than what they would be otherwise

\footnotetext{
${ }^{4}$ https://treasury.govt.nz/sites/default/files/2018-01/costcapital-oct97.pdf

${ }^{5}$ https://treasury.govt.nz/information-and-services/state-sector-leadership/guidance/financialreporting-policies-and-guidance/discount-rates
} 
(GWRC, 2015). Most of the opportunity cost of this funding is likely to be in the form of lower private consumption, not lower investment.

If this is the case, the cost of capital would not be the appropriate discount rate to use for the costs and benefits of climate change adaptation (GWRC, 2015). If used, it should be reduced towards the social rate of time preference (SRTP) (GWRC, 2015). The SRTP is described by GWRC (2015) as "the appropriate rate of return for discounting when the opportunity cost of the project is in the form of less consumption" (p.13) of goods and services by households.

GWRC (2015) express the SRTP as:

$" r=d+\varepsilon . g$.

$r$ is the social rate of time preference

$d$ is the rate at which future consumption is discounted over current consumption

$\mathrm{g}$ is the annual growth of consumption per capita

$\varepsilon$ is the elasticity of the marginal utility of consumption

The variable $d$ is frequently further disaggregated into two components:

$d=\rho+C$

$\rho$ is the pure rate of time preference

$C$ is the risk of a catastrophe which severely disrupts life on earth." (p.13).

There is considerable debate on the values of the variables outlined above. This is, however, beyond the scope of this thesis. Parker (2009) provides a good discussion and suggests that a reasonable value of the SRTP for New Zealand is around $3.0 \%-4.0 \%$, which provides more consideration to the future than a rate of return of $6 \%$. A discount rate of $6 \%$ would mean that any costs and benefits that occur more than 74 years in the future are discounted by at least $99 \%$. This could make the cost of long term adaptation (e.g. managed retreat) seem to be disproportionately inexpensive. 


\section{Network Impacts}

The implementation of any strategy that manages coastal hazard risk is likely to have network impacts that stretch beyond the specific geographic area within which these measures are being taken. For example, the relocation or abandonment of a state highway from a coastal region may impact many who live elsewhere, yet depend on the road either for travel or for the movement of goods and services. Another example could be the relocation or abandonment of a sewage treatment plant from an at-risk coastal location which may be servicing communities situated inland and away from the coastal hazards. As such, the removal, relocation or abandonment of this sewage treatment plant will have impacts that stretch beyond the immediate location where the 'retreat' is occurring. It is therefore important to ensure that the scope of any costing of managed retreat is broad enough to capture all of the users and beneficiaries of the assets that are exposed to the particular climate change risk.

\section{Health Impacts/Value of Lives Saved}

The use of managed retreat has the potential to have positive health impacts on the retreated community. This could involve the avoidance of impacts to critical infrastructure (e.g. drinking and waste water infrastructure), the avoidance of storm related injuries, the removal of anxiety for communities and individuals due to uncertainty of potential damage and loss of property and place, as well as limiting exposure to life-threatening hazards. These points place significant value on the benefit side of a managed retreat cost/benefit analysis and should be considered as part of an evaluation of coastal risk adaptation options such as managed retreat.

\subsection{Chapter Summary}

Managed retreat is a complex management option which encompasses many components and their respective costs. This chapter has provided a costing framework that can be used to value a proposed managed retreat strategy, no matter which components ultimately make up a specific strategy. Establishing this framework has been achieved through first identifying valuation methodologies that can be used to value the costs, or benefits, associated with the many managed retreat components, and then determining which costing methodologies are appropriate for the costing of 
individual components, with the reasons provided. Chapter Five has then presented in more detail what costs are associated with the different components, and identified which methodologies could be used to value the different cost aspects of these components. As is the case with the component typology from Chapter Four, this chapter has set out all of the component options that might be relevant to a managed retreat strategy, and indicates methods for their costing. Whichever components planners ultimately decide to make up their specific managed retreat strategy, this valuation methodology provides guidance as to how they might cost their various components, whichever they may be. 


\section{Chapter Six: Discussion}

\subsection{Chapter Introduction}

Chapters Four and Five of this thesis have outlined a component typology and a costing framework which identify managed retreat components and provide a new approach for costing them. Chapter Six provides a discussion of the context surrounding the typology and framework, as well as a discussion on their use and relevance for managed retreat. Discussions on the context and implementation issues involved with managed retreat are included throughout this chapter linking back to address research question one: 'what are the issues related to the implementation of managed retreat as an adaptation strategy in coastal areas, now and moving into the future?'

\subsection{Context}

The following section discusses the context that surrounds this research, by presenting the requirement for climate change adaptation options (such as managed retreat) to be understood and remain flexible, and the need to avoid path dependency and the development of safety paradoxes.

\subsubsection{The Need for Understanding Climate Change Adaptation Options}

As discussed in Section 1.1, there is a growing necessity to adapt to coastal hazards. This necessity is due to effects of global warming already experienced at coasts (e.g. coastal flooding and erosion), consequences of atmospheric warming due to global emissions of greenhouse gases. Atmospheric warming causes rising seas through the melting of ice sheets and thermal expansion of the oceans (Church et al., 2013). As there is a lag time between emissions reductions and their effect, the seas will rise for at least well into the next century (Bell et al., 2017). As a result, coastal hazards will increase in frequency and severity, and continue to do so for the foreseeable future. It is therefore important that adaptation options that significantly reduce or remove the risk to coastal communities (e.g. managed retreat), are understood.

Through the deconstruction of the strategy into its component parts with approaches developed for its staging and costing, this thesis has contributed to the understanding 
of the managed retreat option. What managed retreat involves, how it may evolve over time, and how it can be costed are important factors to understand for today's decisions on long-term investments (such as housing and essential infrastructure).

\subsubsection{The Uncertainty of Climate Change - Flexibility of Adaptation Options}

As discussed in Section 1.1, global warming and its associated impacts (e.g. sea-level rise) are present and are set to worsen. Warming of the atmosphere results in warming of oceans leading to thermal expansion of the oceans, and thus, rising seas. While the rate of rise is projected out to mid-century with certainty (Bell et al., 2017), the rate beyond that is very uncertain as it depends on the rate of polar ice sheet melt, whether it reaches a tipping point of irreversibility, and on the rate at which humans reduce their carbon emissions. It is therefore important that adaptation options that are designed to be flexible, changeable, and staged over time, are available (Kwakkel et al., 2016; Lawrence \& Haasnoot, 2017; Bloemen et al., 2018). Flexibility of options refers to their ability to be adapted and changed to fit whatever future eventuates. One such example could be the early or delayed activation of a property relocation process under a climate change and sea-level rise future that may unfold differently to what is expected. Retaining flexibility over time enables uncertainties to be addressed by adjusting actions to suit whatever situation eventuates.

Managed retreat has flexibility with regard to how it is staged over time. Staging in this context refers to the activation of managed retreat components over time in relation to pre-determined signals and triggers (Kwakkel et al., 2016; Lawrence \& Haasnoot, 2017; Bloemen et al., 2018 Stephens et al., 2018). The typology and framework can be used in a range of situations, both at particular locations and across time (e.g. the Grantham and Newtok managed retreat strategies).

Flexibility in the application and implementation of managed retreat is built into the typology and framework. The component typology does not prescribe what has to be included within a managed retreat plan, rather, it sets out the possible component parts of a possible managed retreat strategy (see Table 4.1, p.52). Users can assess, compare, and select those components that best fit their specific context depending on the geophysical (e.g. topography and rates of uplift/subsidence) (Bell et al., 2017) and societal (e.g. the assets at-risk) characteristics of a location in addition to how sea-level 
rise propagates over time. The examples of different staging of managed retreat (Figures 4.2-4.8, p.59-p.69) are presented using a tailored pathways approach, and in a manner consistent with using a DAPP optioneering and assessment approach as set out in the Ministry for the Environment Coastal Hazards and Climate Change Guidance 2017.

Maintaining flexibility within managed retreat strategies is important, because components may require activation earlier or later than planned depending on the future that eventuates. Beginning the managed retreat process early enables effective planning, community engagement, and development of signals and trigger points to be achieved.

\subsubsection{Avoiding Policy Path Dependency and Safety Paradox}

Linked to the ability of climate change adaptation options to remain flexible is their ability to avoid path dependency, policy lock-in, and the development of safety paradoxes (discussed in Section 2.2). The goal of coastal hazard adaptation is to reduce or remove the risk posed to coastal communities. It is therefore important to avoid options that result in path dependency that makes future options harder or more costly to implement. 'Path dependency' relates to the lock-in of specific policy pathways and the closing off of future adaptation options due to decisions made today. These dependencies could result from the development of safety paradoxes (Burby \& French, 1981; Lawrence et al., 2014) due to the use of defensive or accommodative adaptation approaches (e.g. rock walls or raising the floor level of buildings) which provide a false sense of security to the community, encouraging further development and an expectation of further protection (Tobin, 1995; Lawrence et al., 2014). This is especially relevant for the managed retreat option, as an increase in the value of assets at-risk will result in pressure to maintain protective or accommodative measures and higher implementation costs in the future.

Current conditions (geophysical and societal) and expected future impacts are important when it comes to a discussion of whether other actions are appropriate ahead of the use of 'Active Retreat' in areas where managed retreat is considered to be inevitable. If sea-level rise impacts are imminent, it may make sense to begin the early stages of managed retreat now and plan for an earlier activation of 'Active Retreat' stage 
components such as the relocation of property. If some form of defensive or accommodative option is deemed to be appropriate in the meantime (as is illustrated in certain pathways in Figure 4.1, p.57), it is important that these actions do not create path dependencies or safety paradoxes by enabling higher values to be placed in at-risk areas (Tobin, 1995; Lawrence et al., 2014). This is similar to the DAPP approach where decisions made today do not make future adjustment (such as to 'Active Retreat' components) costlier, harder to implement, or no longer viable.

The DAPP approach (as is illustrated by Figure 4.1, p.57) helps to avoid policy path dependency and the development of safety paradoxes. This process enables planners to pursue the best pathway (most flexible, cost effective, or fair) through a risk management strategy when all viewpoints are considered. This is illustrated by the Lower Hutt River City Centre Upgrade Project, where the option taken was not the most cost effective or flexible over time, but was considered to be the most fair and supported by the effected community (Lawrence et al., 2019b). While the most flexible pathway may not always be implemented, the use of signals and trigger points to activate different options (DAPP approach (Kwakkel et al., 2016; Lawrence \& Haasnoot, 2017; Bloemen et al., 2018)) enables effective and socially acceptable implementation of options.

It is suggested in this thesis that the initial stages of managed retreat begin as early as possible, with initial stages (Community Engagement, Planning and Preparing, Enabling Investment) occurring alongside other shorter-term options (e.g. beach renourishment and dune rebuilding) when necessary. This is to 'buy time' for these initial stages to be completed, and preparations to take place before the activation of the 'Active Retreat' stage occurring. Using the DAPP and tailored pathways approaches together will allow temporary options to occur alongside the early stages of managed retreat ('Community Engagement', 'Planning and Preparing', and 'Enabling Investment') while not impeding or restricting the implementation of 'Active Retreat', or resulting in the development of safety paradoxes and creating policy path dependency. 


\subsubsection{Boundaries of Approach}

This thesis has provided a systematic and technical approach for the planning and costing of managed retreat. It is, however, important to note that the use of this approach should be undertaken alongside consideration of what falls outside the boundaries (Gieryn, 1983; Jasanoff, 2017). These considerations are relevant to the implementation of managed retreat (outside the scope of this thesis) which include the social costs of implementing (and not implementing) managed retreat from the coast (e.g. the splitting of a community), how emerging data of cascading impacts (or network impacts as discussed in section 5.4) will be included, and how issues such as political and institutional risk and a lack of data or resources may impact the staged implementation process. These considerations are not included within the typology and framework but are matters that need to be considered for the implementation of a managed retreat strategy and are discussed in Sections 6.4.4 and 6.5.5 below.

\subsection{Steps for the use of the Typology and Framework}

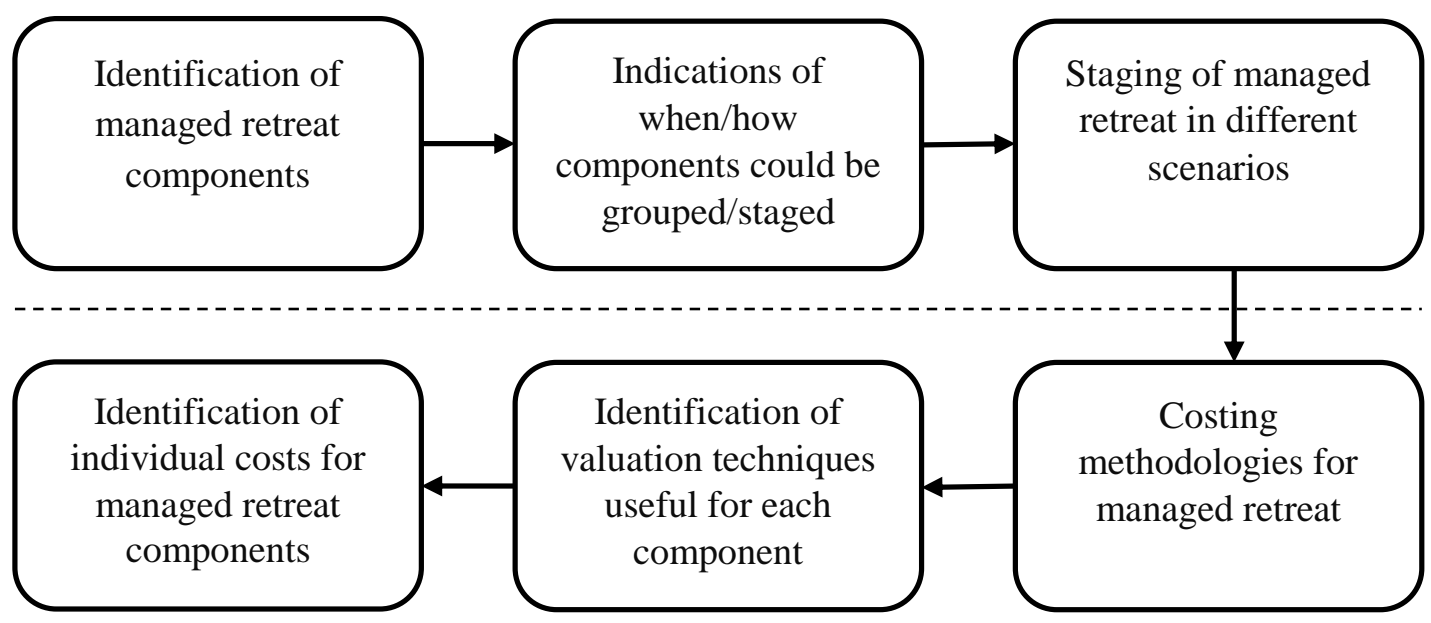

Figure 6.1: Outline of steps for the use of the component typology and costing framework.

Figure 6.1 outlines the different steps within the typology and framework and provides an indication of the order in which they would be applied. Figure 6.1 also provides the structure for the remainder of this discussion chapter. The three steps included above the dotted line represent steps involved in the component typology, whereas the steps below the line are from the costing framework. Arrows indicate the shifts between the steps. The component typology itself is discussed in Section 6.4. Section 6.5 focusses on 
the costing framework, starting with discussion of the different costing methodologies, followed by the attribution of these methods to specific components and the identification of individual costs. Discussions on a number of managed retreat implementation issues are also included within Sections 6.4 and 6.5.

\subsection{Component Typology}

The component typology has been developed in response to research question two: 'what are the components of managed retreat that enable a better understanding of managed retreat as an adaptation option to be considered now, and for its implementation over time?' Steps from the typology are discussed in order of application (illustrated in Figure 6.1 - above the dotted line), with indications made to how users might put them into practice. A series of implementation issues directly relevant to the component typology are then discussed.

\subsubsection{Identification of Managed Retreat Components}

This thesis has identified and grouped managed retreat components (step one of the component typology - Figure 6.1). While current literature has identified some of the components that might constitute managed retreat (e.g. Neal et al., 2005; Turbott, 2006; Siders, 2013; Freudenberg et al., 2016; Hino et al., 2017), the identification of all managed retreat components and the grouping of them does not seem to have been achieved prior to this thesis. The identification and grouping of managed retreat components outlined in the component typology (Chapter Four) therefore provides an answer to the second of the research questions and addresses the identified gap in the literature.

Those using the typology for the planning of managed retreat would begin at this component identification stage, as it begins by providing a list of all managed retreat components that could form part of a managed retreat strategy (Table 4.1, p.52). It allows planners to systematically consider all components and relate their relevance and effectiveness to the specific coastal context within which they will be applied. It is important that effective actions are developed and understood (IPCC, 2018). 


\subsubsection{Staging of Managed Retreat}

Managed retreat staging is achieved in two steps within the component typology (see Figure 6.1), both of which are discussed in more detail below. The first involves timing indications of when components are likely to occur within a managed retreat strategy. The second involves the planning of managed retreat over time using signals and trigger points to establish appropriate activation of specific components.

\section{Indications of When/How Components Could be Staged/Timed}

Following the identification of managed retreat components, the typology introduces the idea of staggering the implementation of managed retreat over time and in many stages (Table 4.2 p.55). The typology provides indications as to when different groups of similar components may be activated or become relevant within a managed retreat strategy (Table 4.2). These indications help to build an overall understanding of managed retreat and develops the concept of the strategy being implemented over time.

Various stages of managed retreat are indicated in Table 4.2 (p.55) ('Community Engagement', 'Planning and Preparing', 'Enabling Investment', 'Active Retreat', and 'Clean-Up'). The presentation of these stages provides additional understanding which will also inform the design of signals (to warn of impending change) and trigger points for deciding the next component ahead of performance thresholds being reached (Lawrence \& Haasnoot, 2017). These signals and triggers are especially important for the final step of the component typology (Figure 6.1) as this is where they are developed and applied.

\section{Staging of Managed Retreat in Different Scenarios}

As has been discussed in Section 4.4.2, managed retreat will look different for every context in which it is applied. This is due to differences in geophysical (e.g. rates of uplift and topography (Bell et al., 2017)) and societal conditions (e.g. assets at-risk) which make each location unique. The component typology has been developed with these differences in mind and applies a tailored pathways approach (described in Section 3.2.3 and applied in Section 4.4.1 and 4.4.2) to the staging of managed retreat components. This tailored pathways approach is based on the DAPP approach (Kwakkel et al., 2016; 
Lawrence \& Haasnoot, 2017; Bloemen et al., 2018) and uses signals and trigger points to time appropriate and effective adaptation (or managed retreat components in this case) actions. Doing so enables the issues of early activation (resulting in an opportunity cost of lost productive land and buildings) or late activation (resulting in damage, repair costs, and emergency removal of people and structures) (Yohe \& Schlesinger, 1998) to be avoided. Planners using the component typology would be able to develop signals and trigger points that relate to their specific context and would be able to gain an understanding for how their managed retreat strategy would look and how to cost it and make investments over time.

\subsubsection{Summary of the Component Typology Section}

The component typology has deconstructed managed retreat, identified and presented its component parts, and developed a new approach for the staging of the strategy over time and in response to an uncertain and changing future. Therefore, the typology has provided an answer to the second of the three research questions. This typology has also achieved the research objectives by providing a contribution to the overall understanding of managed retreat, while also providing guidance to those planning use of the option for adaptation to coastal risk.

\subsubsection{Implementation Issues Related to the Component Typology}

The following section discusses implementation issues of managed retreat that are relevant to the component typology, and which are discussed in the literature. These issues include: the value of starting early; community understanding and acceptance of managed retreat; staged vs one-off retreat; and maintaining infrastructure until retreat is complete.

\section{The Value of Starting Early}

Starting the process of managed retreat early enables communities to be prepared. As managed retreat requires a lead in time ahead of the activation of 'Active Retreat' components, it is important that signals are given early. In some coastal locations, managed retreat will be an inevitability. Undertaking preparations ahead of time in these locations will help ensure that the active stages of retreat can be implemented 
effectively and appropriately when they are required. This process is illustrated in Figure 4.1 (p.52) where managed retreat begins now and occurs alongside other options (either current or future).

Beginning the managed retreat process by activating planning rules for example, can halt further entrenchment of exposed developments. It also provides time for local governments to consider all the components and to establish a managed retreat plan that will work best for the specific context within which it will be used. Starting early also allows local governments to consider implementation issues and implications of their managed retreat strategy, such as the consent-ability (Lawrence, Bell \& Stroombergen, 2019) of different components, and the social costs of moving people or a community from their location and how this will be dealt with.

\section{Community Understanding and Acceptance of Managed Retreat}

Starting the managed retreat process early enables local governments to engage with the affected community early and effectively. This is important, as community understanding and acceptance/uptake of managed retreat has been identified in the literature as a key issue for the implementation of the strategy (Vandenbeld \& McDonald, 2013; Hino et al., 2017). Early and effective communication and engagement with the community is vital for building this community understanding and acceptance of the option (Vandenbeld \& McDonald, 2013). While the approach to managed retreat planning in this thesis does not outline how to undertake community engagement, it identifies early engagement as a part of any effective managed retreat strategy. The value in starting the managed retreat process as early as possible in the adaptation process also enables local governments to signal the increasing risk to a community ahead of time, and that relocation of the affected community can be one of the chosen options. This enables communities to understand what is at risk and why managed retreat may be considered the inevitable option for their area.

The Mapua/Ruby Bay example presented in Chapter Four showed an extensive community engagement stage which has led to a majority acceptance and understanding that coastal flooding will continue to get worse. As such, when, or if, managed retreat is required, the community is better prepared and will understand why 
and how the option will be implemented since planning rules have halted further development. Early engagement with the community is especially important in areas where managed retreat is considered to be an inevitability in response to an imminent threat. The typology recognises this by indicating community engagement should occur early in the managed retreat process (Tables 4.1, p.52 and 4.2, p.55). Achieving community understanding and acceptance of managed retreat early allows for the easier and more effective implementation of active managed retreat when it is eventually required.

\section{Staged vs One-Off Retreat}

Whether managed retreat is completed in a staged or one-off manner is likely to impact the acceptance of the option within the community and should be considered when planning the use of the adaptation option. When considering the social impacts, a community may wish to relocate at another site away from the hazard to maintain the integrity of the community. Both staged and one-off retreat may have different noneconomic costs such as the extent and duration of community separation. Economic costs (e.g. those associated with the physical relocation of structures) are likely to be similar between the two strategies except for the effect of the time value of money, as reflected in the discount rate.

\section{Maintaining Infrastructure until Retreat is Completed}

Problems may arise for local governments regarding the maintenance of specific infrastructure if managed retreat is undertaken in a staged manner or people decide to remain. While some infrastructure levels of service may be able to be reduced (e.g. the maintenance of roads or flood protection structures (Laing, 2018)), other services must be maintained until a retreat is completed which may lead to issues for local governments in maintaining services. Drinking water services for example are statutorily required to be maintained in New Zealand (Laing, 2018), yet may be able to be maintained through means other than reticulation via pipes (e.g. water tankers providing fresh water to tanks). 


\subsection{Costing Framework}

The following section discusses the costing framework using the structure in Figure 6.1. It first discusses the steps involved in the costing framework before discussing managed retreat implementation issues directly relevant to the costing framework.

\subsubsection{Costing Methodologies for Managed Retreat}

The costing framework (Chapter Five) has been developed for use alongside the components typology where managed retreat is being considered as an adaptation option at the coast. Analysis of the literature has revealed that there are many methodologies that can be used for the costing of managed retreat, for example, Watkiss et al. (2014) examine the various methods and their use - Appendix E presents a figure taken from Bell et al. (2017) which describes these various methods. The first step of the costing framework (Figure 6.1) outlines which of these methods are best suited to the costing of managed retreat components (Table 5.1, p.75). Users of the framework can use this initial step to gain an understanding of the various methodologies that are relevant to the costing of managed retreat ahead of applying them to the costing of their selected components in the following attribution step.

\subsubsection{Application of Costing Methodologies to Components}

Table 5.2 (p.76) applies costing methodologies to the components that have been identified in the component typology, providing users with options for the costing of managed retreat components. While the literature discusses many methodologies that can be applied to the costing of climate change adaptation in general (e.g. in NZIER, 2000; Birol et al., 2006; Fletcher et al., 2016; \& Fu et al., 2016), the costing framework applies the appropriate methods to specific managed retreat components. Table 5.2 indicates that many costing methods could be used for the costing of different components (e.g. market prices, ODV, hedonic pricing, travel cost method, and contingent valuation/choice experiment methods are indicated as options for the costing of relocating or replacing community facilities). For many components, there is more than one costing method. In some cases, data limitations will dictate which 
methodology can be used, but robustness will be increased if several methods can be used.

\subsubsection{Identification of Individual Costs of Components}

The costing framework identifies all the individual costs of components and attributes costing methodologies to these costs. Doing so allows users to easily identify what methods could be used to cost these components, giving users the information ahead of completing the costing of their managed retreat strategy. Deconstructing managed retreat into individual component, and then into individual costs of the components provides a contribution to the overall understanding of the adaptation option.

\subsubsection{Summary of the Costing Framework Section}

The costing framework has developed an approach to the costing of managed retreat components, achieved through the identification of relevant methodologies for managed retreat, and the identification of which individual costs require valuation when planning for the use of specific components. The costing framework has therefore provided an answer to the third of the three research questions: 'What framework could be built for planning and costing managed retreat as an adaptation option within a coastal risk management strategy?' Sections 6.5.1, 6.5.2 and 6.5.3 have discussed the use of the costing framework and have indicated its contribution to the literature and understanding for the costing of managed retreat.

\subsubsection{Implementation Issues Related to the Costing Framework}

There are implementation issues of managed retreat related to the costing framework, which include: the counterfactual; the social implications and costs of managed retreat; health and safety issues associated with some acquisition methods; the impact on property values from the announcement of intentions to undertake managed retreat; whether it is worth relocating certain assets; the value of gained amenity; and the costs associated with shifting between adaptation actions. All of these issues are discussed below. 


\section{$\underline{\text { The Counterfactual }}$}

All cost-benefit analysis, including that for a managed retreat, has to be expressed relative to some baseline or counterfactual, which is normally described as the 'do nothing' option, as discussed by Twigger-Ross et al. (2015). This concept seems simple, but the time element can cause issues when valuing existing assets. For example, if past wave action has already damaged coastal properties before the risk of further damage is recognised and adaptation (possibly including managed retreat) is warranted, those past economic losses should be excluded from a cost-benefit analysis. In a situation where an announcement of a decision for protection works or managed retreat leads to an increase in property values, this increase should also be excluded from a cost-benefit analysis. Econometric analysis may be required to estimate what property values were just before an announcement of this kind.

\section{Social Implications of Costs}

Managed retreat, whether staged or completed in a one-off fashion, will result in significant community disruption. This would also be the case for the 'do nothing' option. Significant social impacts and costs will be incurred as a result (Fullilove, 1996; Freudenberg et al., 2016; Binder et al., 2015; Hino et al., 2017). Some people who live in these communities will have a strong attachment to the area and the community they belong to, while others may wish to leave. Each group will have different psychological needs that will be a factor in the costing of social support services as part of the managed retreat option (e.g. residents and business owners who are being displaced may require counselling support). Local and national governments are likely to come under pressure to provide such services and to cover the costs associated with them. Such social costs are relevant for discussions on the implementation of managed retreat.

\section{Acquisition Health and Safety Issues}

While buy-and-lease-back and buy-covenant-sell methods provide local governments with an opportunity to recoup property acquisition costs, there are safety implications that require consideration. Given that the buy-lease/covenant-sell methods would be undertaken in the knowledge that the property will eventually be subject to unacceptable risk, this could open up the council to a health and safety breach under its 
bylaws, if subsequent climate-related impacts resulted in injuries to the residents. ${ }^{6}$ This is a serious consideration for those planning to use buyouts as part of their managed retreat plan, especially if they are going to permit people to either remain living in or buy the acquired property with covenants.

\section{Hazard Risk vs Pre-Announcement of Managed Retreat - Impact on Property Values}

The timing of an announcement to retreat needs to be considered by those planning the adaptation strategy. While the component typology indicates that the sequencing of managed retreat components shows the planning provisions that support the option starting early, so that further developments do not take place in the at-risk area before the retreat begins its 'Active' stage, it may have impacts on property values in the affected areas. This raises the question of who pays for this reduction in value, and, if people are to be compensated, how is a price to be set? There are already examples of how this has been approached in New Zealand: after the Canterbury earthquake swarms in 2010 and 2012, the government set the price in the red zones at the previous valuation (Boston \& Lawrence, 2018). In the Hutt CBD project, the Greater Wellington Regional Council negotiated market value for buy-outs on the western Hutt River to make 'room for the river' for the management of flood risk, on the basis of fair market value (Lawrence et al., 2019b). Both examples are managed retreat in action.

It could be argued, however, that the reduction in property values following the announcement of the intentions to retreat is the result of the hazard risk being signalled, rather than the result of the announced intention to retreat.

\section{Is it Worth Relocating Certain Assets?}

There will be instances where the value of at-risk coastal assets and property does not justify the cost of relocating or rebuilding them elsewhere. In a CBA the benefit of saving an asset is equal to its market value, given a fair market. When it comes to replacing a depreciated asset, however, it may not be possible or sensible to find or construct a similar asset. For example, a house with a severely leaking roof that is reflected in its market value could be replaced by a smaller house with a good roof of equal market

\footnotetext{
${ }^{6}$ Local government can issue health and safety bylaws under Section 145 of the Local Government Act 2002 for protecting the public from nuisance, and for promoting, and maintaining public health and safety.
} 
value. In practice it can be difficult to determine such equivalence and in some cases, it would not make sense. It would not be sensible to replace an old water treatment facility with anything other than a new facility elsewhere. The costing framework presented in Chapter Five, notably the ODV approach (which is the lower of either the optimised depreciated replacement cost or the economic value (the higher of the disposal or user value) of an asset (NZIER, 2000)), ensures that the correct cost or value goes into the cost-benefit analysis. In practice, however, rebuilding the plant will include additional costs that are not strictly part of the CBA of managed retreat. In the counterfactual situation, those additional costs would be in the form of deferred repairs and maintenance, nothing to do with managed retreat. This distinction is important if managed retreat is to be properly assessed against other adaptation options.

It is not hard to visualise a situation where an asset is so damaged or derelict that its value in a CBA of managed retreat is close to zero. In other words, there is no further economic loss from the potential total destruction of the asset (due to sea-level rise and its associated impacts) which would reduce the benefit-cost ratio of any adaptation strategy. Only clean-up related components, such as demolition and land rehabilitation, would likely be justified.

\section{Gained Amenity Value Opportunities}

As was the case in the Medmerry example presented in Chapter Four, coastal risk adaptation options, like managed coastal realignment and managed retreat, could present the opportunity to gain amenity value. This is possible through flooding of and development of new intertidal habitat that provides ecosystem services (mangroves or mud flats that provide carbon sequestration, or areas for intertidal species to develop), or the development of new public land (such as parks or esplanades) that provide both an economic opportunity through recreational and tourism benefits and provide value to the community through gaining public space near the coast. It is important to recognise that these benefits can be the result of managed retreat and should be included in a cost-benefit analysis. 


\section{Transfer Costs}

'Transfer costs' refers to those costs associated with switching to alternative pathways/options within a DAPP framework (Haasnoot et al., 2019). The costs of removing previous actions and implementing new ones are described by Haasnoot et al. (2019) as common examples of transfer costs. Transfer costs could also be associated with the effect on investments made in future actions which have been costed over a period of time but need to be brought forward due to changing conditions. Such transfer costs are relevant to a discussion of managed retreat because of the adaptive nature of the decision choices as shown in Figure 4.1 (p.57) as this process involves the shifting of actions from the current situation to other actions (possibly including beach renourishment and dune rebuilding ahead of managed retreat (see Figure 4.1)).

In the case of the managed retreat, costing and investments could have been made for components over a period of time, but changing conditions require these components to be brought forward (e.g. the relocation or abandonment of property). In this situation, the cost associated with 'transferring' to a specific component at an earlier time will have impacts on its costing. It is therefore essential that these transfer costs are taken into account when using the framework to cost managed retreat.

\subsection{Chapter Summary}

This chapter has discussed the component typology and costing framework for managed retreat that has been developed in this thesis. Discussions of how the typology and framework could be used by planners and how they contribute to the literature have been included. Several managed retreat issues have been discussed which addresses the first of the three research questions; what are the issues related to the implementation of managed retreat as an adaptation strategy in coastal areas, now and moving into the future?

The systematic approach to the planning and costing of managed retreat developed in this thesis enables users to build their understanding of what managed retreat might comprise as an adaptation option, facilitating consideration of its components and the implementation of managed retreat in response to coastal risk. The component typology can inform users' managed retreat strategies and how implementation and investment 
can be staged over time. This also allows users to see which costing methods (as identified in the costing framework - Chapter Five) are likely to be the most relevant to their local conditions. The component typology and costing framework together answer the second and third research questions (as outlined is Sections 6.4 and 6.5) by building a framework within which the costs of managed retreat are identified and can be staged over time, depending on the context within which they are applied. 



\section{Chapter Seven: Conclusions}

\subsection{Research Objectives and Approach}

The purpose of this thesis is to provide a contribution to the understanding of managed retreat as a climate change adaptation option, and to show how it might be costed. The thesis has been designed to address a gap in the literature about what managed retreat comprises, and how to go about costing it. As a result, three research questions were developed to address this literature gap:

1. What are the issues related to the implementation of managed retreat as an adaptation strategy in coastal areas, now and moving into the future?

2. What are the components of managed retreat that enable a better understanding of managed retreat as an adaptation option to be considered now, and for its implementation over time?

3. What economic framework could be built for planning and costing managed retreat as an adaptation option within a coastal risk management strategy?

To answer these research questions, a qualitative research process was followed to develop a typology and framework. The outputs of this thesis (typology and framework) were tested through a series of semi-structured discussion with key practitioners working in the climate change adaptation space.

\subsection{Knowledge Contribution}

This thesis has developed a component typology and costing framework for managed retreat which unpacks this adaptation option by identifying the many components of managed retreat, presents them in a novel staged manner using a pathways approach and provides an approach for its costing. The thesis also highlights implementation issues associated with managed retreat. As such, the thesis has advanced the knowledge about managed retreat as an adaptation option and has addressed the research questions. 
The component typology and costing framework will help local governments to unbundle managed retreat and consider how it can be advanced with their communities in situations where the impacts of sea-level rise are inevitable. It does this by presenting the components in stages, presenting them as overlapping and parallel pathways, providing groupings of components according to the types of costs, and appropriate costing methodologies that can enable the implementation of managed retreat.

Staging managed retreat also enables local governments and communities to spread the implementation and investment over a period of time. As a result, managed retreat can be implemented appropriately and effectively when the components are required through the use of signals and trigger points.

This thesis shows why the process of managed retreat needs to begin as early as possible. This is to ensure that in locations where managed retreat is considered inevitable, local governments and their communities can undertake the initial stages of managed retreat in order to be prepared for when 'Active Retreat' components require activation. As a result, the thesis achieves the research objectives by contributing to the overall understanding of managed retreat as a coastal risk adaptation option, while providing guidance to those involved with the planning, costing, and implementation of the option.

\subsection{Future Research Opportunities}

This thesis has provided a starting point which can be developed further and built upon in the future to improve its usefulness, applicability, and relevance to those planning and costing managed retreat. The discussions and literature analysis carried out through the process of this thesis identified two significant 'next steps' for further research that will assist the implementation plans for managed retreat. These are (1) establishing who funds the different components of managed retreat, as identified in this thesis; and (2) how the planning stage of managed retreat via district and regional plan rules can support implementation of managed retreat. 


\subsection{Final Comments}

While this thesis has been undertaken in the context of sea-level rise and adaptation to coastal hazards, the component typology and costing framework can be applied to managed retreat in different contexts (such as river flooding, drought, bushfires, and landslide risk, etc.). As a result, this thesis not only addresses a gap in coastal adaptation knowledge, but can also aid those managing risks to communities from other hazards that are being exacerbated by climate change. 



\section{Reference List}

Abel, N., Gorddard, R., Harman, B., Leitch, A., Langridge, J., Ryan, A., \& Heyenga, S. (2011). Sea level rise, coastal development and planned retreat: analytical framework, governance principles and an Australian case study. Environmental Science \& Policy, 14(3), 279288. doi: 10.1016/j.envsci.2010.12.002

Alexander, K. S., Ryan, A., \& Measham, T. G. (2012). Managed retreat of coastal communities: understanding responses to projected sea level rise. Journal of Environmental Planning and Management, 55(4), 409-433. doi: 10.1080/09640568.2011.604193

Bell, R., Lawrence, J., Allan, S., Blackett, P. E., \& Stephens, S. (2017). Coastal hazards and climate change: Guidance for local government. (ME 1341). Ministry for the Environment. 297p. Retrieved from https://www.mfe.govt.nz/publications/climatechange/coastal-hazards-and-climate-change-guidance-local-government

Bendall, S. (2018). Clifton to Tangoio Coastal Hazards Strategy 2120. Report of the Northern and Southern Cell Assessment Panels, February 14, 2018. 81p. Retrieved from https://www.hbcoast.co.nz/assets/Document-Library/Assessment-Panel-ReportFINAL-28.2.18-reduced-size.pdf

Berrang-Ford, L., Pearce, T., \& Ford, J. D. (2015). Systematic review approaches for climate change adaptation research. Regional Environmental Change, 15(5), 755-769. doi: 10.1007/s10113-014-0708-7

Binder, S. B., Baker, C. K., \& Barile, J. P. (2015). Rebuild or Relocate? Resilience and Postdisaster Decision-Making After Hurricane Sandy. American Journal of Community Psychology, 56(1), 180-196. doi: 10.1007/s10464-015-9727-x

Birol, E., Karousakis, K., \& Koundouri, P. (2006). Using economic valuation techniques to inform water resources management: A survey and critical appraisal of available techniques and an application. Science of the Total Environment, 365(1), 105-122. doi: https://doi.org/10.1016/j.scitotenv.2006.02.032

Bloemen, P., Reeder, T., Zevenbergen, C., Rijke, J., \& Kingsborough, A. (2018). Lessons learned from applying adaptation pathways in flood risk management and challenges for the further development of this approach. Mitigation and adaptation strategies for global change, 23(7), 1083-1108. doi: 10.1007/s11027-017-9773-9

Boston, J., \& Lawrence, J. (2018). Funding Climate Change Adaptation: the case for a new policy framework. Policy Quarterly, 14(2), 40-49. doi:10.26686/pq.v14i2.5093

Bronen, R., \& Chapin, F. S. (2013). Adaptive governance and institutional strategies for climateinduced community relocations in Alaska. Proceedings of the National Academy of Sciences, 110(23), 9320. doi: 10.1073/pnas.1210508110

Burby, R. J., \& French, S. P. (1981). Coping With Floods: The Land Use Management Paradox. Journal of the American Planning Association, 47(3), 289-300. doi: 10.1080/01944368108976511 
Chambwera, M., Heal, G., Dubeux, S., Hallegatte, S., Leclerc, L., Markandya, A., . . Neumann, J. E. (2014). Economics of adaptation. In C. B. Field, V. R. Barros, D. J. Dokken, K. J. Mach, M. D. Mastrandrea, T. E. Bilir, M. Chatterjee, K. L. Ebi, Y. O. Estrada, R. C. Genova, B. Girma, E. S. Kissel, A. N. Levy, S. MacCraken, P. R. Mastrandrea, \& L. L. White (Eds.), Climate Change 2014: Impacts, adaptation, and vulnerability. Part A: Global and sectoral aspects. Contribution of Working Group II to the Fifth Assessment Report or the Intergovernmental Panel on Climate Change. (pp. 945-977). Cambridge, UK \& New York, NY, USA: Cambridge University Press.

Church, J. A., Clark, P. U., Cazenave, A., Gregory, J. M., Jevrejeva, S., Levermann, A., . . Unnikrishnan, A. S. (2013). Sea level change. In T. F. Stocker, D. Qin, G. K. Plattner, M. Tignor, S. K. Allen, J. Boschung, A. Nauels, Y. Xia, Y. Bex, \& P. M. Midgley (Eds.), Climate change 2013: The Physical Science Basis. Contribution of Working Group I to the Fifth Assessment Report of the Intergovernmental Panel on Climate Change (pp. 13111394). United Kingdom \& New York: Cambridge University Press.

Clark, P. U., Shakun, J. D., Marcott, S. A., Mix, A. C., Eby, M., Kulp, S., . . Plattner, G.-K. (2016). Consequences of twenty-first-century policy for multi-millennial climate and sea-level change. Nature Climate Change, 6, 360. doi: 10.1038/nclimate2923.

Correa, E., Ramírez, F., \& Sanahuja, H. (2011). Populations at risk of disaster: A resettlement guide: World Bank. Washington DC: The World Bank: GRDRR, 2011. 142p.

Crotty, M. (1998). The foundations of social research: Meaning and perspective in the research process. St Leonards, NSW: Allen \& Unwin.

Dawson, R. J., Dickson, M. E., Nicholls, R. J., Hall, J. W., Walkden, M. J., Stansby, P. K., . . Milligan, J. (2009). Integrated analysis of risks of coastal flooding and cliff erosion under scenarios of long term change. Climatic Change, 95(1-2), 249-288. doi: $10.1007 / \mathrm{s} 10584-008-9532-8$

Department of Conservation. (2017). New Zealand Coastal Policy Statement 2010 Guidance Note: Coastal Hazards. Objective 5 and Policies 24, 25, 26, \& 27. Wellington: Department of Conservation.

Dittrich, R., Wreford, A., \& Moran, D. (2016). A survey of decision-making approaches for climate change adaptation: Are robust methods the way forward? Ecological Economics, 122, 79-89. doi: 10.1016/j.ecolecon.2015.12.006

Elkin, R. S., \& Keenan, J. M. (2018). Retreat or Rebuild: Exploring Geographic Retreat in Humanitarian Practices in Coastal Communities. In W. Leal Filho (Ed.), Climate Change Impacts and Adaptation Strategies for Coastal Communities (pp. 149-165). Cham: Springer.

Esteves, L. S. (2014). What is managed realignment? In Managed realignment: A viable longterm coastal management strategy? Dordrecht: Springer Netherlands.

Fletcher, C. S., Rambaldi, A. N., Lipkin, F., \& McAllister, R. R. J. (2016). Economic, equitable, and affordable adaptations to protect coastal settlements against storm surge inundation. Regional Environmental Change, 16(4), 1023-1034. doi: 10.1007/s10113-015-0814-1 
Fletcher, C. S. (2013). Costs and coasts: an empirical assessment of physical and institutional climate adaptation pathways. Gold Coast: National Climate Change Adaptation Research Facility. 54p. Retrieved from https://apo.org.au/node/34006

Freudenberg, R., Calvin, E., Tolkoff, L., \& Brawley, D. (2016). Buy-in for buyouts: The case for managed retreat from flood zones. Cambridge, MA: Lincoln Institute of Land Policy. $72 \mathrm{p}$.

Fu, X., \& Song, J. (2017). Assessing the Economic Costs of Sea Level Rise and Benefits of Coastal Protection: A Spatiotemporal Approach. Sustainability, 9(8), 1495. doi: $10.3390 /$ su9081495

Fu, X., Song, J., Sun, B., \& Peng, Z.-R. (2016). "Living on the edge": Estimating the economic cost of sea level rise on coastal real estate in the Tampa Bay region, Florida. Ocean \& Coastal Management, 133, 11-17. doi: 10.1016/j.ocecoaman.2016.09.009

Fullilove, M. T. (1996). Psychiatric implications of displacement: Contributions from the psychology of place. American Journal of Psychiatry, 153, 12. doi: 10.1176/ajp.153.12.1516

Gehrels, W. R., Hayward, B. W., Newnham, R. M., \& Southall, K. E. (2008). A 20th century acceleration of sea-level rise in New Zealand. Geophysical Research Letters, 35(2). doi: 10.1029/2007GL032632

Gieryn, T. F. (1983). Boundary-Work and the Demarcation of Science from Non-Science: Strains and Interests in Professional Ideologies of Scientists. American Sociological Review, 48(6): 781-795.

Gough, D., Thomas, J., \& Oliver, S. (2012). Clarifying differences between review designs and methods. Systematic Reviews, 1(1), 28. doi: 10.1186/2046-4053-1-28

Greater Wellington Regional Council. (2015). Flood Protection: Option flexibility and its value Hutt River City Centre Upgrade River Corridor Option Report. Prepared for GWRC by Infometrics \& PSConsulting. Wellington. Retrieved from http://www.gw.govt.nz/assets/floodprotection/Hutt-RiverFMGM/Optionflexibilityanditsvalue.pdf

Haasnoot, M., Kwakkel, J. H., Walker, W. E., \& ter Maat, J. (2013). Dynamic adaptive policy pathways: A method for crafting robust decisions for a deeply uncertain world. Global Environmental Change, 23(2), 485-498. doi: 10.1016/j.gloenvcha.2012.12.006

Haasnoot, M., van Aalst, M., Rozenberg, J., Dominique, K., Matthews, J., Bouwer, L. M., . . . Poff, N. L. (2019). Investments under non-stationarity: economic evaluation of adaptation pathways. Climatic Change. doi: 10.1007/s10584-019-02409-6

Hanna, C., White, I., \& Glavovic, B. (2018). Managed retreat governance: Insights from Matata, New Zealand. Report for the National Science Challenge: Resilience to Nature's Challenges. New Zealand: University of Waikato. 26p.

Hanna, C., White. I., Glavovic. B. (2017). Managed retreat in New Zealand: Revealing the terminology, approaches and direction of local planning instruments. Report for the National Science Challenge: Resilience to Nature's Challenges. New Zealand: University of Waikato. 27p. 
Hannah, J., \& Bell, R. G. (2012). Regional sea level trends in New Zealand. Journal of Geophysical Research: Oceans, 117(C1). C01004. doi: 10.1029/2011jc007591

Henderson, R. T. (2018). Sink or Sell: Using Real Estate Purchase Options to Facilitate Coastal Retreat. Vanderbilt Law Review Notes, 71(2), 641-680. Retrieved from https://vanderbiltlawreview.org/lawreview/2018/03/sink-or-sell-using-real-estatepurchase-options-to-facilitate-coastal-retreat/

Hermans, L. M., Haasnoot, M., ter Maat, J., \& Kwakkel, J. H. (2017). Designing monitoring arrangements for collaborative learning about adaptation pathways. Environmental Science \& Policy, 69, 29-38. doi: 10.1016/j.envsci.2016.12.005

Higuchi, T., Bruggemann, T., Obeahon, S., Gosden, J., \& Elder, A. (2013). Medmerry Realignment Scheme: Design and Construction of an Earth Embankment on Soft Clay Foundation. Paper presented ICE Coasts, Marine Structures and Breakwaters conference. Edinburgh. Retrieved from https://www.researchgate.net/profile/Toru Higuchi3/publication/284183371 Medme rry Realignment Scheme Design and Construction of an Earth Embankment on Soft Clay Foundation/links/564f045c08aeafc2aab366c4/Medmerry-RealignmentScheme-Design-and-Construction-of-an-Earth-Embankment-on-Soft-ClayFoundation.pdf

Hino, M., Field, C. B., \& Mach, K. J. (2017). Managed retreat as a response to natural hazard risk. Nature Climate Change, 7, 364. doi: 10.1038/nclimate3252

Infometrics. (2017). Real Options Analysis of Strategies to Managed Coastal Hazard Risks: Northern Units B-E 7 Southern Units J-L. Report for Hawke's Bay Regional Council November 2017. Retrieved from https://www.hbcoast.co.nz/assets/DocumentLibrary/Other-documents/Real-Options-Analysis-of-Strategies-to-Manage-CoastalHazard-Risks-Northern-Units-B-E.pdf. https://www.hbcoast.co.nz/assets/DocumentLibrary/Other-documents/Real-Options-Analysis-of-Strategies-to-Manage-CoastalHazard-Risks-Southern-Units-J-L.pdf

IPCC. (2014). Climate Change 2014: Synthesis Report. Contribution of Working Groups I, II and III to the Fifth Assessment Report of the Intergovernmental Panel on Climate Change. Geneva: IPCC. Retrieved from http://ar5-syr.ipcc.ch/

IPCC. (2018). Summary for Policymakers. In Global Warming of $1.5^{\circ} \mathrm{C}$. An IPCC Special Report on the impacts of global warming of $1.5^{\circ} \mathrm{C}$ above pre-industrial levels and related global greenhouse gas emission pathways, in the context of strengthening the global response to the threat of climate change, sustainable development, and efforts to eradicate poverty. V. Masson-Delmotte, P. Zhai, H. -O. Pörtner, D. Roberts, J. Skea, P. R. Shukla, A. Pirani, W. Moufouma-Okia, C. Péan, R. Pidock, S. Connors, J. B. R. Matthews, Y. Chen, X. Zhou, M. I. Gomis, E. Lonnoy, Maycock, M. Tignor\& T. Waterfield (eds.). Geneva: World Meteorological Organisation. Retrieved from https://www.ipcc.ch/sr15/chapter/summary-for-policy-makers/

Jasanoff, S. (2017). Virtual, Visible, and Actionable: Data Assemblages and the Sightlines of Justice. Big Data and Society, July-December: 1-15.

Kalra, N., Hallegatte, S., Lempert, R., Brown, C., Fozzard, A., Gill, S., \& Shah, A. (2014). Agreeing on Robust Decisions: New Processes for Decision Making under Deep Uncertainty. 
Policy research working paper (6906). Washington, DC: The World Bank. doi 10.1596/1813-9450-6906

Kind, J. M. (2014). Economically efficient flood protection standards for the Netherlands. Journal of Flood Risk Management, 7(2), 103-117. doi:10.1111/jfr3.12026

Kopp, R. E., Kemp, A. C., Bittermann, K., Horton, B. P., Donnelly, J. P., Gehrels, W. R., . . . Rahmstorf, S. (2016). Temperature-driven global sea-level variability in the Common Era. Proceedings of the National Academy of Sciences, 113(11), E1434-E1441. doi: 10.1073/pnas.1517056113

Koraim, A. S., \& Negm, A. (2016). Protection methods against sea-level rise caused by climatic change: case study of the Nile Delta coastal zones. In A. Negm (Ed.), The Nile Delta (Vol. 55, pp. 397-423). Cham: Springer.

Koslov, L. (2016). The Case for Retreat. Public Culture, $28(2$ (79)), 359-387. doi: 10.1215/08992363-3427487

Kousky, C. (2014). Managing shoreline retreat: a US perspective. Climatic Change, 124(1-2), 920. doi: $10.1007 / \mathrm{s} 10584-014-1106-3$

Kwakkel, J. H., Haasnoot, M., \& Walker, W. E. (2016). Comparing Robust Decision-Making and Dynamic Adaptive Policy Pathways for model-based decision support under deep uncertainty. Environmental Modelling \& Software, 86, 168-183. doi: 10.1016/j.envsoft.2016.09.017

Laing, D. (2018). Ability to stop or limit the provision of services infrastructure and potential liability consequences. Report prepared for Local Government New Zealand. 25p. Retrieved from http://www.lgnz.co.nz/assets/Uploads/0e7261636b/Legal-opinion-2Ability-to-stop-or-limit-the-provision-of-services-infrastructure-and-potential-liabilityconsequences2.pdf

Landscape Institute. (2016, September 7). Medmerry Managed Realignment Scheme. Retrieved from https://www.landscapeinstitute.org/casestudies/medmerry managed realignment scheme/

Lawrence, J., Bell, R., Blackett, P., Stephens, S., \& Allan, S. (2018). National guidance for adapting to coastal hazards and sea-level rise: Anticipating change, when and how to change pathway. Environmental Science \& Policy, 82, 100-107. doi: 10.1016/j.envsci.2018.01.012

Lawrence, J., Bell, R., \& Stroombergen, A. (2019a). A Hybrid Process to Address Uncertainty and Changing Climate Risk in Coastal Areas Using Dynamic Adaptive Pathways Planning, Multi-Criteria Decision Analysis \&; Real Options Analysis: A New Zealand Application. Sustainability, 11(2), 406. doi: https://doi.org/10.3390/su11020406

Lawrence, J., \& Haasnoot, M. (2017). What it took to catalyse uptake of dynamic adaptive pathways planning to address climate change uncertainty. Environmental Science \& Policy, 68, 47-57. doi: 10.1016/j.envsci.2016.12.003

Lawrence, J., Haasnoot, M., McKim, L., Atapattu, D., Campbell, G., \& Stroombergen, A. (2019b). Dynamic Adaptive Policy Pathways (DAPP): From Theory to Practice. In V. A. W. J. Marchau, W. E. Walker, P. J. T. M. Bloemen, \& S. W. Popper (Eds.), Decision Making 
under Deep Uncertainty: From Theory to Practice (pp. 187-199). Cham: Springer International Publishing.

Lawrence, J., Quade, D., \& Becker, J. (2014). Integrating the effects of flood experience on risk perception with responses to changing climate risk. Natural Hazards, 74(3), 17731794. doi: 10.1007/s11069-014-1288-z

Lawrence, J., Sullivan, F., Lash, A., Ide, G., Cameron, C., \& McGlinchey, L. (2015). Adapting to changing climate risk by local government in New Zealand: institutional practice barriers and enablers. Local Environment, 20(3), 298-320. doi:

$10.1080 / 13549839.2013 .839643$

Le Cozannet, G., Rohmer, J., Cazenave, A., Idier, D., van de Wal, R., de Winter, R., . . . Oliveros, C. (2015). Evaluating uncertainties of future marine flooding occurrence as sea-level rises. Environmental Modelling \& Software, 73, 44-56. doi:

10.1016/j.envsoft.2015.07.021

Ledoux, L., Cornell, S., O'Riordan, T., Harvey, R., \& Banyard, L. (2005). Towards sustainable flood and coastal management: identifying drivers of, and obstacles to, managed realignment. Land Use Policy, 22(2), 129-144. doi: 10.1016/j.landusepol.2004.03.001

Lempert, R., Scheffran, J., \& Sprinz, D. F. (2009). Methods for Long-Term Environmental Policy Challenges. Global Environmental Politics, 9(3), 106-133. doi: 10.1162/glep.2009.9.3.106

Lin, B. B., Khoo, Y. B., Inman, M., Wang, C.-H., Tapsuwan, S., \& Wang, X. (2014). Assessing inundation damage and timing of adaptation: sea level rise and the complexities of land use in coastal communities. Mitigation and adaptation strategies for global change, 19(5), 551-568. doi: 10.1007/s11027-013-9448-0

Linham, M. M., \& Nicholls, R. J. (2010). Technologies for climate change adaptation-Coastal erosion and flooding. TNA Guidebook Series. Roskilde, Denmark: UNEP Ris $\varnothing$ Centre on Energy, Climate and Sustainable Development. 156p.

Lu, Q. C., Peng, Z.-R., \& Du, R. (2012). Economic analysis of impacts of sea level rise and adaptation strategies in transportation. Transportation Research Record, 2273(1), 5461. doi: $10.3141 \% 2 F 2273-07$

Luisetti, T., Turner, R. K., Bateman, I. J., Morse-Jones, S., Adams, C., \& Fonseca, L. (2011). Coastal and marine ecosystem services valuation for policy and management: Managed realignment case studies in England. Ocean \& Coastal Management, 54(3), 212-224. doi: 10.1016/j.ocecoaman.2010.11.003

Magnan, A. K., Colombier, M., Billé, R., Joos, F., Hoegh-Guldberg, O., Pörtner, H.-O., . . . Gattuso, J.-P. (2016). Implications of the Paris agreement for the ocean. Nature Climate Change, 6, 732. doi: 10.1038/nclimate3038

Marchau, V. A., Walker, W. E., Bloemen, P., \& Popper, S. (2019). Decision making under deep uncertainty (pp. 405). Cham: Springer. doi: 10.1007/978-3-030-05252-2 
Matthews, T., \& Potts, R. (2018). Planning for climigration: a framework for effective action. Climatic Change, 148, 607-621. doi: 10.1007/s10584-018-2205-3

McAlinden, B. (2015). Managed realignment at Medmerry, Sussex. Retrieved January 25, 2019, from https://www.ice.org.uk/knowledge-and-resources/case-studies/managedrealignment-at-medmerry-sussex

Minister of Conservation. (2010). New Zealand Coastal Policy Statement. Wellington. Retrieved from https://www.doc.govt.nz/about-us/science-publications/conservationpublications/marine-and-coastal/new-zealand-coastal-policy-statement/new-zealandcoastal-policy-statement-2010

Myatt, L. B., Scrimshaw, M. D., \& Lester, J. N. (2003). Public perceptions and attitudes towards a forthcoming managed realignment scheme: Freiston Shore, Lincolnshire, UK. Ocean \& Coastal Management, 46(6), 565-582. doi: 10.1016/S0964-5691(03)00035-8

NCCARF. (2017). Managed coastal realignment projects in the UK. Snapshot for CoastAdapt. Gold Coast: National Climate Change Adaptation Research Facility. Retrieved April 3, 2019, from https://coastadapt.com.au/sites/default/files/case_studies/SS46_UK_Coastal_Realign ment.pdf

Neal, W. J., Bush, D. M., \& Pilkey, O. H. (2005). Managed Retreat. In M. L. Schwartz (Ed.), Encyclopedia of Coastal Science (pp. 602-606). Dordrecht: Springer Netherlands.

New Zealand Environment Guide. (2018). Managing Natural Hazard Risks in New Zealand. Retrieved May 15, 2019, from http://www.environmentguide.org.nz/issues/naturalhazards/managing-natural-hazard-risks-in-new-zealand/

New Zealand Institute of Economic Research. (2000). The origins of ODV. Report to Air NZ, August 2000. Retrieved from https://nzier.org.nz/static/media/filer public/40/68/40686af5-52ca-4a0c-bb2e1259dc34c94f/origins of odv.pdf

Nicholls, R. J., Marinova, N., Lowe, J. A., Brown, S., Vellinga, P., Gusmão, d. D., . . Tol, R. S. J. (2011). Sea-level rise and its possible impacts given a 'beyond $4^{\circ} \mathrm{C}$ world' in the twentyfirst century. Philosophical Transactions of the Royal Society A: Mathematical, Physical and Engineering Sciences, 369(1934), 161-181. doi: 10.1098/rsta.2010.0291

Niven, R. J., \& Bardsley, D. K. (2013). Planned retreat as a management response to coastal risk: a case study from the Fleurieu Peninsula, South Australia. Regional Environmental Change, 13(1), 193-209. doi: 10.1007/s10113-012-0315-4

Owen, S. D., Turner, T., Ryan, E. J., \& Kench, P. (2017). Rethinking Coastal Margins: The implementation of managed retreat options in New Zealand, The USA, Australia and the UK. Unpublished report for the Technical Advisory Group of the Clifton to Tangoio Coastal Hazards Strategy 2120.

Parker, C. (2009). The implications of discount rate reductions on transport investments and sustainable transport futures. NZTA research report 392, December 2009. Retrieved from https://www.nzta.govt.nz/assets/resources/research/reports/392/docs/392.pdf 
Parliamentary Commissioner for the Environment. (2015). Preparing New Zealand for rising seas: Certainty and uncertainty. Wellington: Parliamentary Commissioner for the Environment. Retrieved from https://www.pce.parliament.nz/publications/preparingnew-zealand-for-rising-seas-certainty-and-uncertainty

Pattle Delamore Partners LTD. (2011). New Zealand Guidelines for the Monitoring and Management of Sea Water Intrusion Risks on Groundwater. Prepared for Envirolink Project 420-NRLC50. Retrieved from http://envirolink.govt.nz/assets/Envirolink/420NLRC50-Guidelines-for-the-monitoring-and-management-of-sea-water-intrusion-riskson-groundwater.pdf

Rangel-Buitrago, N., de Jonge, V. N., \& Neal, W. (2018). How to make Integrated Coastal Erosion Management a reality. Ocean \& Coastal Management, 156, 290-299. doi: 10.1016/j.ocecoaman.2018.01.027

Reisinger, A., Lawrence, J., Hart, G., \& Chapman, R. (2015). The role of managed retreat in highly developed coastal regions of New Zealand. In B. Glavovic, M. Kelly, R. Kay \& A. Travers (Eds.), Climate Change and the Coast: Building Resilient Communities. Boca Raton, Florida: CRC Press.

Rouse, H. L., Bell, R. G., Lundquist, C. J., Blackett, P. E., Hicks, D. M., \& King, D. N. (2017). Coastal adaptation to climate change in Aotearoa-New Zealand. New Zealand Journal of Marine and Freshwater Research, 51(2), 183-222. doi: 10.1080/00288330.2016.1185736

Rulleau, B., Rey-Valette, H., \& Clément, V. (2017). Impact of justice and solidarity variables on the acceptability of managed realignment. Climate Policy, 17(3), 361-377. doi: 10.1080/14693062.2015.1119097

Rupp-Armstrong, S., \& Nicholls, R. J. (2007). Coastal and Estuarine Retreat: A Comparison of the Application of Managed Realignment in England and Germany. Journal of Coastal Research, 1418-1430. doi: 10.2112/04-0426.1

Scarano, M. S. (2018). Withholding Municipal Services to Facilitate Coastal Retreat: Legal Risks and Possibilities. Environmental Claims Journal, 30(2), 151-170. doi: 10.1080/10406026.2018.1442545

Siders, A. (2013). Managed coastal retreat: a legal handbook on shifting development away from vulnerable areas. Center for Climate Law, Columbia Public Law Research Paper (14-365). 140p. Retrieved from https://biotech.law.Isu.edu/blog/ManagedCoasta IRetreat_FINAL_Oct-30.pdf

Silverman, D. (2011). Interpreting qualitative data: a guide to the principles of qualitative research (4th ed.). Los Angeles: Sage.

Sipe, N., \& Vella, K. (2014). Relocating a Flood-Affected Community: Good Planning or Good Politics? Journal of the American Planning Association, 80(4), 400-412. doi: 10.1080/01944363.2014.976586

Song, J., Fu, X., Wang, R., Peng, Z.-R., \& Gu, Z. (2018). Does planned retreat matter? Investigating land use change under the impacts of flooding induced by sea level rise. Mitigation and adaptation strategies for global change, 23(5), 703-733. doi: 10.1007/s11027-017-9756-x 
Stephens, S. A., Bell, R. G., \& Lawrence, J. (2017). Applying Principles of Uncertainty within Coastal Hazard Assessments to Better Support Coastal Adaptation. Journal of Marine Science and Engineering, 5(3), 40. doi: 10.3390/jmse5030040

Stephens, S. A., Bell, R. G., \& Lawrence, J. (2018). Developing signals to trigger adaptation to sea-level rise. Environmental Research Letters, 13(10), 104004. doi: 10.1088/17489326/aadf96

Strauss, B. H., Kulp, S., \& Levermann, A. (2015). Carbon choices determine US cities committed to futures below sea level. Proceedings of the National Academy of Sciences, 112(44), 13508-13513. doi: 10.1073/pnas.1511186112

Tadgell, A., Doberstein, B., \& Mortsch, L. (2018). Principles for climate-related resettlement of informal settlements in less developed nations: a review of resettlement literature and institutional guidelines. Climate and Development, 10(2), 102-115. doi: 10.1080/17565529.2017.1291401

Tobin, G. A. (1995). The levee love affair: a stormy relationship? JAWRA Journal of the American Water Resources Association, 31(3), 359-367. doi10.1111/j.17521688.1995.tb04025.x

Trudeau, C. (2017). Newtok marks relocation progress with celebration at new village site. Retrieved January 21, 2019, from https://www.adn.com/alaska-news/ruralalaska/2017/08/16/newtok-marks-relocation-progress-with-celebration-at-newvillage-site/

Tsvetanov, T. G., \& Shah, F. A. (2013). The economic value of delaying adaptation to sea-level rise: An application to coastal properties in Connecticut. Climatic Change, 121(2), 177193. doi: 10.1007/s10584-013-0848-7

Turbott, C. (2006). Managed retreat from coastal hazards: Options for implementation. Waikato Regional Council Technical Report 2006/48. Retrieved from https://www.waikatoregion.govt.nz/assets/PageFiles/5405/tr06-48.pdf

Turner, R. K., Burgess, D., Hadley, D., Coombes, E., \& Jackson, N. (2007). A cost-benefit appraisal of coastal managed realignment policy. Global Environmental Change, 17(3), 397-407. doi: 10.1016/j.gloenvcha.2007.05.006

Twigger-Ross, C., Orr, P., Brooks, K., Sadauskis, R., Deeming, H., Fielding, J., . . Tapsell, S. (2015). Flood Resilience Community Pathfinder Evaluation. Final evaluation report FD1664). Retrieved from http://www.nationalfloodforum.org.uk/

Vandenbeld, A., \& MacDonald, J. (2013). Fostering community acceptance of managed retreat in New Zealand. In J. Palutikof, S. L. Boulter, A. J. Ash, M. Stafford Smith, M. Parry, M. Waschka, \& D. Guitart (Eds.), Climate Adaptation Futures. UK: Wiley-Blackwell.

Watkiss, P., Hunt, A., Blyth, W., \& Dyszynski, J. (2015). The use of new economic decision support tools for adaptation assessment: A review of methods and applications, towards guidance on applicability. Climatic Change, 132(3), 401-416. doi: 10.1007/s10584-014-1250-9 
Waldholz, R. (2017, January 10). Alaskan Village, Citing Climate Change, Seeks Disaster Relief In Order To Relocate. Retrieved January 21, 2019, from https://www.npr.org/2017/01/10/509176361/alaskan-village-citing-climate-changeseeks-disaster-relief-in-order-to-relocate

Whakatane District Council. (2017). Debris flow risk: A way forward for the Awataraiki fanhead Indicative Business Case. Whakatane District Council: Whakatane District Council. $122 \mathrm{p}$. Retrieved from https://www.whakatane.govt.nz/sites/www.whakatane.govt.nz/files/documents/abou $\mathrm{t}$-council/council-projects/debris-flow-and-landslidehazards/indicative business case - awatarariki fanhead - final draft pdf augus.pdf

Williams, A. T., Rangel-Buitrago, N., Pranzini, E., \& Anfuso, G. (2018). The management of coastal erosion. Ocean \& Coastal Management, 156, 4-20. doi: 10.1016/j.ocecoaman.2017.03.022

World Economic Forum. (2019). The Global Risks Report 2019 (14 th ed.). Geneva: The World Bank. 108p. Retrieved from https://www.weforum.org/reports/the-global-risksreport-2019

Yohe, G. W. (1991). Uncertainty, climate change and the economic value of information: an economic methodology for evaluating the timing and relative efficacy of alternative response to climate change with application to protecting developed property from greenhouse induced sea level rise. Policy Sciences, 24(3), 245-269. doi: 10.1007/BF00186329

Yohe, G. W., \& Schlesinger, M. E. (1998). Sea-level change: the expected economic cost of protection or abandonment in the United States. Climatic Change, 38(4), 447-472. doi: 10.1023/A:1005338413531 


\section{Glossary of Terms}

\section{Coastal Squeeze:}

Refers to the loss of intertidal habitat along protected stretches of coast as seas rise. Protective structures inhibit the ability of these habitats to migrate inland as sea-level rises, therefore 'squeezing' the intertidal habitat.

\section{Cost-Benefit Analysis:}

A process for the analysis of decisions which sums the benefits of a proposed investment and subtracts the costs of that investment. Usually the benefits and costs are discounted (see below) to a common year to ensure that the analysis is not distorted by differences in the timing of costs and benefits. Cost-benefit analysis is applied to adaptation options and comparing them (e.g. managed retreat vs protective structures).

\section{Discount Rate:}

The factor used to determine the present value of future costs and benefits (e.g. a $5 \%$ discount rate would value $\$ 1$ in a year's time as $\$ 0.95$ today).

\section{Envirolink:}

A New Zealand, regional council driven funding scheme (administered by the Ministry of Business, Innovation \& Employment - Science and Innovation), which funds research organisations to provide regional councils with advice and support for environmental research.

\section{Hedonic Regression:}

A process where individual components of an asset are assessed for their impact on the overall value of the asset

\section{Intergovernmental Panel on Climate Change (IPCC):}

The 'IPCC' is the United Nations body which is designed to analyse the science related to climate change 


\section{Managed Realignment:}

A coastal adaptation option that involves the shift inland or removal of coastal defences, allowing for the flooding of coastal land to form new intertidal habitats that act as a natural barrier.

\section{Municipal Services:}

Services that are supplied to the public by a local authority. For example; roads, storm water, wastewater and water supply infrastructure.

\section{National Climate Change Adaptation Research Facility (NCCARF):}

NCCARF is an Australian Government venture designed to coordinate Australia's researchers to generate and communicate climate change and adaptation information that decision makers require.

\section{Pathways:}

For the purposes of this study, 'pathways' refers to adaptation strategy pathways that consist of many different actions that can be activated over time either subsequent or alongside earlier actions.

\section{Real-Options Analysis:}

An extension to cost-benefit analysis that assesses the value of waiting for new information, before undertaking expensive and sometimes irreversible investments.

\section{Representative Concentration Pathway (RCP):}

Projections of atmospheric greenhouse gas concentrations based on emissions scenarios.

\section{Scenario:}

For the purposes of this study, scenario refers to different futures which could occur under a changing climate. 


\section{Strategy:}

For the purposes of this thesis, strategy refers to a set of different climate change adaptation options that are presented as pathways over time (e.g. managed retreat and sea walls).

\section{Three-Waters:}

This refers the potable water, wastewater, and storm water services. 



\section{Appendices}

\section{Appendix A: Managed Retreat and Coastal Hazard Management Context}

The various Acts and supporting statues and policies outlined in Section 1.2, are discussed below:

\section{Resource Management Act:}

Regional and local councils have specific functions to managed natural hazards. The purpose of the RMA (outlined in Section 5(1)) is to promote sustainable management of physical and natural resources (Bell et al., 2017). Part 2 of the RMA (purposes and principles) outlines the preservation of natural character of the coastal environment and the management of significant natural coastal hazard risks as matters of national importance (Bell et al., 2017). Requirements for managing coastal environments are clarified in the NZCPS 2010 (Sections 56-58 of the RMA) (Bell et al., 2017). District and regionals plans, and regional policy statements must comply with the RMA and give effect to the NZCPS (Bell et al., 2017).

Section 6 of the RMA outlines matters of national importance that require recognition:

(a) the preservation of the natural character of the coastal environment (including the coastal marine area)

(b) the protection of outstanding natural features and landscapes from inappropriate subdivision, use, and development

(d) the maintenance and enhancement of public access to and along the coastal marine area

(e) the relationship of Māori and their culture and traditions with their ancestral lands, water, sites, waahi tapu, and other taonga

(h) the management of significant risks from natural hazards. 
Section 7 requires that significant consideration is undertaken for a number of matters, including:

(a) kaitiakitanga

(aa) the ethic of stewardship

(c) the maintenance and enhancement of amenity values

(g) any finite characteristics of natural and physical resources

(i) the effects of climate change

\section{New Zealand Coastal Policy Statement (NZCPS):}

The NZCPS (Minister of Conservation, 2010) includes policies to achieve the purpose of the RMA while managing coastal environment. The NZCPS is prepared under the RMA and is required to be 'given effect to' in district and regional plans, regional policy statements and regional coastal plans. The NZCPS must also be had 'regard to' in resource consent applications decisions (Bell et al., 2017).

Below are listed several provisions from the NZCPS which are relevant to response actions to natural coastal hazards (e.g. sea-level rise) (Bell et al., 2017):

- Objective 1 and 2, policies 1,5,11 and 17 - address features of natural and heritage character

- Objective 6, policies 6, 7, 9 and 10 - consider appropriate subdivision, land-use and development in coastal areas

- Policy 3 - directs a precautionary approach towards proposed activities in the coastal zone

- Objective 5, policies 24-24 - recognise natural hazards and outline methods for the management of coastal hazard risk (discussed below)

- Objective 4, policies 18-20 - address the maintenance and enhancement of public access and open space at the coast 
Policy 24 provides guidance for the identification of coastal hazards and requires the identification of areas that will be potentially affected by coastal hazards (New Zealand Environment Guide (NZEG), 2018). Under this policy, coastal hazard risk must be assessed over a 100 year timeframe.

Policy 25 identifies the requirements regarding subdivision and development in areas of coastal hazard risk. The policy states that in areas potentially affected by coastal hazards in the next 100 years local government is required to: avoid increasing coastal risk, encourage redevelopment or changes in land use (including managed retreat through relocation or removal of structures), encourage the location of infrastructure away from the risk where practical, and to discourage hard protection structures. These set the requirements for managed retreat at the coast in New Zealand and are now supported by guidance as to their implementation (Department of Conservation, 2017).

Policy 26 outlines the significance of natural defences in protecting and reducing coastal hazards (NZEG, 2018). This policy requires local authorities to protect, restore and enhance natural defences. Policy 26 outlines that regional plans should identify these natural features that provide defence against coastal hazards, and rules to be implemented which protect them (NZEG, 2018). It is also outlined in Policy 26 that no new development should be permitted if it will have negative impacts on natural defence systems (NZEG, 2018).

Policy 27 begins by outlining several options that should be assessed for areas where significant existing development is likely to be affected by coastal hazards. These options include: (a) the identification of sustainable, long-term approaches for risk reduction including the relocation or removal of existing development or structures, (b) the identification of consequences of options relative to a 'do nothing' approach, (c) recognising that hard protective structures may be the only means of protecting existing infrastructure of national or regional importance, (d) recognising and considering the social and environmental costs of permitting hard defences for the protection of private property, (e) and the identification and planning for transition mechanisms and timeframes for moving to more sustainable hazard management approaches (NZEG, 2018). 
Policy 27 also outlines that the evaluation of options should focus on those that reduce the requirement for hard protection measures and that take into account the nature of the natural hazard today and how it might change in the future under continuing climate change (NZEG, 2018). In addition, it states that the likely costs and benefits of proposed coastal hazard risk management approaches should be evaluated (NZEG, 2018).

\section{The Building Act:}

The Building Act ensures the safety and integrity of a structure through its construction and use (Bell et al., 2017). The Building Act addresses the effects that a structure (or its use) has on the environment, and the effect that the environment has on the structure (and its use) (Bell et al., 2017).

Section 71 of the Building Act outlines that a consenting authority must refuse building consent for construction or major alterations to buildings if;

1. the land on which the building work is to be carried out is subject or is likely to be subject to one or more natural hazards; or

2. the building work is likely to accelerate, worsen, or result in a natural hazard on that land or to another property.

Building regulations, which includes the Building Code, are made in accordance with the Building Act (Bell et al., 2017). Clause E1 of the Building Code aims to protect from injury or damage to people or structures from surface water (fresh or sea water) (Bell et al., 2017). Clause E.1.3.2 states that surface water occurring from events with a 2 percent annual occurrence probability shall not enter buildings (Bell et al., 2017).

\section{Local Government Act (LGA):}

The LGA outlines the obligations, restrictions and framework under which local governments operate (NZEG, 2018). The 2002 LGA requires communities to prepare long-term plans which outline community outcomes and long term financial planning (Bell et al., 2017). These long term plans must include infrastructure strategies over at 
least a 30 year period which also include provisions for their resilience to natural hazards (Bell et al., 2017).

The avoidance or mitigation of natural hazard impacts is described in the LGA as a core service that must be contributed to communities by local governments (NZEG, 2018). The LGA also provides local governments with the power to make bylaws with the purpose of protecting and maintaining public health and safety (NZEG, 2018).

\section{Local Government Official Information and Meetings Act (LGOIMA):}

Section 44A (land information memorandum) of the Local Government Official Information and Meetings Act is relevant for the management of coastal hazards and other climate change effects (Bell et al., 2017).The LGOIMA provides the ability for the public to access official information held by local authorities. This includes Land Information Memorandums (LIM). A person may apply to territorial authorities for the issue of a LIM. One matter to be considered when deciding what is included on a LIM is:

(2)(a) information identifying each (if any) special feature or characteristic of the land concerned, including but not limited to potential erosion, avulsion, falling debris, subsidence, slippage, alluvion, or inundation, or likely presence of hazardous contaminants, being a feature or characteristic that

(i) is known to the territorial authority; but

(ii) is not apparent from the district scheme under the Town and Country Planning Act 1977 or a district plan under the Resource Management Act 1991.

There are no grounds for a territorial authority to withhold the information listed above or to refuse to provide a LIM when requested (Bell et al., 2017). 


\section{The Soil Conservation and Rivers Control Act:}

The Soil Conservation and Rivers Control Act 1941 includes objectives and responsibilities for catchment management and the conservation of soil (Bell et al., 2017), including provisions for "the prevention of damage by floods" (Section 10). This legislation complements the powers of the LGA for regional councils to create bylaws for flood protection and undertake control works (Bell et al., 2017). The Act allows for the seizing of land under the Public Works Act 1981 when it is required to meet the Act's responsibilities (Bell et al., 2017).

\section{Civil Defence and Emergency Act (CDEM):}

The CDEM ACT aims to

- improve and promote sustainable management of hazards

- encourage and enable communities to achieve acceptable levels of risk

- provide for planning and preparation for emergencies, and for response and recovery

- require local authorities to coordinate planning and activities about reduction, readiness, response and recovery

- encourage coordination across agencies

(Bell et al., 2017; NZEG, 2018):

The CDEM Act requires a risk management approach to be taken when dealing with hazards and considered across the reduction, readiness, response and recovery that may occur in an event, both the likelihood of a hazardous event and its consequences must be considered (Bell et al., 2017). The CDEM Act provides regional and territorial authorities a framework for the planning and coordination of hazard management across their roles and responsibilities (Bell et al., 2017).

This Act requires that local authorities to establish a joint Civil Defence Emergency Management Group (CDEM) in their region (NZEG, 2018). The role of these CDEM Groups is to potential hazards that may impact the area and establish mitigation or management measures. 
These statutes are supported by national policies, including the statutory New Zealand Coastal Policy Statement 2010 and National CDEM Strategy and National CDEM Plan. 



\section{Appendix B: Search Terms Used for the Literature Review}

The following tables outline the search terms that were applied to academic databases.

The databases that were used for this thesis were Scopus, Springerlink, Web of Science, and Google Scholar. The following tables follow an 'AND' 'OR' format where one term from the first box was searched for as a keyword along with words from the other boxes in the same row.

\section{Managed Retreat Components Literature Searches:}

\begin{tabular}{|c|c|c|}
\hline Managed Retreat & & \\
\hline Managed Retreat & $\begin{array}{l}\text { AND } \\
\text { Components }\end{array}$ & \\
\hline $\begin{array}{l}\text { Managed Retreat OR } \\
\text { Planned Retreat OR } \\
\text { Planned Coastal Retreat } \\
\text { OR Community Relocation } \\
\text { OR Community } \\
\text { Abandonment }\end{array}$ & $\begin{array}{l}\text { AND } \\
\text { Adaptation } O R \\
\text { Components }\end{array}$ & \\
\hline $\begin{array}{l}\text { Managed Retreat OR } \\
\text { Planned Retreat OR } \\
\text { Planned Coastal Retreat } \\
\text { OR Community Relocation } \\
\text { OR Community } \\
\text { Abandonment }\end{array}$ & $\begin{array}{l}\text { AND } \\
\text { Adaptation } O R \\
\text { Components }\end{array}$ & $\begin{array}{l}A N D \\
\text { Sea-Level Rise OR Storm } \\
\text { Tide OR Coastal } \\
\text { Inundation OR Flooding } \\
\text { OR Coastal Hazards OR } \\
\text { Coastal Flooding }\end{array}$ \\
\hline
\end{tabular}


Managed Retreat Costing Literature Searches:

\begin{tabular}{|l|l|l|}
\hline $\begin{array}{l}\text { Climate Change OR Sea- } \\
\text { Level Rise OR Coastal } \\
\text { Hazard OR Coastal } \\
\text { Flooding OR Flooding OR } \\
\text { Coastal Inundation OR } \\
\text { Coastal Hazards }\end{array}$ & $\begin{array}{l}\text { AND } \\
\text { Adaptation OR } \\
\text { Management }\end{array}$ & $\begin{array}{l}\text { AND } \\
\text { Costing OR Costs OR } \\
\text { Economic Costs }\end{array}$ \\
\hline $\begin{array}{l}\text { Managed Retreat OR } \\
\text { Planned Retreat OR } \\
\text { Planned Coastal Retreat } \\
\text { OR Community Relocation } \\
\text { OR Community } \\
\text { Abandonment }\end{array}$ & $\begin{array}{l}\text { AND } \\
\text { Costing OR Costs OR }\end{array}$ & \\
\hline
\end{tabular}




\section{Appendix C: Rationale for Table 5.2}

The table below outlines the rationale behind Table 5.2 from Chapter Five (Costing Framework). This table provides the reasons why certain costing techniques have been identified as being of use for each of the identified managed retreat components. Costing methodologies are labelled with the same initialisation as Chapter Five with a list of what each label refers to provided.

MP: Market Prices

ODV: Optimised Deprival Value

HP: Hedonic Pricing

CV: Contingent Valuation/Choice Experiments

TC: Travel Cost

NFI: Net Factor Income

\begin{tabular}{|c|c|}
\hline Local government plan/rule changes & $\begin{array}{l}\text { MP: It is likely that the costs (labour/expertise etc.) already } \\
\text { have a market price cost associated with them. }\end{array}$ \\
\hline $\begin{array}{l}\text { Planning/consulting for the reduction in infrastructure level } \\
\text { of service }\end{array}$ & $\begin{array}{l}\text { MP: It is likely that the costs (labour/expertise etc.) already } \\
\text { have a market price cost associated with them. }\end{array}$ \\
\hline $\begin{array}{l}\text { Monitoring of conditions (including the establishment of } \\
\text { trigger points for future actions) }\end{array}$ & $\begin{array}{l}\text { MP: It is likely that the costs (labour/expertise etc.) already } \\
\text { have a market price cost associated with them. }\end{array}$ \\
\hline Community Engagement & $\begin{array}{l}\text { MP: It is likely that the costs involved with community } \\
\text { engagement (workshops, information sessions etc.) will } \\
\text { already have market prices associated with them. }\end{array}$ \\
\hline $\begin{array}{l}\text { Acquisition offers (including buy and lease back, covenant } \\
\text { and sell, buy and demolish and sea-level purchase options } \\
\text { (SLPO's)) }\end{array}$ & $\begin{array}{l}\text { MP: The cost of acquiring a property could be at its current } \\
\text { market value. } \\
\text { ODV: } D V \text { - There could be an element of disposal value of } \\
\text { acquired property. }\end{array}$ \\
\hline Acquisition of alternative land for relocation & $\begin{array}{l}\text { MP: Again, it is likely that the land has a market value already } \\
\text { attached to it. Acquisition may be at this cost. }\end{array}$ \\
\hline $\begin{array}{l}\text { Development of new community facilities (town centre, roads } \\
\text { etc.) }\end{array}$ & $\begin{array}{l}\text { MP: There will likely be market based costs already } \\
\text { associated with these activities (labour, materials etc.). }\end{array}$ \\
\hline Reduction of service levels of public infrastructure & $\begin{array}{l}\text { ODV: UV - The reduction in service levels is likely to have an } \\
\text { impact on those using the infrastructure. As a result, the user } \\
\text { value of the asset may be relevant here. }\end{array}$ \\
\hline
\end{tabular}




\begin{tabular}{|c|c|}
\hline Replacement/relocation of public infrastructure elsewhere & $\begin{array}{l}\text { RC: The cost of replacing the infrastructure is relevant here, } \\
\text { albeit in another location (the cost of upgrading the existing } \\
\text { asset does not apply in this case, only the cost of replacing } \\
\text { the asset in its current state) } \\
\text { ODV: UV - The value of the asset to the users may also have } \\
\text { relevance here. }\end{array}$ \\
\hline $\begin{array}{l}\text { Private companies relocate/reduce/remove investment in } \\
\text { privately owned infrastructure (to the extent permitted by } \\
\text { law) - including telecommunications, power, ports etc. }\end{array}$ & $\begin{array}{l}\text { MP: Market prices for the relocation of private infrastructure } \\
\text { may be relevant here. } \\
\text { ODV: ODRC - The cost of replacing private infrastructure is } \\
\text { relevant here. Alternatively, the market prices of just } \\
\text { relocating infrastructure could also apply here. } \\
\text { ODV: UV - The removal of private infrastructure will have an } \\
\text { impact on those who are using it. This value may be relevant. } \\
\text { NFI: Net factor income could be affected through this } \\
\text { component. Either the service provider or those using it in } \\
\text { this case. }\end{array}$ \\
\hline Activation of covenants on property & $\begin{array}{l}\text { ODV: UV - The activation of covenants will have an impact on } \\
\text { those using the assets as their use is restricted or halted } \\
\text { entirely at this point. }\end{array}$ \\
\hline Rebuilding and development restrictions & $\begin{array}{l}\text { HP: May be able to capture the effects of restriction on } \\
\text { property values. } \\
\text { ODV: UV } \\
\text { MP: }\end{array}$ \\
\hline $\begin{array}{l}\text { Relocation/abandonment of privately owned residential and } \\
\text { commercial property }\end{array}$ & $\begin{array}{l}\text { MP: It is likely that the costs (labour/expertise etc.) already } \\
\text { have a market price cost associated with them. } \\
\text { ODV: ODRC - The cost of replacing the lost or depreciated } \\
\text { asset (in the case of abandonment) may be relevant here. } \\
\text { ODV: DV - If the asset could have been used elsewhere. } \\
\text { NFI: It is likely that relocating a business may have an impact } \\
\text { on the income of a business (such as tourism or retail-based } \\
\text { businesses near a beach). }\end{array}$ \\
\hline Providing of temporary housing & $\begin{array}{l}\text { MP: There will already be a market-based price associated } \\
\text { with the providing of temporary housing. }\end{array}$ \\
\hline $\begin{array}{l}\text { Relocation of 'critical-facility' structures (including hospitals, } \\
\text { schools, police \& fire stations, government buildings etc.) }\end{array}$ & $\begin{array}{l}\text { MP: It is likely that the costs (labour/expertise etc.) already } \\
\text { have a market price cost associated with them. } \\
\text { ODV: ODRC - This would relate to the replacement costs of } \\
\text { these depreciated assets in another location. } \\
\text { ODV: UV - People use these assets in their current locations, } \\
\text { and by shifting them elsewhere, there could be an impact on } \\
\text { these people using them. } \\
\text { HP: The relocation of these assets could affect the value of } \\
\text { property in the areas from which they are being removed or } \\
\text { moved to. }\end{array}$ \\
\hline
\end{tabular}




\begin{tabular}{|c|c|}
\hline $\begin{array}{l}\text { Relocation/replacement of community facilities/assets } \\
\text { (community halls, parks \& reserves etc.) }\end{array}$ & $\begin{array}{l}\text { MP: There will be market prices associated with the } \\
\text { relocation process of these community assets } \\
\text { (labour/equipment etc.) } \\
\text { ODV: ODRC - Replacing the depreciated assets with similar } \\
\text { assets in a new location may be relevant in this case as } \\
\text { ODV: UV - Taking away these assets and moving them to } \\
\text { another location could mean that people that were using } \\
\text { them previously are restricted now. The value of the asset to } \\
\text { the community before relocation could be affected in some } \\
\text { way. } \\
\text { TC: If these parks etc. are further away, there may be an } \\
\text { element of higher travel costs for them to be utilised by the } \\
\text { community. } \\
\text { CV: The value of these assets to the community can be } \\
\text { estimated using the contingent and choice experiment } \\
\text { methods. } \\
\text { HP: There is likely to be an impact on the value of surrounding } \\
\text { property following the use of this component. }\end{array}$ \\
\hline Demolition & $\begin{array}{l}\text { MP: It is likely that the costs (labour/equipment etc.) already } \\
\text { have a market price cost associated with them. }\end{array}$ \\
\hline Land rehabilitation & $\begin{array}{l}\text { MP: It is likely that the costs (labour/expertise/equipment } \\
\text { etc.) already have a market price cost associated with them. } \\
\text { HP: By rehabilitating the land and making it a nice public } \\
\text { space, there could very well be an impact on the value of } \\
\text { nearby property for a time (property not currently at-risk). } \\
\text { CV: Through choice experiments, the value of rehabilitating } \\
\text { an area to be used as public amenity (parks for example) } \\
\text { could be estimated. }\end{array}$ \\
\hline Land maintenance & $\begin{array}{l}\text { MP: It is likely that the costs (labour/expertise etc.) already } \\
\text { have a market price cost associated with them. } \\
\text { HP: maintain abandoned land as a public space may influence } \\
\text { the value of nearby property. } \\
\text { CV: maintaining new council owned land as publicly accessible } \\
\text { space will have a value to the surrounding community. This } \\
\text { could be estimated through contingent valuation. }\end{array}$ \\
\hline Removal of marine structures & $\begin{array}{l}\text { MP: It is likely that the costs (labour/expertise etc.) already } \\
\text { have a market price cost associated with them. } \\
\text { ODV: UV - By removing wharves or protective coastal } \\
\text { structures, you are essentially depriving people of their use. It } \\
\text { may therefore be relevant for user values to be used in this } \\
\text { case. } \\
\text { TC: Travel cost may be higher for some of these structures to } \\
\text { be utilised in future by the community. (Jetties for fishing } \\
\text { etc.) } \\
\text { CV: Contingent valuation and choice experiment methods } \\
\text { would allow for an estimation of the value for these } \\
\text { structures. }\end{array}$ \\
\hline
\end{tabular}





\section{Appendix D: Information Sheet Provided For Discussions}

The information sheet included on the page below outlines the information that was provided to practitioners ahead of the discussions. It provides a background about the researcher, what the objectives are, what has been completed, what the process of the discussion will be, what will be done with the information provided, and contact information.

As outlined in Chapter Three of this thesis (Methodology), this thesis is part of the 'Living at the Edge' project under the Resilience National Science Challenge for which ethics approval was gained. Ethics approval was held by my primary supervisor within this programme through University of Auckland Ethics Approval \#018448. 


\section{Components and Costing of Managed Retreat in a Coastal Setting}

\section{INFORMATION SHEET FOR PARTICIPANTS- discussions}

Thank you for your interest in this project. Please read this information before deciding whether to take part. If you decide to participate, thank you. If you decide not to take part, thank you for considering my request.

\section{Who am I?}

My name is Sam Olufson and I am a Master's student in the School of Geography, Environment and Earth Sciences at Victoria University of Wellington. My research is part of the Resilience National Science Challenge 'The Living at the Edge' Programme.

\section{Research Background:}

The Resilience to Nature's Challenges 'Living at the Edge' programme is aimed towards developing tools which support communities living in highly vulnerable coastal settings to adapt to the increased risks associated with their location. My research aims to build the understanding of managed retreat as an adaptation option. As part of my research to date, I have developed a typology that identifies the many components that could form part of a managed retreat strategy, and how these components might be sequenced in time in response to growing coastal hazard risk. The second stage of my research involves the development of an approach to cost these different components. It is this costing approach that I wish to take you through and ask questions about to develop this approach more fully, so it has relevance to users.

\section{How can you help?}

If you agree to take part, I will take you through my component typology and test my costing approach with you through discussion. After outlining the approaches that I have taken, I will ask questions about the costing approach, including asking for your opinion on the usefulness and relevance of the current approach for people working in your sector. I will also ask for recommendations for improving the typology and framework.

\section{What will happen to the information you give?}

The information I gain through our discussion will be used to inform the costing approach and discussion of it as part of my thesis. Any feedback you give will not be attributed to you, rather the type of sector (e.g. local government, infrastructure operator).

\section{What will the project produce?}

My thesis will produce the components and costing typologies. In addition, it will produce a discussion of how they were built, their utility, and where further research might be targeted. 
If you accept this invitation, what are your rights as a research participant?

As a participant in this research, you have the right to:

- choose not to answer any question;

- withdraw from the study before the interview;

- $\quad$ ask any questions about the study at any time;

- be able to read any reports of this research by emailing the researcher to request a copy.

If you have any questions or problems, who can you contact?

If you have any questions, either now or in the future, please feel free to contact:

Candidate Contact Details

Sam Olufson, Master's Candidate

School of Geography, Environment and Earth Sciences,

Victoria University of Wellington.

Email: sam.olufson@vuw.ac.nz

Phone: 0210770269

Supervisors:

Dr Judy Lawrence,

Senior Research Fellow,

NZ Climate Change Institute,

Victoria University of Wellington,

Email: judy.lawrence@vuw.ac.nz

Phone: 021499011

Dr Adolf Stroombergen

Chief Economist

Infometrics

Email: adolfs@infometrics.co.nz 



\section{Appendix E: Summary of Costing Tools}

The following figure is taken from Bell et al. (2017) and outlines the many methodologies that can be used for the costing and valuing of climate change adaptation.

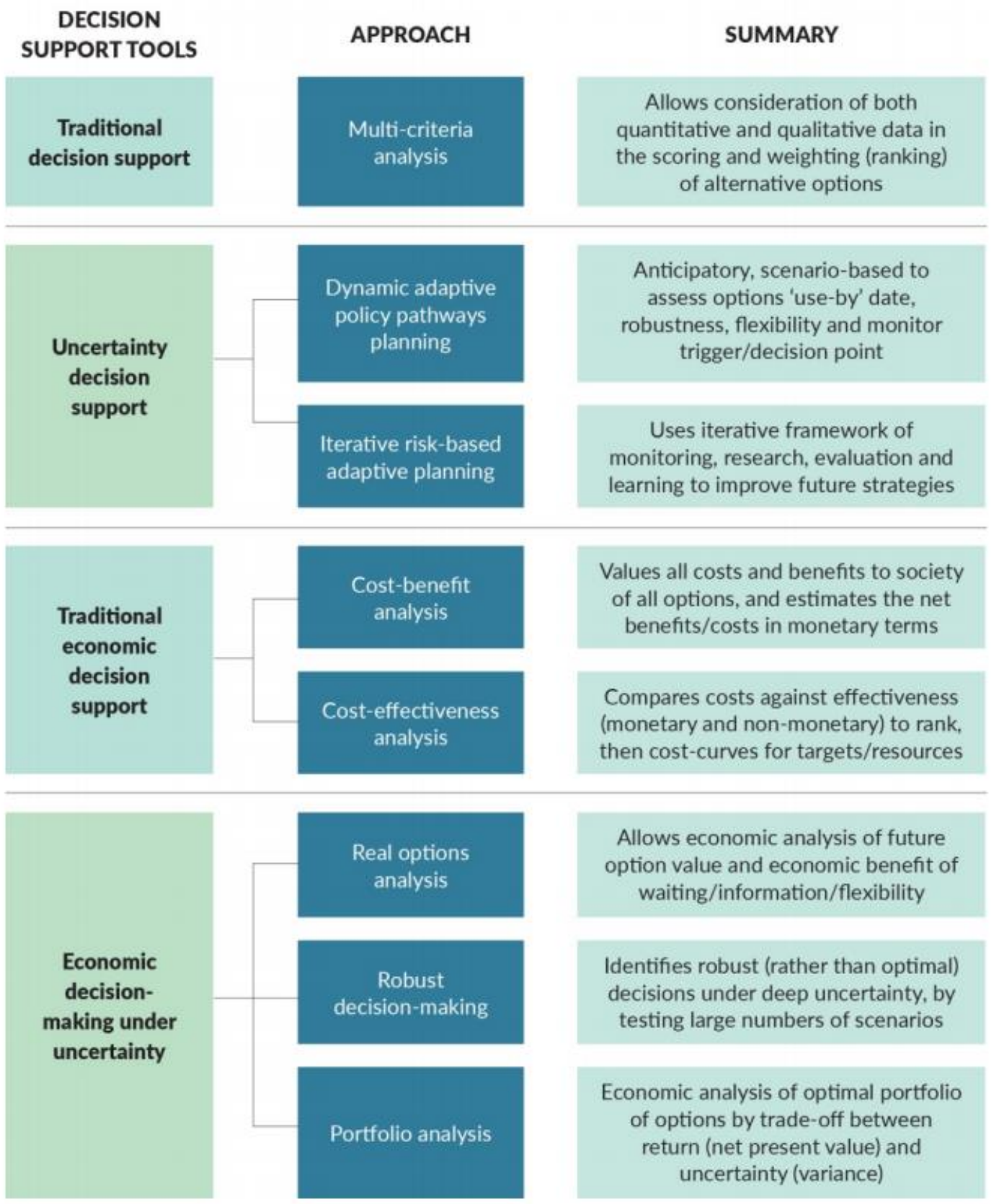

Source: (Bell et al., 2017). 